\title{
Development of an In Situ Method to Define the Rheological Properties of Slurries and Sludges Stored in Underground Tanks
}

W. O. Heath

April 1987

Prepared for the U.S. Department of Energy under Contract DE-AC06-76RLO 1830

Pacific Northwest Laboratory

Operated for the U.S. Department of Energy by Battelle Memorial Institute 


\section{DISCLAIMER}

This report was prepared as an account of work sponsored by an agency of the United States Government. Neither the United States Government nor any agency thereof, nor Battelle Memorial Institute, nor any of their employees, makes any warranty, expressed or implied, or assumes any legal liability or responsibility for the accuracy, completeness, or usefulness of any information, apparatus, product, or process disclosed, or represents that its use would not infringe privately owned rights. Reference herein to any specific commercial product, process, or service by trade name, trademark, manufacturer, or otherwise, does not necessarily constitute or imply its endorsement, recommendation, or favoring by the United States Government of any agency thereof, or Battelle Memorial Institute. The views and opinions of authors expressed herein do not necessarly state or reflect those of the United States Government or any agency thereof, or Battelle Memorial Institute.

\section{PACIFIC NORTHWEST LABORATORY operated by \\ BATTELLE MEMORIAL INSTITUTE \\ for the \\ UNITED STATES DEPARTMENT OF ENERGY under Contract DE-AC06-76RLO 1830}

\begin{tabular}{|c|c|}
\hline \multirow{2}{*}{\multicolumn{2}{|c|}{ Printed in the United States of America }} \\
\hline & \\
\hline \multicolumn{2}{|c|}{ National Technical Information Service } \\
\hline \multicolumn{2}{|c|}{$\begin{array}{l}\text { National Technical Information Service } \\
\text { United States Department of Commerce }\end{array}$} \\
\hline \multirow{2}{*}{\multicolumn{2}{|c|}{$\begin{array}{c}5285 \text { Port Royal Road } \\
\text { Springfield, Virginia } 22161\end{array}$}} \\
\hline & \\
\hline \multirow{2}{*}{\multicolumn{2}{|c|}{$\begin{array}{l}\text { NTIS Price Codes } \\
\text { Microfiche } \mathrm{A} 01\end{array}$}} \\
\hline & \\
\hline \multicolumn{2}{|c|}{ Printed Copy } \\
\hline & Price \\
\hline Pages & Codes \\
\hline $001-025$ & $\mathrm{~A} 02$ \\
\hline $026-050$ & $\mathrm{~A} 03$ \\
\hline $051-075$ & A04 \\
\hline $076-100$ & A05 \\
\hline $101-125$ & A06 \\
\hline $126-150$ & $\mathrm{~A} 07$ \\
\hline $151-175$ & $\mathrm{~A} 0 \mathrm{~B}$ \\
\hline $176-200$ & A09 \\
\hline $201-225$ & A010 \\
\hline $226-250$ & A011 \\
\hline $251-275$ & A012 \\
\hline $276-300$ & A013 \\
\hline
\end{tabular}


DEVELOPMENT OF AN IN SITU

METHOD TO DEFINE THE RHEOLOGICAL

PROPERTIES OF SLURRIES AND SLUDGES

STORED IN UNDERGROUND TANKS

W. O. Heath

Apri1 1987

Prepared for the U.S. Department of Energy under Contract DE-ACO6-76RLO 1830

Pac if ic Northwest Laboratory

Richland, Washington 99352 


\section{ABSTRACT}

A method for measuring the in situ flow properties of high-level radioactive waste (HLW) sludges has been developed at Pacific Northwest Laboratory, along with a preconceptual design for a shear vane device that can be installed in underground HLW storage tanks and used to make those measurements remotely. The data obtained with this device will assist in the design of mixing equipment used to resuspend and remove HLW sludges from their storage tanks for downstream processing. This method is also suitable for remotely characterizing other types of waste sludges and slurries. Commonly available viscometric methods were adapted to allow characterization of sludge samples in the laboratory such that the laboratory and in-tank data can be directly compared (scaled up). Procedures for conducting measurements and analyzing the results in terms of useful mathematical models describing both start-up and steady-state flow behavior are presented, as is a brief tutorial on the types of flow behavior that can be exhibited by tank sludges. 


\section{,}




\section{SUMMARY}

Double-shell tanks (DST) are used to store nuclear wastes in the form of solutions and sludges at Hanford. Current plans include the retrieval of the high-level (HLW) and transuranic (TRU) fractions of these wastes and their processing to create immobile waste forms suitable for long-term storage in geologic repositories. Prior to their retrieval and subsequent processing, the properties (chemical, physical, and rheological) of these wastes must be determined. The goal of the Pacific Northwest Laboratory's (PNL) Double Shell Tank Sampling and Analysis Program, supported by the Department of Energy's Richland Operations Office (DOE-RL), is to characterize these properties.

The objective of one of the activities within this program was to develop methods for characterizing the rheological (flow behavior) properties of DST wastes. This report documents the adaptation of standard viscometric techniques to allow sludge characterization in the laboratory and describes the development of a novel method for measuring the in situ flow properties of OST contents. A preconceptual design is presented for a modified shear vane device that can be installed in DSTs and used to measure the following properties in situ:

- shear strength (sludge)

- apparent viscosity versus shear rate (slurry)

- yield strength (slurry)

- flow behavior index (slurry)

- consistency index (slurry).

These properties collectively determine the flow and dispersion behavior of settled tank sludges. Knowledge of them is essential to the design of mixing and pumping equipment that will be used to retrieve the DST contents. Shear strength is the most significant property used for sizing tank-mixing equipment; it provides a direct measure of the shear conditions that will be required to successfully break up and disperse settled sludge layers. Because many of the slurries and sludges in DSTs have remained substantially undisturbed for years and have settled into extremely durable layers, it is this initial dispersion that may prove to be the most difficult step invoived in 
waste retrieval. Therefore, accurate measurement of shear strength is especially critical to the success of waste retrieval operations. The remaining properties determine the flow. behavior of the slurry formed after the sludge is dispersed. These properties and their engineering significance are fully described in the report.

Procedures are provided for measuring rheological properties: 1) in situ, using an in-tank shear vane device; and 2) in the laboratory, in conjunction with tank core samples. The in-tank shear vane must be used to obtain accurate measurements of the in-place sludge shear strength because it circumvents the disturbance and consequent weakening of the sludge caused by core sampling. If core samples cannot be taken (due to cost or other constraints), the shear vane can be used to measure all of the other needed sludge flow properties as well.

Shear vanes comprise a standard method for measuring the in situ shear strength of soils. The extension of traditional shear vane methods to allow measurement of apparent viscosity versus shear rate required a substantial testing and development effort. Most of this initial development was undertaken by PNL's West Valley Support Task sponsored by the West Valley Nuclear Services Co., Inc. (WVNS) for DOE. This report documents these developmental efforts so as to provide a complete overview of the research that culminated in the preconceptual in-tank shear vane design.

Procedures are described for analyzing the rheological data obtained by shear vanes and laboratory viscometers and reporting the data in terms of useful mathematical models. A calculator program was developed to assist in reducing the raw data. This program is provided as an appendix to the report. 


\section{ACKNOWLEDGMENTS}

The author wishes to thank M. T. Cross and G. T. Thornton for their invaluable assistance in conducting laboratory experiments and for the indefatigable enthusiasm they display toward their work. In preparing this report, comrnents from D. McCarthy, E. M. Lane, J. R. Carrell, and M. E. Peterson were extremely helpful in conjunction with the editing skill and insight provided by S. F. Liebetrau. Finally, the author wishes to thank B. D. Gottsch's and D. T. Foley's teams for providing word processing and graphics support. 


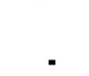


CONTENTS

SUMMARY . i i i

1.0 INTRODUCTION I. 1

2.0 MOBILIZATION AND DISPERSION OF TANK SLUDGES $\ldots \ldots \ldots \ldots \ldots \ldots \ldots \ldots \ldots .1$

2.1 SLUDGE DISPERSION MECHANISMS $\ldots \ldots \ldots \ldots \ldots \ldots \ldots \ldots \ldots \ldots \ldots \ldots \ldots \ldots$

2.2 PHYSICAL PROPERTIES CONTROLLING THE MOBILIZATION AND

DISPERSION CHARACTERISTICS OF SLURRIES AND SLUDGES $\ldots \ldots \ldots \ldots \ldots 2.2$

2.2.1 The Elastic Regime: Stress-Strain Relationships ....... 2.2

2.2.2 The Plastic Regime: Shear Stress, Shear Rate, and Viscosity Relationships .................... 2.4

3.0 MECHANICAL AND RHEOLOGICAL MODELS FOR SLUDGE FLOW BEHAVIOR ....... 3.1 3.1 FLOW BEHAVIOR IN THE ELASTIC REGIME $\ldots \ldots \ldots \ldots \ldots \ldots \ldots \ldots \ldots \ldots \ldots . . \ldots$

3.1.1 Mises-Hencky Flow Condition for Plastic Materials ...... 3.1

3.1.2 Effect of Settling Time on Shear Strength of Sample .... 3.2

3.2 FLOW BEHAVIOR IN THE VISCOUS REGIME $\ldots \ldots \ldots \ldots \ldots \ldots \ldots \ldots \ldots \ldots .2$

3.2.1 Flow Behavior for Non-Newtonian Fluids,

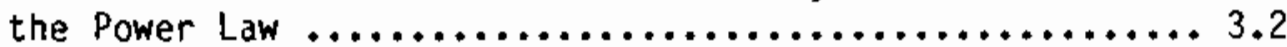

3.2.2 Flow Behavior of Non-Newtonian Fluids Exhibiting

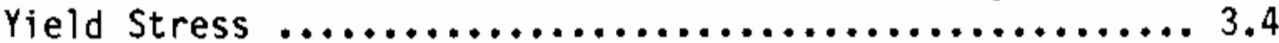

3.2.3 Time-Dependent Flow Behavior in Non-Newtonian Fluids,

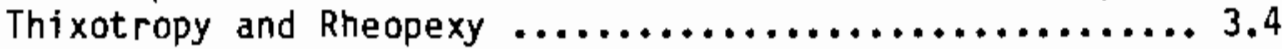

3.3 SHEAR STRENGTH AND YIELD STRESS $\ldots \ldots \ldots \ldots \ldots \ldots \ldots \ldots \ldots \ldots \ldots \ldots$

4.0 MEASUREMENT OF SLUDGE PARAMETERS IN THE LABORATORY USING ROTATIONAL VISCOMETERS

4.1 MEASUREMENT OF APPARENT VISCOSITY AND MAXIMUM PLASTIC VISCOSITY BY MEANS OF STANOARD BROOKFIELD DISC AND T-BAR SPINDLES $\ldots \ldots \ldots . .3$

4.2 MEASUREMENT OF APPARENT VISCOSITY, SHEAR STRESS AND SHEAR RATE USING CONCENTRIC CYLINDER SPINDLES

4.3 MEASUREMENT OF APPARENT VISCOSITY, SHEAR STRESS AND SHEAR RATE BY MEANS OF MINIATURE SHEAR VANES 
4.4 MEASUREMENT OF STEAdY-STATE YIELD STRESS $\ldots \ldots \ldots \ldots \ldots \ldots \ldots \ldots \ldots . \ldots$

4.4.1 Extrapolation of Test Data to Zero Shear Rate ......... 4.15

4.4.2 Optimizing the Extrapolation Method ............... 4.19

4.4 .3 Shear Vane Torque Decay at $\mathrm{N}=\dot{S}=0 \ldots \ldots \ldots \ldots \ldots \ldots \ldots . \ldots \ldots$

4.5 DETERMINING POWER LAW COEFFICIENTS FROM RHEOGRAMS $\ldots \ldots \ldots \ldots \ldots .21$

4.5.1 Example: Determining Power Law Coefficients with a

Brookfield Viscometer Fitted with a Concentric

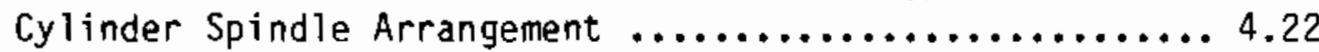

4.5.2 Example: Determining Power Law Coefficients with a Haake Rotovisco Viscometer Fitted with a Concentric

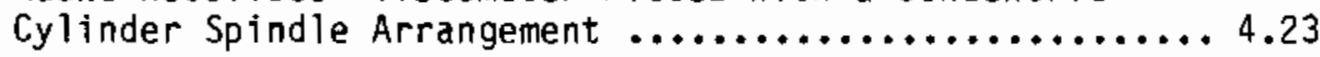

4.6 TESTS FOR DETECTING TIME-DEPENDENT BEHAVIOR $\ldots \ldots \ldots \ldots \ldots \ldots \ldots \ldots .25$

4.6 .1 Constant Shear Rate Method .................... 4.25

4.6.2 Variable Shear Rate Flow Curve Hysteresis ........... 4.26

4.7 MEASUREMENT OF NON-STEADY-STATE SHEAR STRENGTH $\ldots \ldots \ldots \ldots \ldots \ldots .28$

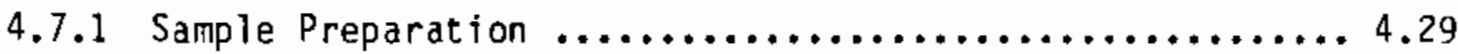

4.7.2 Test Method for a Miniature Shear Vane ............. 4.31

4.7.3 Effect of Pore Pressure on Laboratory Shear Strength

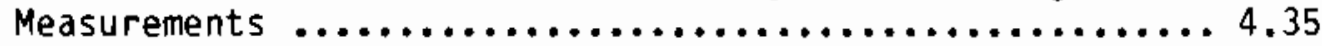

5.D DEVELOPMENT OF A SHEAR VANE METHOD FOR IN-TANK MEASUREMENT OF

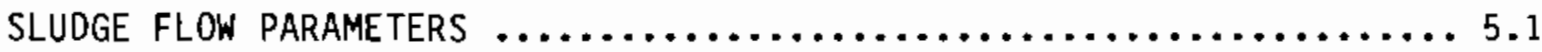

5.1 SCALE-UP OF SHEAR VANE SHEAR STRENGTH DATA $\ldots \ldots \ldots \ldots \ldots \ldots \ldots \ldots .2$

5.2 MEASUREMENT OF APPARENT VISCOSITY USING SHEAR VANES $\ldots \ldots \ldots \ldots .4$

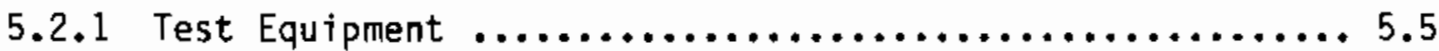

5.2 .2 Experimental Procedure $\ldots \ldots \ldots \ldots \ldots \ldots \ldots \ldots \ldots \ldots \ldots \ldots .6$

5.2 .3 Shaft Friction Correction $\ldots \ldots \ldots \ldots \ldots \ldots \ldots \ldots \ldots \ldots . . \ldots \ldots$

5.2.4 Correlation of Test Data Via Reynolds Number/Power

Number Relationship ........................... 5.

5.2 .5 Discussion of Experimental Results $\ldots \ldots \ldots \ldots \ldots \ldots \ldots \ldots .11$ 
5.3 RELATIDNSHIP BETWEEN VANE RPM AND SHEAR RATE $\ldots \ldots \ldots \ldots \ldots \ldots \ldots .11$ 6.0 CONCEPTUAL DESIGN OF FULL-SCALE IN-SITU SHEAR VANE DEVICE $\ldots \ldots \ldots \ldots .1$

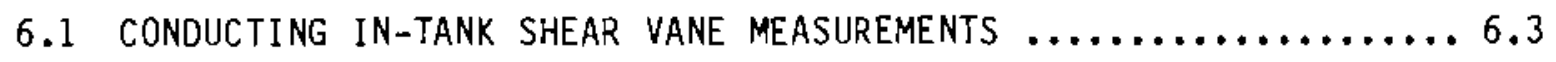

6.2 EXAMPLE CALCULATION: ESTIMATION OF SLUDGE VISCOSITY FROM IN-TANK SHEAR VANE DATA $\ldots \ldots \ldots \ldots \ldots \ldots \ldots \ldots \ldots .6 \ldots$

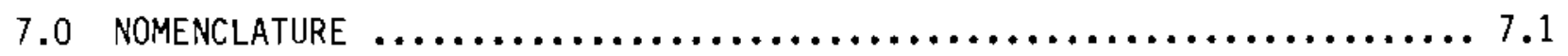

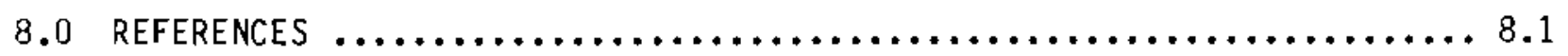
APPENDIX A: CONCEPTUAL DESIGN OF FULL SCALE, IN SITU

SHEAR VANE DEVTCE...............................

APPENDIX B: PROCEDURE FOR USING CALCULATOR PROGRAM "VANE-2" FOR

REDUCING SHEAR VANE SLUDGE/SLURRY DATA ................ 


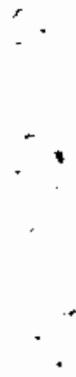




\section{FIGURES}

2.1 Stress-Strain Diagram for a Ductile Material with a Yield Point ..... 2.3

2.2 The Geometry of Elastic Shear Strain $\ldots \ldots \ldots \ldots \ldots \ldots \ldots \ldots \ldots \ldots \ldots . \ldots . \ldots$

3.1 Rheograms for Time-Independent Non-Newtonian Fluids

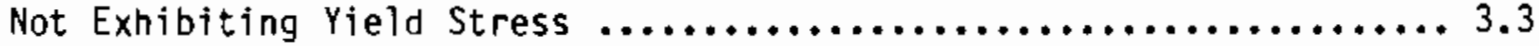

3.2 Rheograms for Time-Independent Non-Newtonian Fluids

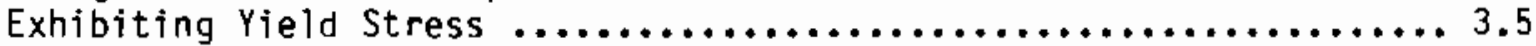

3.3 Plot of Shear Stress Versus Time at Constant Shear Rate

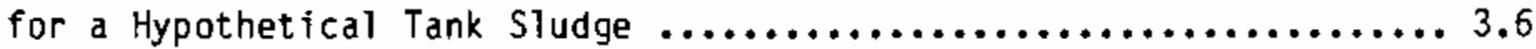

4.1 Schenatic of a Hake viscometer $\ldots \ldots \ldots \ldots \ldots \ldots \ldots \ldots \ldots \ldots \ldots \ldots \ldots . \ldots . \ldots . \ldots . \ldots$

4.2 Geometry of Various Brookfield Spindles ....................4.4

4.3 Plot of Viscometer Torque Output Versus Time at Constant

RPM Using a T-Bar Spindle in a Gelled STudge ................. 4.4

4.4 Rheogram of a Sludge Exhibiting Flow Curve Hysteresis ...........4.7

4.5 Plot of Viscometer Output Versus Time at Constant

Spindle RPM for a Hypothetical Sludge Sample ................4.8

4.6 Shear Vane Geometry $\ldots \ldots \ldots \ldots \ldots \ldots \ldots \ldots \ldots \ldots \ldots \ldots \ldots \ldots \ldots \ldots \ldots \ldots . \ldots . \ldots . \ldots . \ldots . \ldots \ldots$

4.7 Three Shear Vanes Used During Testing at PNL .................. 4.10

4.8 Dimensions of Miniature Shear Vanes Used in Testing at PNL ........4.11

4.9 Flow Curve for a Typical Sludge, 0 to $468 \mathrm{~s}^{-1} \ldots \ldots \ldots \ldots \ldots \ldots \ldots . \ldots . \ldots . \ldots$

4.10 Typical Flow Curve for a Yield-Pseudoplastic Fluid ............. 4.16

4.11 Flow Curve for a Typical Sludge, 0 to $11.7 \mathrm{~s}^{-1} \ldots \ldots \ldots \ldots \ldots . \ldots . . . .49$

4.12 Comparison of Elastic and Creep Behavior as Shear Rate

Approaches Zero .................................. 4.21

4.13 Haake Rheogram of Melter Feed Sample Taken at $t=5$ min $\ldots \ldots \ldots . .4 .24$

4.14 Flow Curve Hysteresis Indicating Sludge Thixotropy ............ 4.27

4.15 Up and Down Flow Curves Produced with Brookfield RVDT Viscometer ... 4.27

4.16 Haake Rheogram of Melter Feed Sample Taken at $t=18.5 \mathrm{~h} \ldots \ldots . \ldots 4.29$ 
4.17 Plot of Viscometer Output Versus Time at a Constant Shear

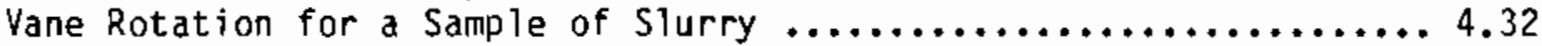

4.18 Plot of Viscometer Output Versus Time at a Constant Shear Vane

Rotation for a Sample of Radioactive NCRW Sludge $\ldots \ldots \ldots \ldots \ldots \ldots . . .6 .33$

4.19 Location of Shear Vane During Determinations of

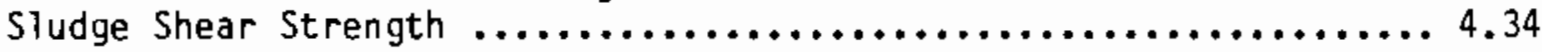

5.1 Effect of Shear Vane RPM on Sludge Shear Strength Measurement ...... 5.4

5.2 Plots of Power Number and Reynolds Number for Some Turbine Agitator

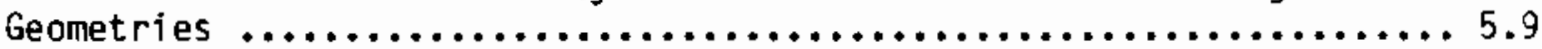

5.3 Plot of Power Number Versus Reynolds Number from the Shear Vane Test Data ............................................. 5.10

6.1 Conceptual Design of a Shear Vane Installed in a

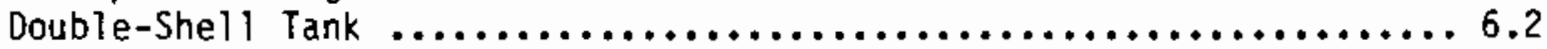

6.2 In-Tank Test Configuration Assumed in Example Calculation .........6.7

A.1 Conceptual Design of Full Scale, In-Situ Shear Vane Device .............

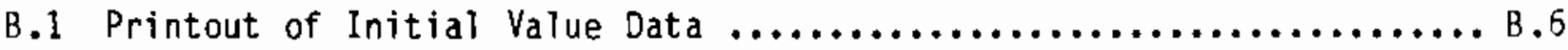

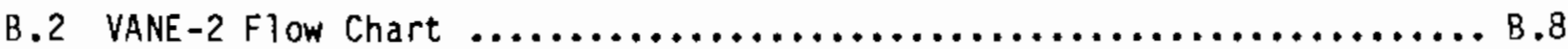

B.3 Example Calculation of Apparent Sludge Viscosity from Shear

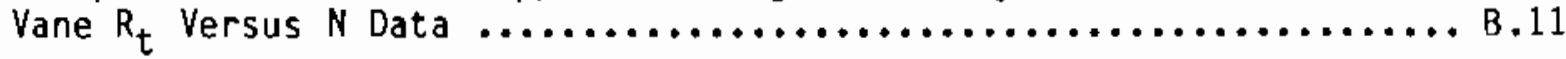

B.4 Example Calculation Test Configuration $\ldots \ldots \ldots \ldots \ldots \ldots \ldots \ldots \ldots \ldots$ B. 12

B.5 Rheograms for Time-Independent Non-Newtonian Fluids ............. B.15

B.6 Plot of $\log \dot{S}$ Versus $\log t$ for Typical Melter Feed ..................17 


\section{TABLES}

4.1 Maximum Shear Vane Rotational Speed for Apparent

Viscosity Measurement ................................... 4.14

4.2 Viscometer Spring Constants $\ldots \ldots \ldots \ldots \ldots \ldots \ldots \ldots \ldots \ldots \ldots \ldots \ldots \ldots \ldots . \ldots \ldots$

4.3 Values of Shear Stress and Shear Rate Obtained by Using a Brookfield RV Viscometer with Brookfield UL Adapter .............4.23

4.4 Values of Shear Stress and Shear Rate Obtained by Using a Haake Rotovisco RV-100 Viscometer with System M150,

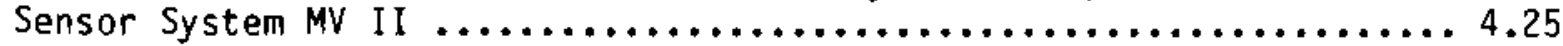

4.5 Viscometer/Shear Vane Selection for Shear Strength Measurements .... 4.30

4.6 Viscometer RPM for Shear Strength Determination $\ldots \ldots \ldots \ldots \ldots \ldots . \ldots . \ldots . \ldots$

5.1 Shear Vane/Tank/Test Fluid Configurations Investigated $\ldots \ldots \ldots \ldots . \ldots 5$

5.2 Shear Rate Data as a Function of Shear Vane Diameter and

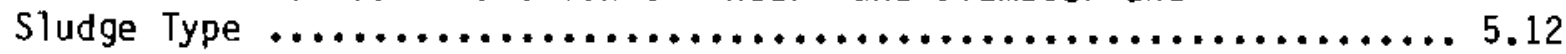

B.1 Viscometer Spring Factor $\ldots \ldots \ldots \ldots \ldots \ldots \ldots \ldots \ldots \ldots \ldots \ldots \ldots \ldots \ldots \ldots \ldots$

B.2 VANE-2 Subroutine Options and How to Control Them $\ldots . . \ldots \ldots \ldots \ldots . . . .7$

B.3 Equations Employed by VANE $-2 \ldots \ldots \ldots \ldots \ldots \ldots \ldots \ldots \ldots \ldots \ldots \ldots \ldots$

B.4 Values for Shear Stress and Shear Rate Obtained
for a Sample of Melter Feed Slurry $\ldots \ldots \ldots \ldots \ldots \ldots \ldots \ldots \ldots \ldots \ldots \ldots \ldots$

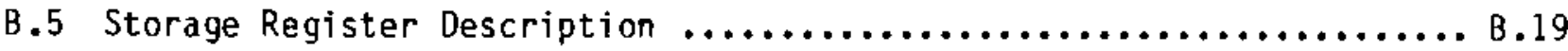

B.6 VANE-2 Program Listing $\ldots \ldots \ldots \ldots \ldots \ldots \ldots \ldots \ldots \ldots \ldots \ldots \ldots \ldots \ldots \ldots \ldots . . \ldots . . \ldots$ 


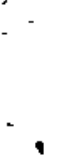

.

.

.

$\because$ 


\subsection{INTRODUCTION}

Before the nuclear wastes stored in underground storage tanks can be retrieved and transferred to existing or new facilities (and finally immobilized), their chemical, physical, and rheological properties must be identified. The goal of the Double-Shell Tank (DST) Sampling and Analysis Program at the Pacific Northwest Laboratory (PNL) is to characterize these chemical, physical, and rheological properties. The Department of Energy's Richland Operations office (DOE $\rightarrow \mathrm{RL})$ funds the program, which has been conducted in conjunction with related ongoing activities at Rockwell Hanford Operations. One objective of the program was the development of an in situ method to determine the rheological properties of neutralized cladding removal waste (NCRW) and other slurries and sludges contained in DSTs. Research at PNL culminated in a preconceptual design for a shear vane to be used in situ to identify the rheological properties of sludges and slurries in waste tanks.

Shear vane devices are not new; soil scientists have used them since the 1950 s to test the shear strength of various soils. More recently, West valley Nuclear Services, Inc. (WVNS), utilized shear vanes to measure the shear strengths of radioactive wastes contained in tanks at their site in West Valley, New York (Abdelhamid 1982). The work conducted by WVNS provided the baseline for the in situ shear vane development work described in this report.

Research at PNL focused on five objectives:

- modify the in situ methods developed by WVNS so that they could be used to determine the rheological properties of slurries and sludges contained in DSTs at Hanford

- investigate the scale-up of shear strength data to allow direct comparison between laboratory-scale data and full-scale data obtained in situ

- develop a method for using shear vanes to measure the viscosity of tank sludges as well as their shear strengths

- prepare a standard data analysis calculator program for shear vanes 
- develop a preconceptual design for a shear vane that can be used in situ in the DSTs at Manford.

Current plans are to install and operate in situ shear vane devices in waste tanks at both Hanford and West Valley, to obtain rheological data on the sludges stored at these sites. This data will be used in conjunction with FY 1987 scale-model DST mixing studies to assist in the development of DST retrieval systems to resuspend and remove OST sludges for downstream processing.

The format of this report follows the sequence in which the work was conducted. Initial activity was concerned with gaining an understanding of the theoretical foundation of non-Newtonian slurry/sludge flow systems, and Chapter 2 describes the physical properties that control the mobilization and dispersion of slurries and sludges. Classical mechanical and rheological models that can be used to characterize the flow behavior of slurries and sludges are discussed in Chapter 3. Laboratory-scale methods of measuring slurry/sludge flow parameters are presented in Chapter 4 . Some details of the early developmental research are noted in Chapter 5, as are the further developments by PNL that enabled measurement of sludge viscosity and other rheological parameters. These methods and a modified shear vane design have resulted in a new technology for in-tank testing, which is summarized in Chapter 6. Appendix A provides an engineering sketch of a conceptual design for the modified shear vane device, and Appendix B presents the procedure by which a calculator program, VANE-2, can be used to reduce shear vane sludge and slurry data. 


\subsection{MOBILIZATION AND DISPERSION OF TANK SLUDGES}

An in situ device designed to define the rheological behavior of slurries and sludges in underground tanks must provide information needed to design the process equipment that will be used to mobilize and retrieve the slurries and siudges. However, the mechanics of slurry/studge mobilization must be understood before the nature of that information can be specified. A rescription of siudge dispersion mechanisms is provided in Section 2.1. The physical properties that control the mobilization and dispersion of sludges are discussed in Section 2.2.

\subsection{SLUDGE DISPERSION MECHANISMS}

The sludge layer at the bottom of a tank can be considered a cohesive solid. The word "cohesive" refers to the "self-stickiness" of the sludge material, which results from interparticle attractive forces. As an example, river clays and similar materials are cohesive solids, whereas dry sand and other materials that are not self-sticking are not cohesive. From a practical viewpoint, the sludge at the bottom of a tank can be considered a solid, or at least a "pseudo solid" (Rehbinder 1954).

When tank sludge is viewed as a solid, it becomes clear that its dispersion will involve two different physical processes in sequence:

- conversion of the solid sludge to a liquid slurry

- dispersion of the slurry particles throughout the tank.

The first process occurs in the elastic or solid regime, whereas the second process occurs in the plastic or viscous regime. Each regime has a separate set of parameters that determine the flow behavior and dispersion characteristics of the sludge Tayer.

For the first process to occur, local shear at the surface of the sludge layer is required. A certain magnitude of local shear stress will be required to overcome the cohesiveness of the sludge, which binds the sludge particles into a solid mass. If a sufficient level of shear can be developed, the sludge will fail, break up, and start to liquefy. 
The second physical process is the actual dispersion of the slurry particles throughout the tank. The shear field developed by the mixing equipment must be sufficient to disperse them.

\subsection{PHYSICAL PROPERTIES CONTROLLING THE MOBILIZATION ANO DISPERSION CHARACTERISTICS DF SLURRIES AND SLUDGES}

The ability of slurries and sludges to flow and be dispersed depends on their behavior in the elastic and viscous regimes. Important physical properties of sludges in these two regimes are described below.

\subsubsection{The Elastic (or Solid) Regime: Stress-Strain Relationships}

The reaction of nonbrittle solids to stress is characterized by reversible (elastic) deformation (strain) until failure occurs, whereupon further stress causes permanent (plastic) deformation. A typical stress-strain model for a nonbrittle solid is illustrated in Figure 2.1. In this model, increased stress causes increased strain, and the two vary linearly throughout the elastic regime up to the point of material failure. The ratio of stress to strain in the elastic regime is a characteristic of a given material and is known as Young's modulus of elasticity, $E$. It is defined by Van Vlack (1975) as

$$
E=\frac{\sigma}{E}
$$

where, in cgs units, $E=$ Young's modutus, dyne $/ \mathrm{cm}^{2}$

$$
\begin{aligned}
\sigma= & \text { applied stress, dyne } / \mathrm{cm}^{2} \\
\varepsilon= & \text { strain, usually defined as the percentage of axial or } \\
& \text { cross-sectional deformation caused by stress, } \\
& \text { dimensionless. }
\end{aligned}
$$

The stress at which plastic deformation occurs (leading to failure), called the "yield strength" or "yield stress," is also a characteristic of a given material and is denoted by $\sigma_{s}$.

Analogous to the stress-strain behavior of nonbrittle solids, cohesive tank sludge will undergo shear-induced elastic strain until the yield strength 


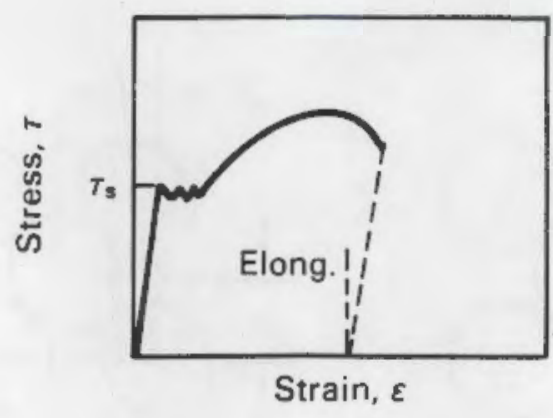

FIGURE 2.1. Stress-Strain Diagram for a Ductile Material with a Yield Point

is exceeded and plastic failure occurs. In sludge mobilization, the principal stresses will be in the direction of plane shear rather than axial compression or extension so that the shear modulus, $G$ instead of $E$, is appropriate for describing the stress strain relationship in the elastic regime. The shear modulus is defined by Van Vlack (1975):

$$
G=\frac{\tau}{\varepsilon_{\mathrm{S}}}
$$

where, in egs units, $G=$ shear modulus, dyne $/ \mathrm{cm}^{2}$

$$
\begin{aligned}
\tau & =\text { applied shear stress, dyne } / \mathrm{cm}^{2} \\
\varepsilon_{\mathrm{s}} & =\text { elastic shear strain, dimensionless. }
\end{aligned}
$$

The geometry of elastic shear strain is shown schematically in Figure 2.2.

The shear stress at which plastic deformation occurs (leading to failure) is denoted as the "shear strength," $\tau_{s}$. Shear strength is a property exhibited by all cohesive materials, such as all clays, most or all tank sludges and sediments, and some slurries. In terms of sludge mobilization, the shear strength of the sludge will determine whether the available level of tank agitation can successfully break up the sludge. The relevance of shear strength is that in specifying a sludge mobilization (mixing) system, $\tau_{s}$ will determine the peak operating characteristics of the system. During startup 


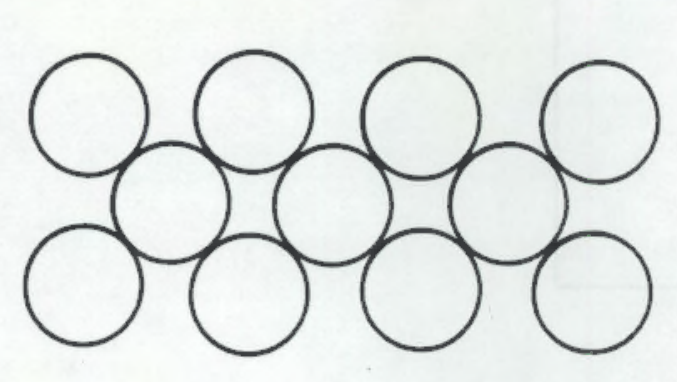

(a) Before stress is applied

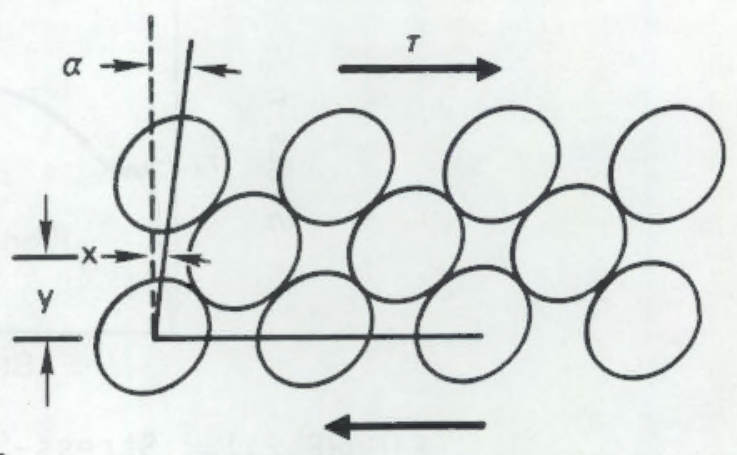

(b) After stress is applied

FIGURE 2.2. The Geometry of Elastic Shear Strain. Shear displaces atoms.

operations, the mixing system must produce enough local stress at the surface of the sludge layer to overcome shear strength, or "the sludge will not budge."

An important thing to remember from this discussion is that the resistance to flow of a sludge can be described by two parameters: the shear modulus and the shear strength. Only when local shear fields at the sludge/supernatant interface exceed $\tau_{s}$ will the sludge be transformed from a solid in the elastic regime to a viscous slurry in the plastic regime. In the plastic or viscous regime, viscosity is the appropriate quantity for describing stress-strain relationships.

\subsubsection{The Plastic (or Viscous) Regime: Shear Stress, Shear Rate, and Viscosity Relationships}

Viscosity is a physical property of fluids that determines how easily a fluid will flow. Consider two parallel plates, one on top of the other, separated by a fluid layer of uniform thickness, H. Assume that the plates each have an area equal to $A$. Suppose that the bottom plate is held fixed while the top plate is forced to slide at a constant speed, $U$, causing the intervening fluid to be sheared between the plates. The force, $F$, required to slide the top plate, is divided by the area of the plate, A, to obtain the shear stress, $\tau$ :

$$
\tau=\frac{F}{A}
$$


The rate at which the fluid is sheared by the sliding plates is called the shear rate, $\dot{s}$, defined as

$$
\dot{S}=\frac{U}{H}
$$

From this definition it can be seen that shear rate is independent of the fluid's properties. Viscosity, $\eta$, is defined as the ratio of shear stress to shear rate, or

$$
\eta=\frac{\tau}{\dot{s}}
$$

Viscosity is thus an indication of the amount of stress (force/area) required to cause a fluid to flow at a given rate.

Fluids for which the ratio $\tau / \dot{S}$ is constant for all values of $\dot{S}$ are called Newtonian fluids. A plot of shear stress versus shear rate for a Newtonian fluid results in a straight line through the origin with a slope equal to $\eta$. In general, sludges, sediments, and most slurries are non-Newtonian fluids in that the ratio $\tau / \dot{S}$ is not constant, but rather varies with shear rate. The behavior of non-Newtonian fluids is discussed in Chapter 3. 


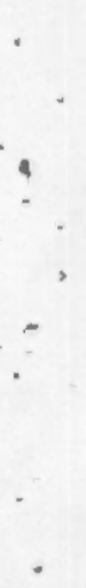




\subsection{MECHANICAL AND RHEOLOGICAL MODELS FOR SLUDGE FLOW BEHAVIOR}

The mobilization of slurries and sludges involves the transformation from a solid (or pseudo-solid) to a viscous fluid. Mathematical models that describe slurry/sludge flow behavior are discussed in this chapter. Flow behavior in the elastic regime is discussed in Section 3.1; the flow behavior present in the viscous regime, in Section 3.2. The relationship between an important elastic regime property, shear strength $\left(\tau_{s}\right)$, and a significant viscous regime property, yield stress $\left(\tau_{y}\right)$, is explored in Section 3.3 .

\subsection{FLOW BEHAVIOR IN THE ELASTIC REGIME}

The simple physical model of a nonbrittle, elastic body was presented in Chapter 2. This model describes the cohesive behavior of a sludge in an undisturbed state. The idealized shear-stress/shear-strain relationship for this model was shown schematically in Figure 2.1 and is characterized by the parameters $G$ and $\tau_{s}$. The validity of this model depends on whether the sludge behaves elastically until the shear strength is exceeded. In reality, it has been shown that many cohesive solids, e.g. clays, exhibit irreversible strain, or creep, at constant stress (Evans, Hanley and Hess 1984; Vaid and Campanella 1977; Athanasopoulous and Richart 1983). Practically speaking, this means that rather than being elastic, clays often behave as extremely viscous fluids, with viscosity approaching infinity but still being finite as shear rate approaches zero (Tanner 1983; Rehbinder 1954). However, the stress-strain behavior of such clays still reaches a peak value of stress beyond which viscosity rapidly decreases at constant shear rate. For our purpose, this peak stress can be considered the same as a yield stress; i.e., the question whether the path leading to failure involves reversible elastic strain or permanent plastic strain is not within the scope of this report.

\subsubsection{Mises-Hencky Flow Condition for Plastic Materials}

An interesting parameter sometimes used by rheologists to define the resistance of a cohesive solid to flow is the plastic resistance, $E_{p l}$, defined by Reiner (1949) as 


$$
E_{p 1}=\tau_{s}{ }^{2} / 2 G
$$

This equation is known as the Mises-Hencky flow condition, which, according to Mises (Reiner 1949) is the flow condition for any plastic material whether it obeys ideal elastic behavior in the elastic regime or not.

\subsubsection{Effect of Settling Time on Shear Strength of Sample}

There is one more complexity associated with time-dependent flow behavior, which appears to be the rule rather than the exception in both simulated and actual (Abdelhamid 1982) tank sludges. The shear strength of a material often depends on that material's shear history. For example, a non-radioactive sludge sample allowed to sit undisturbed in a viscometer for $18.5 \mathrm{~h}$ exhibited a shear strength of $24.6 \mathrm{dyne} / \mathrm{cm}^{2}$, whereas initial measurements taken approximately 5 min after loading the sample in the viscometer indicated a maximum shear strength of only 8.2 dyne $/ \mathrm{cm}^{2}$ (data cited in Section 4.7 ). Therefore, for materials that form gels, shear strength depends on shear history.

\subsection{FLOW BEHAVIOR IN THE VISCOUS REGIME}

In the viscous regime, flow behavior is described by viscosity, which is the relationship between shear stress, $\tau$, and shear rate, $\dot{S}$. The ratio $\tau / \mathcal{S}$ is equal to viscosity, $\eta$, and is constant over all shear rates for Newtonian fluids. In general, tank sludges and slurries are non-Newtonian in that the ratio $\tau / \dot{S}$ is not constant over all values of $\dot{S}$. For this reason, the viscosity of non-Newtonian fluids is referred to as "apparent viscosity," $\eta_{a p p}$.

The flow behavior of time-independent, non-Newtonian fluids that display pseudoplastic properties is described in Section 3.2.1. The behavior of timeindependent, non-Newtonian fluids that exhibit yield stresses is discussed in Section 3.2.2. Time-dependent, non-Newtonian flow sytems are described in Section 3.2.3.

\subsubsection{Flow Behavior of Non-Newtonian Fluids, the Power Law}

The shear-stress/shear-rate relationships for several time-independent, non-Newtonian fluids are plotted in Figure 3.1. The pseudoplastic curve in 


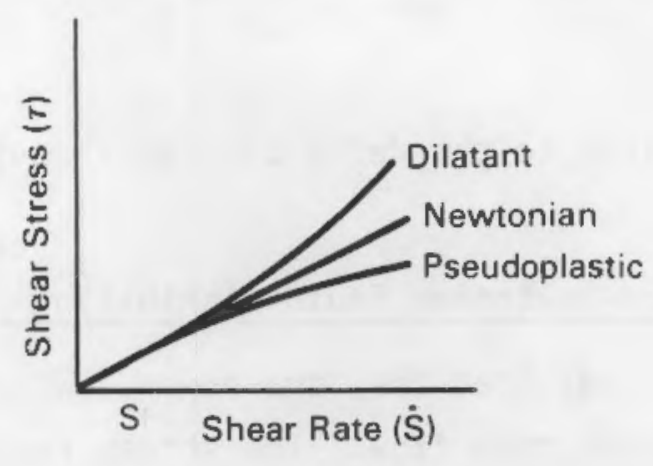

FIGURE 3.1. Rheograms for Time-Independent Non-Newtonian Fluids Not Exhibiting Yield Stress (MeCarthy, Chan and Lokken 1985)

Figure 3.1 falls below the Newtonian line, indicating that at high shear rates, a pseudoplastic fluid "thins out" so that less stress is required to sustain fluid motion. Pseudoplastic behavior is for this reason also called "shearthinning" behavior. Dilatant fluids on the other hand, exhibit "shearthickening" behavior.

The shear-stress/shear-rate behavior of these non-Newtonian fluids has been successfully described by the power law equation (Merrington 1949; Govier and Aziz 1972):

$$
\tau=k \dot{S}^{n}
$$

where $k=$ consistency index, dyne $/ \mathrm{cm}^{2} s^{n}$

$n=$ flow behavior index, dimensionless

$\tau=$ shear stress, dyne $/ \mathrm{cm}^{2}$

$\dot{s}=$ shear rate, $s^{-1}$.

The significance of the flow behavior index is that if $n=1$, the fluid is Newtonian; if $n<1$, the fluid is pseudoplastic or "shear thinning; and if $n>1$, the fluid is dilatant or "shear thickening."

For non-Newtonian fluids that obey the power law, the apparent viscosity, $n_{a p p}$, in centipoise at a specific shear rate, is defined by the expression 


$$
\eta_{a p p}=\frac{k \dot{S}^{n-1}}{100}
$$

This expression is equivalent to the definition of viscosity given by Equation 2.5.

\subsubsection{Flow Behavior of Non-Newtonian Fluids Exhibiting Yield Stress}

Some non-Newtonian fluids that obey the power law can sustain a certain amount of shear stress before they flow. The stress required to initiate motion in such fluids is called the "yield stress," $\tau_{y}$ (Denn 1980). Flow curves for fluids exhibiting a yield stress are shown in Figure 3.2. Note that these curves have slopes identical to those in Figure 3.1 but are displaced from the origin by an amount equal to $\tau_{y}$. The shear-stress/shear-rate behavior of these fluids is described by a modified form of the power law (Govier and Aziz 1972):

$$
\tau=\tau_{y}+K \dot{S}^{n}
$$

Note that Equation 3.4 reduces to Equation 3.2 when $\tau_{y}=0$.

\subsubsection{Time-Dependent Flow Behavior in Non-Newtonian Fluids, Thixotropy and Rheopexy}

The flow behavior of many non-Newtonian fluids such as most sludges and some slurries can be time dependent. Fluids that become thinner with time when stirred at a constant rate are called thixotropic, those that thicken with time are called rheopectic fluids (Blair 1949).

The characterization of time-dependent behavior in terms of a mathematical model for shear stress versus time and shear rate has been described by Ford and Steffe (1986). Measurements of shear vane torque versus time at several rates of revolution are required to develop the mathematical model. These data can be somewhat difficult to obtain because pre-shear conditions must be controlled prior to each measurement. Due to the difficulty involved, past 


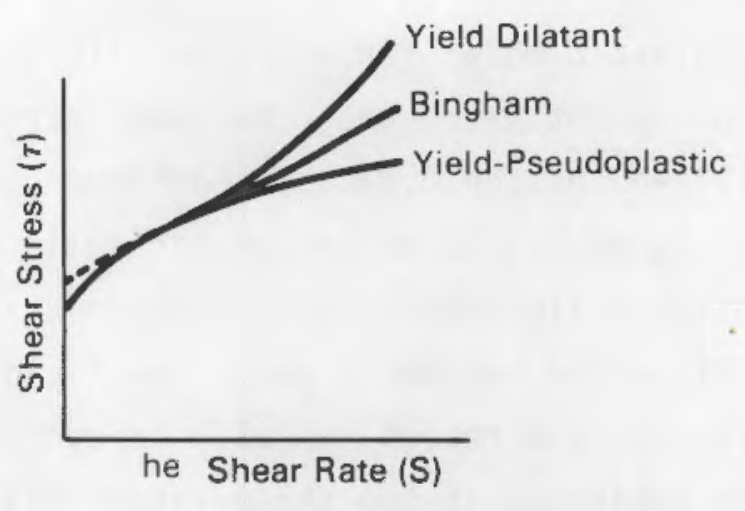

FIGURE 3.2. Rheograms for Time-Independent Non-Newtonian Fluids Exhibiting Yield Stress (McCarthy, Chan and Lokken 1985)

practice at PNL and elsewhere has been merely to note thixotropic behavior rather than to describe it in terms of a mathematical model. Reporting the shear stress required to initiate motion in undisturbed sludge, defined as shear strength, $\tau_{s}$, is usually sufficient.

The viscosity corresponding to the peak value of stress (equivalent to shear strength) at which a material begins to fail through plastic deformation is called the maximum plastic viscosity, $\eta$, defined by Rehbinder (1954) as

$$
\eta_{0}=\lim \left[\frac{\tau}{\dot{s}}\right] \text { as } \tau+\tau_{s}(\dot{s} \rightarrow 0)
$$

Extremely high values of $\eta_{0}$ have been reported as a means of describing the creeping flow behavior of cohesive materials. In particular, Rehbinder reported, "...a peculiar creep in an undisturbed structure with a Newtonian viscosity of the order of $10^{7}-10^{9}$ Poises, for dilute bentonite suspensions, which is $10^{8}$ higher than the minimum viscosity of a disturbed structure." Values of $\eta_{0}$ are occassionally reported as "yield viscosity" or "start-up viscosity." Where possible (see discussion in Section 4.1 ), values of $\tau_{5}$ are reported instead of $\supsetneqq$. 


\subsection{SHEAR STRENGTH AND YIELD STRESS}

In the yield-pseudoplastic model for a viscous fluid, the yield stress will in general have a different value than the shear strength that appears in the elastic solid model (see Section 2.2). The difference, in terms of sludge mobilization, is that a sludge begins as an elastic solid with a shear strength $\tau_{s}$, proceeds to a thixotropic fluid when $\tau_{s}$ is exceeded, and with time eventually achieves steady state and becomes a power law fluid that may exhibit a yield stress. Therefore, in this report, $\tau_{y}$ will be considered the timeindependent yield stress exhibited in the steady-state viscous regime. The shear strength, on the other hand, is dependent upon shear history and, thus, upon time. It is exhibited during transient "start-up" shear, and marks the transition from a solid to a viscous slurry. Although the distinction between $\tau_{y}$ and $\tau_{s}$ is not often made, the values are fundamentally different. Figure 3.3 illustrates the locations of $\tau_{y}$ and $\tau_{s}$ on a plot of stress versus time at constant shear rate for a hypothetical tank sludge.

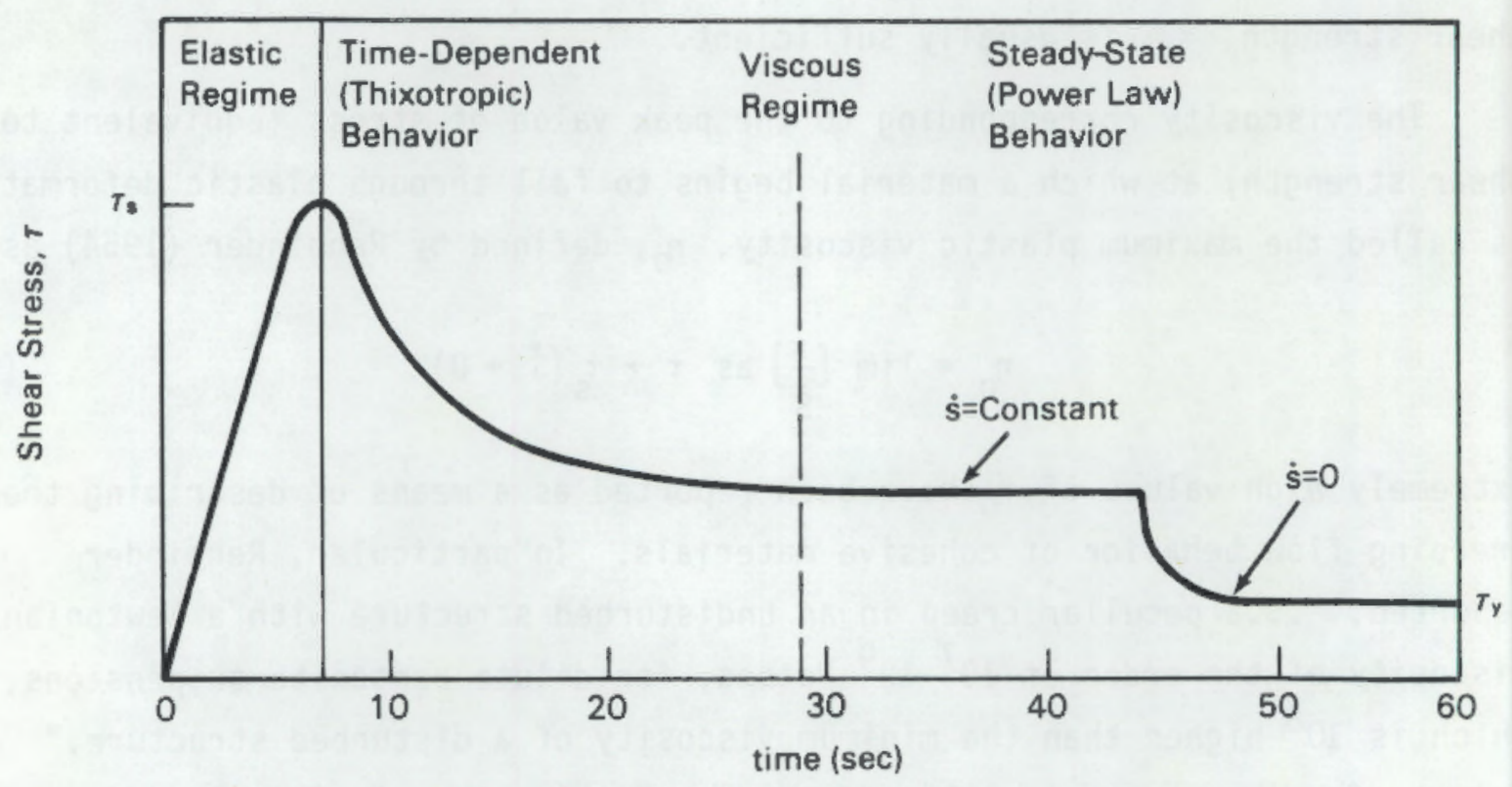

FIGURE 3.3. Plot of Shear Stress Versus Time at Constant Shear Rate for a Hypothetical Tank Sludge. The locations of yield stress $\left(\tau_{y}\right)$ and shear strength $\left(\tau_{s}\right)$ are shown. 


\subsection{MEASUREMENT OF SLUDGE PARAMETERS IN THE LABORATORY USING ROTATIONAL VISCOMETERS}

This chapter describes how the parameters $\tau_{s}$ in the elastic regime and $\eta_{a p p}, \eta_{0}, \tau_{y}, n$, and $k$ in the viscous regime can be measured in the laboratory by means of rotational viscometers. A rotational viscometer is a device that measures the torque required to rotate a spindle through a sample.

Brookfield and Haake Rotovisco rotational viscometers can be used to measure sludge parameters. Both operate according to the same basic principles. Figure 4.1 is a schematic of a Haake viscometer equipped with a concentric cylinder spindle arrangement. A motor rotates the inner cylinder

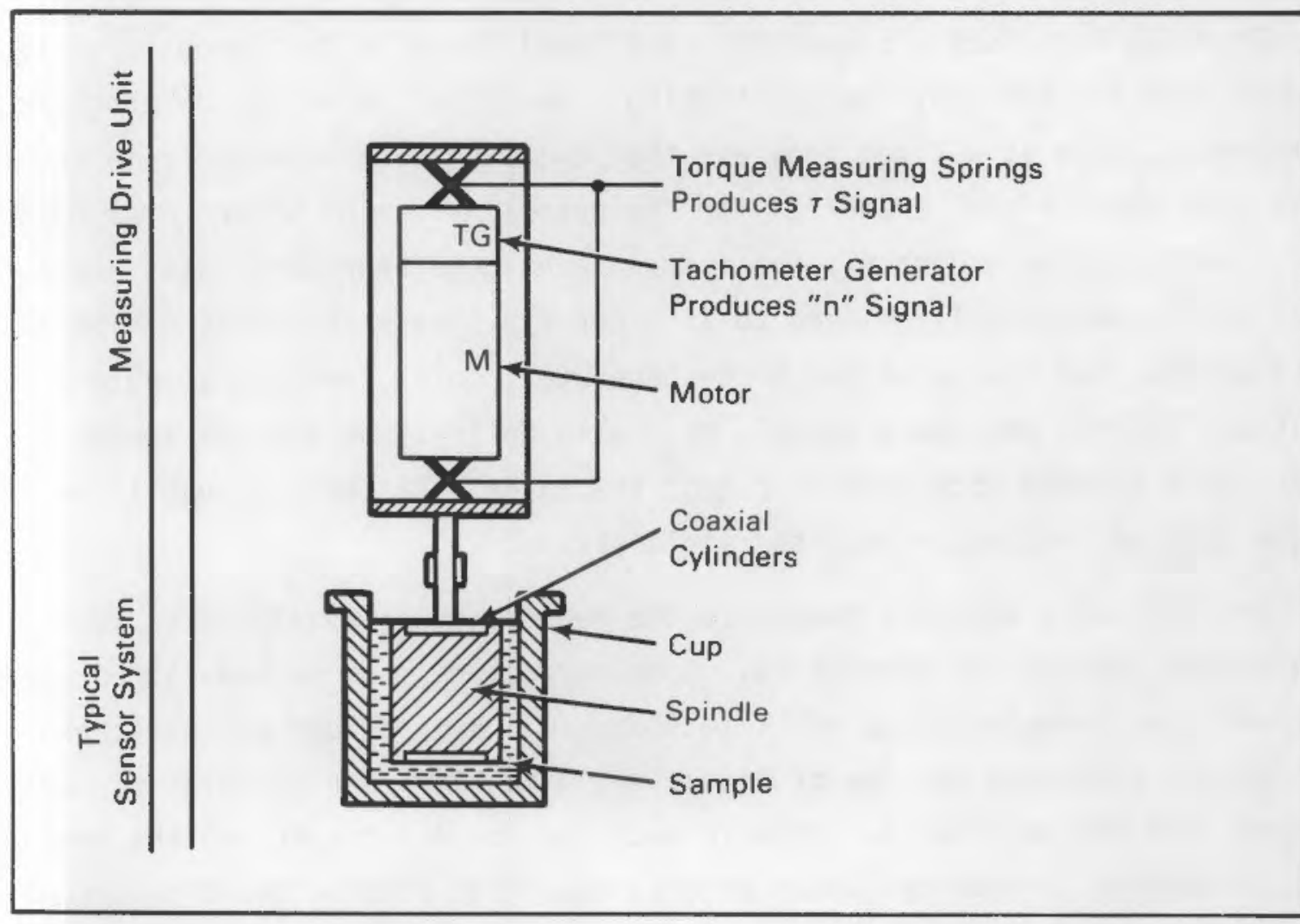

\section{FIGURE 4.1. Schematic of a Haake Viscometer} (adapted from Schramm 1981)

Brookfield Engineering Laboratories, Inc., Stoughton, Massachusetts. गHaake Mess-Technik GmbH and Company, Karlsruhe, West Germany. 
(spindle) through a sample. A torque, caused by the resistance of the sample to shearing, acts on the spindle. This torque deflects a measuring spring placed between the motor and the spindle drive shaft. The spring deflection is transformed into an electrical signal, which is recorded on a chart or pen recorder. The magnitude of the spring deflection correlates linearly with the torque.

On a Brookfield viscometer, spindle speed is variable in eight discrete steps. The rate of spindle rotation is selected by rotating an eight-position knob on the left-hand side of the instrument body. Two Brookfield viscometers are available: the RVDT and the LVDT. The LVDT model has eight available speeds: $0.3,0.6,1.5,3.0,6.0,12,30$, and $60 \mathrm{rpm}$. The RVDT model can be operated at several speeds: $0.5,1.0,2.5,5.0,10,20,50$, and $100 \mathrm{rpm}$.

On Haake Rotovisco viscometers, rotational speed is continuously variable between 0.01 and $500 \mathrm{rpm}$. During testing, rotational speed can be programmed to increase, hold at a fixed rpm, and then decrease over selected time intervals. The speed signal (required for the determination of shear rate) does not come from the spindle directly but from a tacho-generator which sits above the motor and is mechanically linked to it. For slurries that do not exhibit a yield stress, the speeds of the tacho-generator, motor, and the spindle are identical so that the speed signal, $n_{t g}$, also defines the spindle speed, $n_{r}$. A slurry with a yield stress will "clamp" the spindle to the cup, until the torque applied is greater than the yield stress.

The following sections summarize the methodologies available to identify significant rheological parameters. Such parameters must be understood before equipment can be designed to mobilize sludges in underground storage tanks. Section 4.1 discusses the use of Brookfield disc and T-bar spindles to measure apparent and minimum plastic viscosities. Section 4.2 focuses on the measurement of apparent viscosity, shear stress, and shear rate by means of concentric cylinder spindles. An example calculation is provided. Section 4.3 examines the use of miniature shear vanes to measure apparent viscosity, shear stress, and shear rate, and provides two methods. Section 4.4 describes the measurement of steady-state yield stress by means of a rheogram and by torque decay. In Section 4.5, rheograms are used to determine power law coefficients. Two 
examples 11 lustrate the method. Section 4.6 contains tests for detection of time-dependent flow behavior in sludges, and Section 4.7 describes the measurement of non-steady-state shear strength.

\subsection{MEASUREMENT OF APPARENT VISCOSITY ANO MAXIMUM PLASTIC VISCOSITY BY MEANS OF STANDARO BROOKFIELD DISC AND T-BAR SPINDLES}

Several types of spindles are available for use with Brookfield and Haake viscometers. The geometries of various Brookfield standard viscometer spindles are shown in Figure 4.2. Because of their shape, the T-bar and disc spindles allow measurement of viscosity, but at undefined shear rates. These spindles cannot compare shear stress and shear rate; they can measure only viscosity and spindle rotational speed. Values of viscosity are determined by recording the viscometer torque reading, $R_{t}$. A T-bar or disc spindle is rotated at a fixed rpm through a sample and $R_{t}$ is multiplied by an empirical spindle factor to arrive at sample viscosity in centipoise (Brookfield 1984):

$$
\eta=R_{t} \cdot M
$$

where $\eta=$ sample viscosity, centipoise

$R_{t}=$ viscometer torque reading, 0 to 100 full-scale, dimensionless

$M=$ empirical, rpm-dependent factor provided by Brookfield for each disc and T-bar spindle.

The data in Figure 4.3, a hypothetical plot of viscometer torque output reading versus time at constant RPM, was obtained by immersing a T-bar spindle in a gelled, cohesive sludge sample. The plot's peak occurs at the moment that the sludge's shear strength is exceeded. Consistent with the definition given by Equation (3.5), the viscosity calculated from the peak value of torque is the maximum plastic viscosity, $\eta_{b}$. 

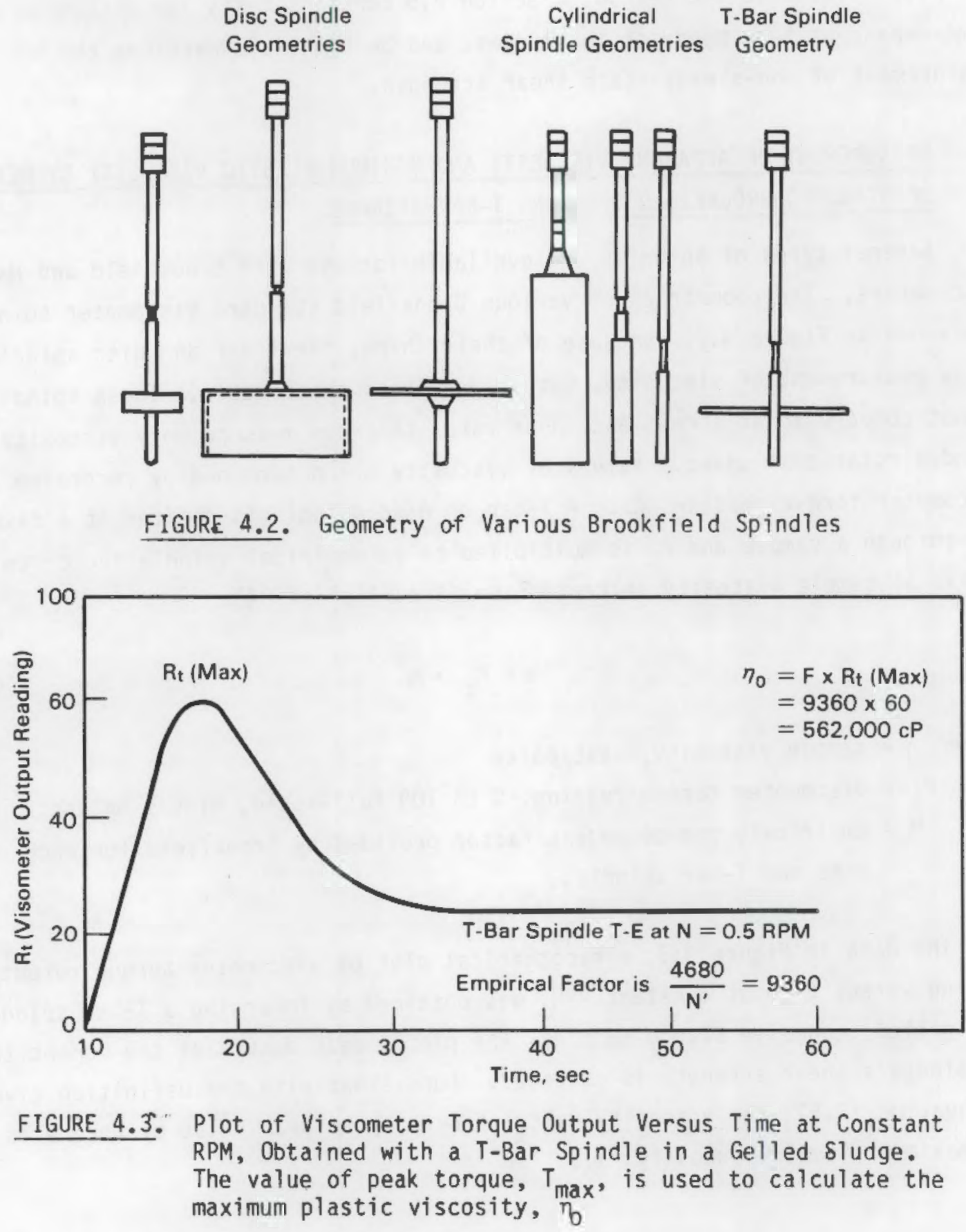

Because shear rate is not defined for T-bar spindles, the shear strength associated with this value of $\eta_{0}$ cannot be calculated. As discussed in Section 4.2, coaxial or concentric cylinder spindles for which shear rates are 
defined should be used, if available, to characterize the flow behavior of non-Newtonian fluids. As described in Section 4.3, shear vanes may also be used, as shear vane rpm can be correlated with shear rate.

\subsection{MEASUREMENT OF APPARENT VISCOSITY, SHEAR STRESS AND SHEAR RATE BY MEANS OF CONCENTRIC CYLINDER SPINDLES}

Concentric cylinder or "Searle-type" rotational viscometers permit direct determination of shear rate versus shear stress and are therefore ideal for characterizing the flow behavior of non-Newtonian fluids. Haake Rotovisco viscometers are Searle types, featuring an inner cylinder (spindle) that rotates within a fixed outer cylinder (cup, see Figure 4.1). Brookfield provides a similar arrangement called the Brookfield UL adapter. Brookfield cylindrical spindles such as those shown in Figure 4.2, can also be used in a concentric cylinder arrangement if the fluid sample is contained in a cylindrical vessel. In this case the outer, fixed cylinder is the sample container itself.

For a concentric cylinder arrangement in which the inner cylinder rotates while the outer cylinder (which may be the inner wall of a sample container) is fixed, shear rate (in inverse seconds) is defined by Brookfield Engineering Laboratories (1984) as

$$
\dot{s}=\frac{2 \cdot \omega \cdot R_{c}^{2} \cdot R_{b}^{2}}{x^{2}\left(R_{c}^{2}-R_{b}^{2}\right)}
$$

where $\omega=$ angular velocity of spindle in rad/s equivalent to $(2 \pi / 60)$ (RPM)

$R_{c}=$ radius of container, $\mathrm{cm}$

$R_{b}=$ radius of spindle, $\mathrm{cm}$

$x=$ radius at which shear rate is being calculated (usually taken as $\left.x=R_{b}\right)$.

Shear stress in dyne/cm is defined as

$$
\tau=\frac{T}{2 \pi \cdot R_{b}^{2} \cdot L}
$$


where $T=$ torque measured by instrument, dyne-cm

$L=$ effective length of spindle, cm.

Brookfield Engineering Laboratories (1984) calculates the value of $T$ from the viscometer torque output, $R_{t}$, by

$$
T=\frac{F \cdot R_{t}}{100}
$$

where $F=$ viscometer spring constant, dyne-cm

$R_{t}=$ viscometer output reading, 0 to 100 full-scale, dimensionless.

The effective length, L, of a cylindrical spindle is different from the actual length and is a calculated value that accounts for spindle end effects. The actual and effective lengths, as well as radius, of Brookfield and Haake cylindrical spindles are provided in the viscometer's operating manual.

The output of a Haake viscometer equipped with a cylindrical spindle is shown in Figure 4.4. The figure shows two plots of the shear stress $\left(S_{\tau}\right.$-axis) developed at the wall of a cylinder rotated through a typical sludge sample as a function of shear rate $\left(S_{0}\right.$-axis). Such plots are called "flow curves" or "rheograms." In this figure, shear rate was programmed to increase from 0 to $20 \mathrm{sec}^{-1}$, producing an "up-curve," was held at $20 \mathrm{sec}^{-1}$, and then was decreased to $0 \mathrm{sec}^{-1}$, producing a "down-curve." Note that the up-curve and down-curve do not coincide; i.e., they exhibit a hysteresis. As discussed in Section 4.6.2, such flow curve hysteresis is indicative of time-dependent, thixotropic flow behavior.

Values of shear stress, $\tau$, versus shear rate, $\dot{S}$, can be determined from a Haake rheogram by reading values of $S_{\tau}$ (y-axis) and $S_{D}$ (x-axis) from points taken on the flow curve, and calculating $\tau$ and $\dot{S}$ as

$$
\begin{gathered}
\tau=S_{\tau} \cdot \tau_{\max } \cdot 10, \text { dyne } / \mathrm{cm}^{2} \\
\dot{S}=S_{D} \cdot \dot{S}_{\max }, \mathrm{sec}^{-1}
\end{gathered}
$$




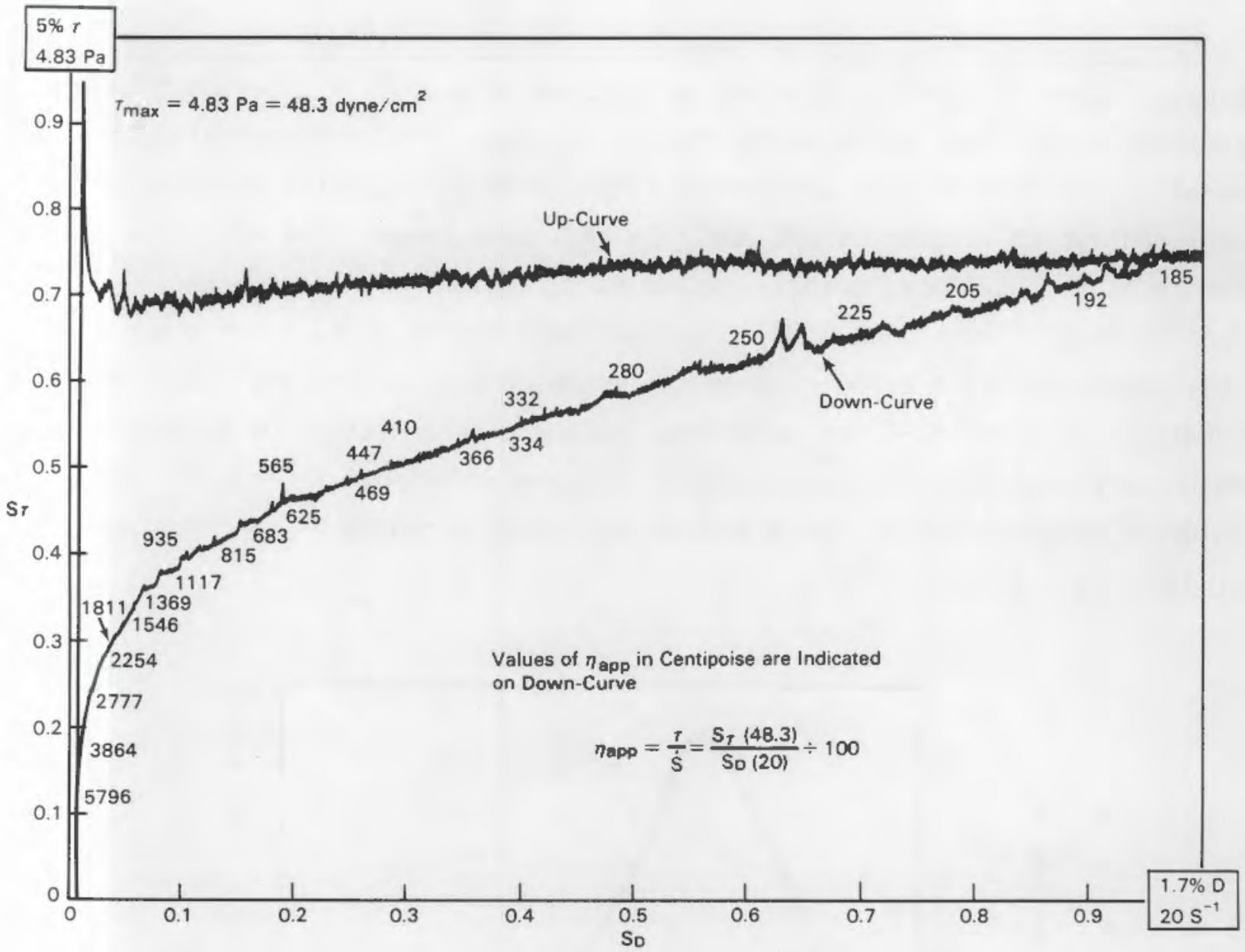

FIGURE 4.4. Rheogram of a Sludge Exhibiting Flow Curve Hysteresis

where $\tau_{\max }=$ full-scale shear stress, $\mathrm{Pa}$

$S_{\max }=$ full-scale shear rate, $\sec ^{-1}$.

The values of $\tau_{\max }$ and $\dot{S}_{\max }$, indicated on each scale of the rheogram, are empirical values (provided by Haake) that depend on the geometry of the specific spindle assembly being used, the torque sensor being used, and the maximum test rpm.

A rheogram can also be produced using a Brookfield viscometer by plotting torque data obtained at several spindle speeds in terms of shear stress versus shear rate. Equations (4.2 and 4.3) are used to convert the data for torque versus rpm to values of shear stress versus shear rate. The following example illustrates how to calculate shear stress from data obtained with a Brookfield concentric cylinder apparatus. 
Example Calculation of $\tau_{s}$ from Brookfield Concentric Cylinder Viscometer

Data. Figure 4.5 , which is a plot of viscometer output, $R_{t}$, versus time at constant shear rate, shows a hypothetical sludge. The hypothetical test incorporates a Brookfield RVDT viscometer fitted with a concentric cylinder arrangement and run at a constant $0.5 \mathrm{rpm}$. In this arrangement, the effective spindle length is $L=9.239 \mathrm{~cm}$, spindle radius is $R_{b}=1.258 \mathrm{~cm}$, and cup radius is $R_{c}=1.381 \mathrm{~cm}$ (Brookfield 1982). By the shape of the plot, it is clear that this sludge exhibits a shear strength, as described in Sections 2.2.1 and 3.3. Equations (4.3 and 4.4) are used to calculate a shear stress of $24.6 \mathrm{dyne} / \mathrm{cm}^{2}$, which corresponds to the peak value of viscometer output, $R_{t}=31.9$. This value of shear stress is equivalent to the shear strength of the hypothetical sludge: $\tau_{\mathrm{s}}=24.6 \mathrm{dyne} / \mathrm{cm}^{2}$.

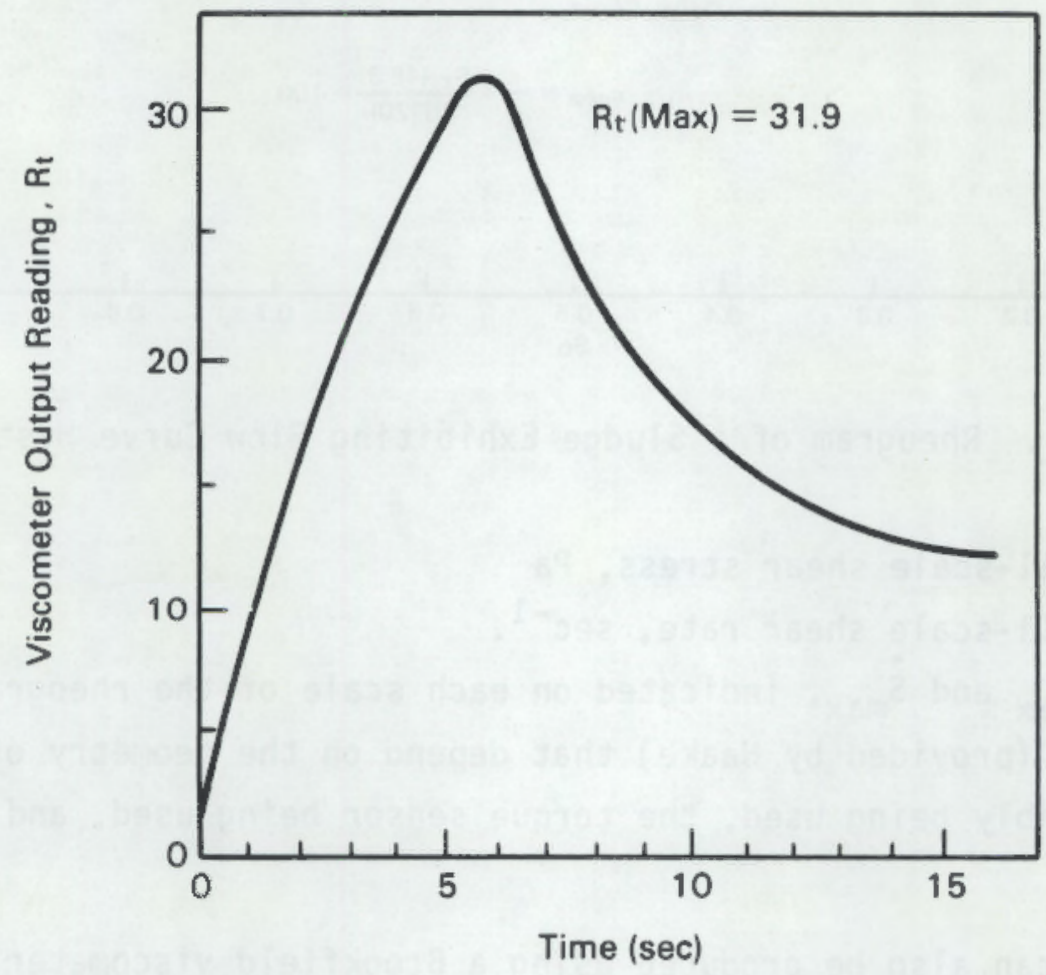

FIGURE 4.5. Plot of Viscometer Output Versus Time at Constant Spindle RPM for a Hypothetical Sludge Sample 


\subsection{MEASUREMENT OF APPARENT VISCOSITY, SHEAR STRESS AND SHEAR RATE BY MEANS OF MINIATURE SHEAR VANES}

Shear vanes have been used for years by soil scientists to obtain convenient and reliable measurements of soil shear strength in the field. A standard shear vane (ASTM 1978) consists of a shaft to which four rectangular vanes or blades are attached as shown in Figure 4.6. Three shear vanes that have been used in testing at PNL are shown in Figure 4.7. As described in Chapter 5, shear vanes can be used to determine viscosity as well as shear strength. A correlation was developed between shear vane rotational speed and shear rate, allowing shear vanes to be used in conjunction with a rotational viscometer (or other torque-measuring device) to produce rheograms.

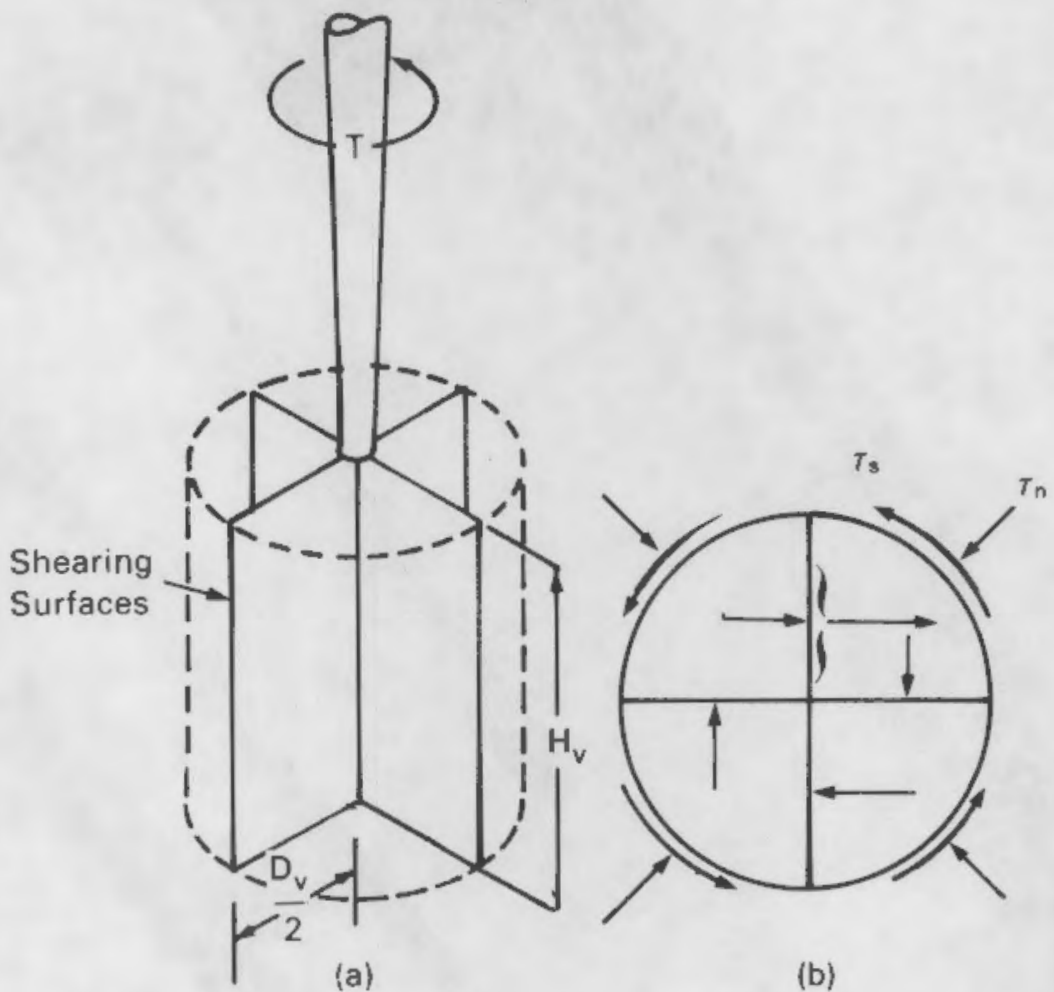

FIGURE 4.6. Shear Vane Geometry. Shearing involves one vertical cylindrical surface and two horizontal end surfaces (a). Twisting of the vane also induces normal stress, $\tau_{n}$, on the shearing surface (b). 


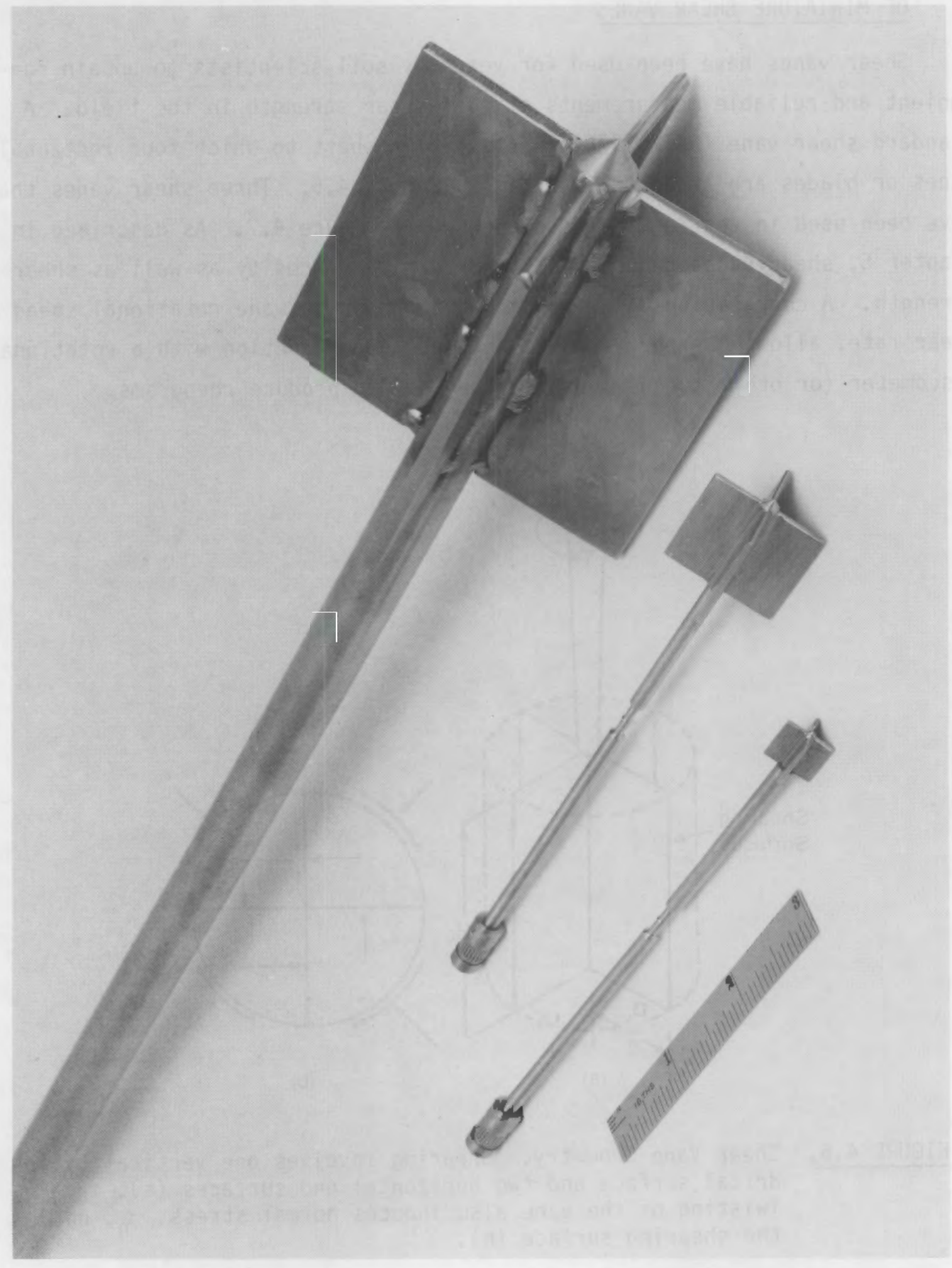

FIGURE 4.7. Three Shear Vanes Used During Testing at PNL 
Shear vanes can be used with Brookfield, Haake, and other rotational viscometers. The two miniature shear vanes shown in Figure 4.7 were made by attaching blades to the end of a standard Brookfield spindle (a) as shown in Figure 4.8. This allowed the miniature vanes to be attached to Brookfield viscometers and operated in the same way as standard Brookfield spindles. A coupling adapter (also fabricated at PNL) was used to attach them to Haake viscometers. The Haake sample cup (Figure 4.1 ) must be removed to accommodate a miniature shear vane.

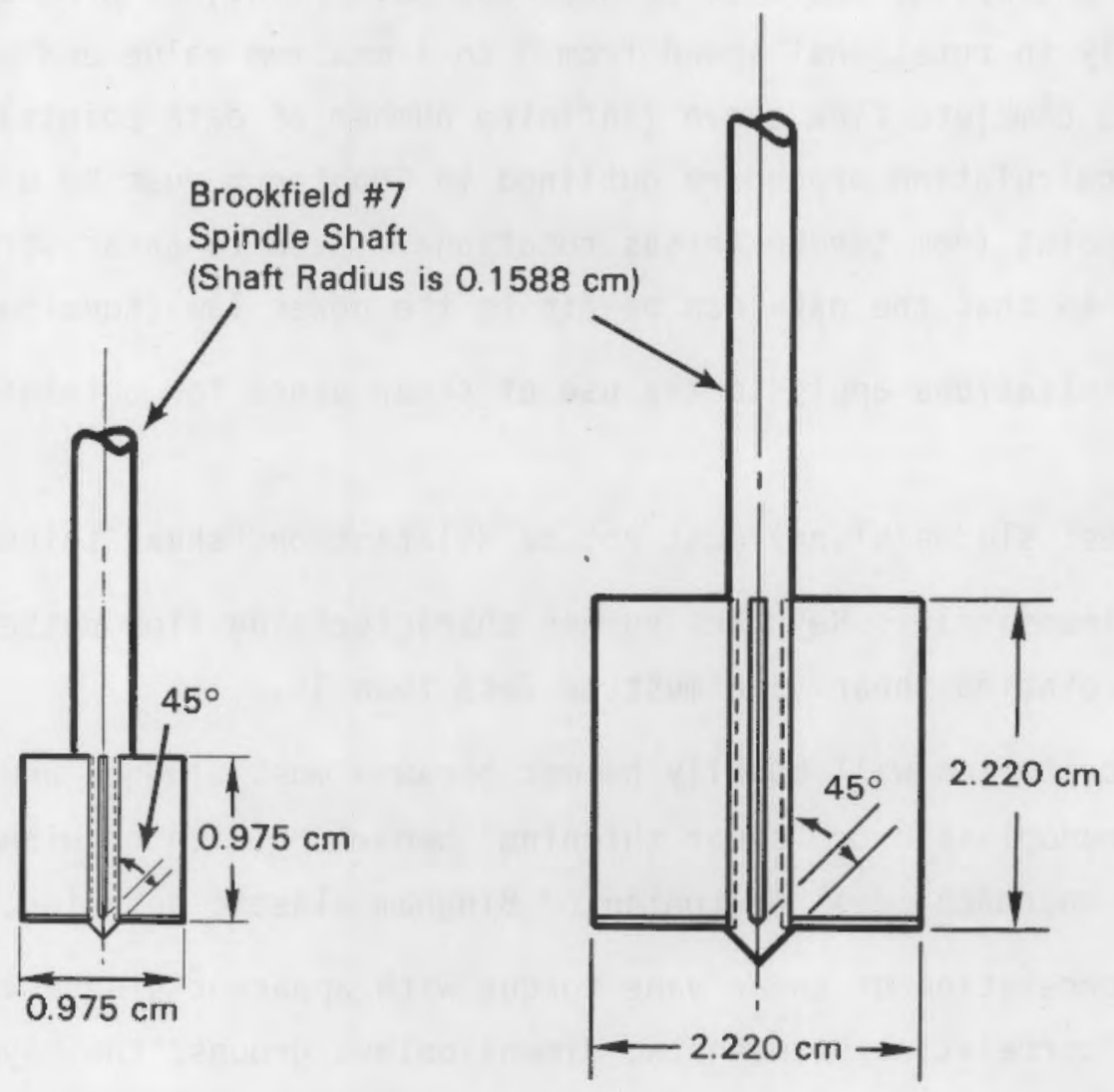

(a) Shear Vane No. 1

(b) Shear Vane No. 2

FIGURE 4.8. Dimensions of Miniature Shear Vanes Used in Testing at PNL

(a) Brookfield spindle No. RV-7. 
Shear vanes are operated in the same way as standard Brookfield and Haake spindles. When a shear vane is attached to a Brookfield viscometer, it is rotated at several speeds. The torque required to rotate the shear vane through a sample is measured at each speed. The calculational procedure outlined in Chapter 5 is used to calculate the viscosity, shear rate, and shear stress associated with each torque versus rpm data point. A rheogram is produced by plotting shear stress versus shear rate for several data points.

Used in conjunction with a Haake viscometer, a shear vane can either be rotated at a constant speed to produce one data point, or programmed to vary continuously in rotational speed from 0 to a maximum value and back down to 0 , producing a complete flow curve (infinite number of data points). In either case, the calculation procedure outlined in Chapter 5 must be used to transform each data point from torque versus rotational speed to shear stress versus shear rate so that the data can be fit to the power law (Equation 3.2).

Two limitations apply to the use of shear vanes for obtaining viscosity data:

1. The test sludge/slurry must not be dilatant or "shear thickening."

2. The dimensionless Reynolds number characterizing flow patterns set up by a rotating shear vane must be less than 15 .

The first criterion will usually be met because most sludges and slurries exhibit pseudoplastic or "shear thinning" behavior (with or without a yield stress) or approach ideal Newtonian or Bingham plastic behavior.

The correlation of shear vane torque with apparent sludge viscosity is based on a correlation between two dimensionless groups, the Reynolds number, $N_{R E}$, and the power number, $N_{p}$, where

$$
N_{R E}=\frac{1.667 \rho D_{v}^{2} \mathrm{~N}}{\eta_{a p p}}
$$




$$
N p=\frac{22,620 T_{v}}{\rho D_{v}^{5} N^{2}}
$$

$$
\text { and where } \begin{aligned}
\rho & =\text { test fluid (sludge) density, } \mathrm{g} / \mathrm{cm}^{3} \\
D_{v} & =\text { shear vane diameter, } \mathrm{cm} \\
\mathrm{N} & =\text { rate of shear vane rotation, rpm } \\
\eta_{a p p} & =\text { test fluid viscosity, cPs } \\
T_{v} & =\text { shear vane torque, dyne-cm. }
\end{aligned}
$$

This correlation, further discussed in Chapter 5, serves to relate values of shear vane torque through the power number to values of sludge viscosity through the Reynolds number. As discussed in Chapter 5, PNL test data confirms that the $\mathrm{N}_{\mathrm{RE}}-\mathrm{Np}$ correlation is valid only for Reynolds numbers less than 15. Above $\mathrm{N}_{\mathrm{RE}}=15$, the power number gradually becomes independent of the Reynolds number.

In practice, one cannot know whether the $\mathrm{N}_{\mathrm{RE}}<15$ criterion has been met until the data have been analyzed. Table 4.1 can be used as a general guide for predicting maximum rotational speeds such that $N_{R E}<15$ for a variety of test fluid viscosities, densities, and shear vane diameters.

A disadvantage of shear vanes for obtaining viscosity data is that analyzing the shear vane data involves more than multiplying viscometer output reading hy an empirical spindle factor (as is the case with standard viscometer spindles). However, a calculator program designed for use with HewlettPackard HP-41 series calculators greatly speeds up and simplifies data analysis. The program calculates viscosity, shear stress, shear rate, dimensionless Reynolds and Power numbers and includes a correction for shear vane shaft friction. This program, VANE-2, and instructions for using it are provided in Appendix B.

\footnotetext{
ه Hewlett-Packard Company, San Diego, California.
} 
TABLE 4.1. Maximum Shear Vane Rotational Speed $\left(\mathrm{N}_{\max }\right)^{(a)}$ for Apparent Viscosity Measurement

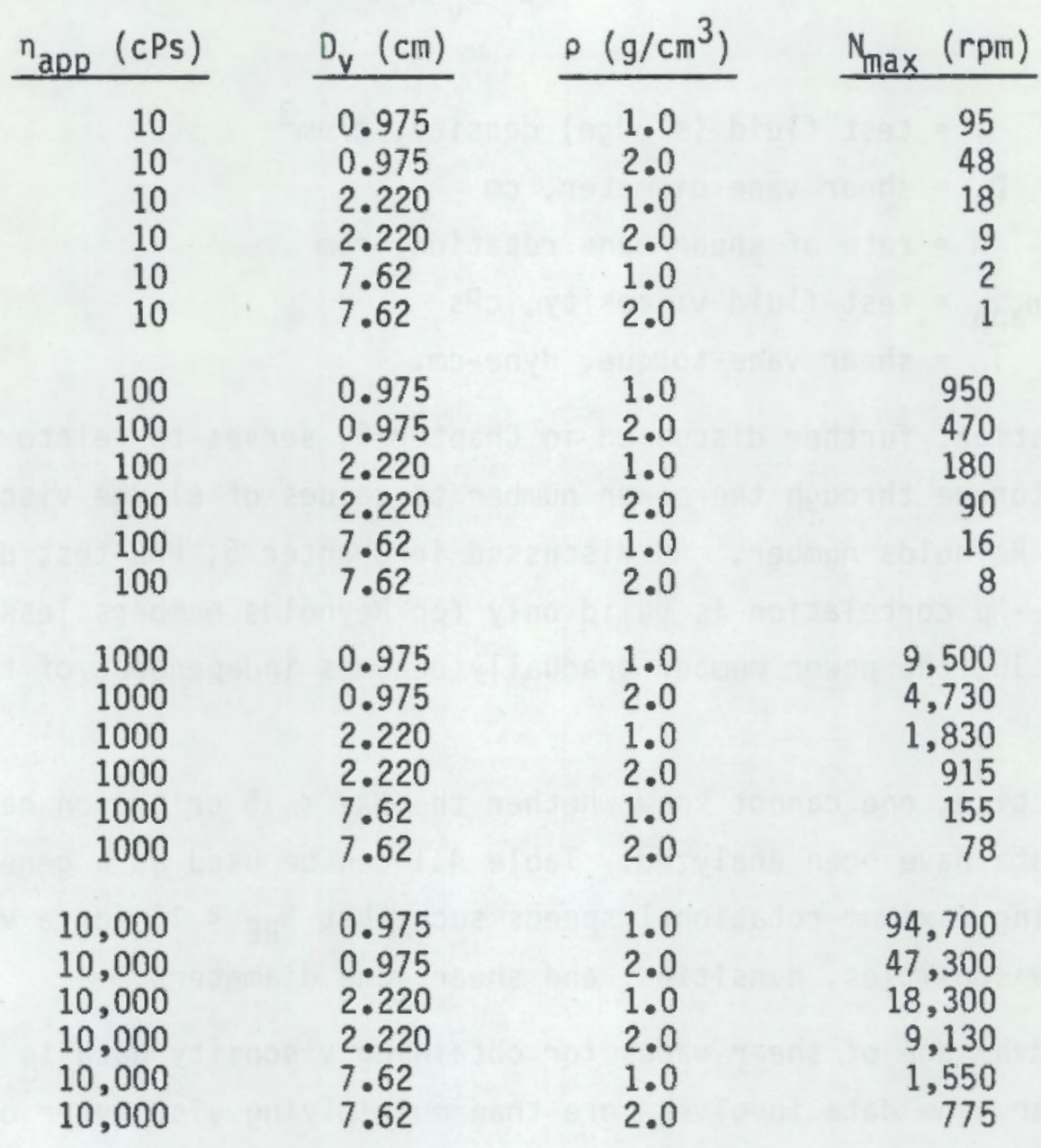

(a) Values of $\mathrm{N}$ at or below $\mathrm{N}_{\max }$ assure that $\mathrm{N}_{\mathrm{RE}}<15$.

\subsection{MEASUREMENT OF STEADY-STATE YIELO STRESS}

There are two general methods for determining yield stress, $\tau_{y}$. The first involves extrapolation of a rheogram ( $p l$ ot of shear stress versus shear rate) to a shear rate of zero as discussed in Sections 4.4.1. An optimization procedure for this method is described in Section 4.4.2. The second method involves measuring residual torque on a spindle that has stopped rotating, and using the measured residual or decay torque to calculate a value of $\tau y^{*}$ This method, which can provide more precise data than the extrapolation procedures, is discussed in Section 4.4 .3 . 


\subsubsection{Extrapolation of Test Data to Zero Shear Rate}

Figure 4.9 illustrates a Haake flow curve produced under steady-state conditions for a sludge that exhibits a yield stress. At low shear rates, the flow curve appears to be a straight line with a slope of about $4^{\circ}$ off of vertical. The curve then abruptly changes (at about $\dot{S}=5 \mathrm{~s}^{-1}$ ) to a flow curve for a non-Newtonian fluid. Flow curves having this general shape, characterized by a marked deflection near a shear rate of zero, indicate the presence of a finite yield stress.

The elastic solid flow curve indicated in Figure 4.9 is produced when a spindle (concentric cylinder or shear vane) stops rotating at a finite level of torque. What happens mechanically is that at and below its yield stress, a

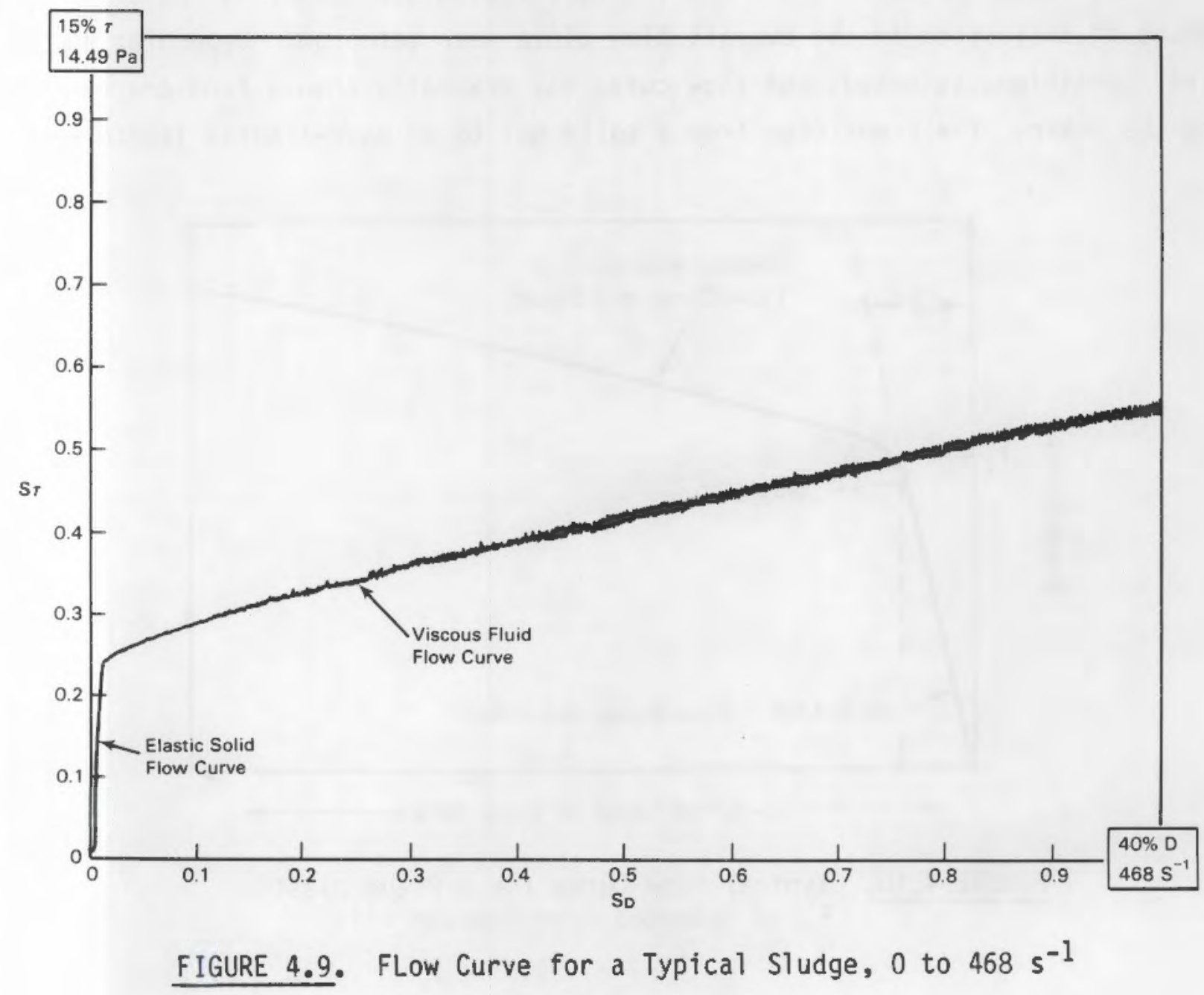


sludge behaves as a non-flowing solid and "clamps" the spindle, preventing rotation. While the spindle is still clamped and remains at a standstill, the motor rotation will cause some spring deflection and consequently a torque signal on the ordinate. For a slurry with a yield stress, a straight line, leaning off the vertical with an angle $\beta$, is recorded initially as shown in Figure 4.10. When the shear stress surpasses the yield value $\tau_{y}$, the spindle breaks loose from its "clamp," and the rotor picks up speed, accelerating almost instantaneously from zero to the value indicated on the $S_{D}$ scale $(X$-axis). Two regimes can be distinguished on the flow curve: the first is a segment of the "flow curve of a solid," while the second regime describes the flow of the material after it has been transformed into a liquid.

The torque at which a spindle begins rotating (up-curve) is indicated by a point of deflection in the overall flow curve near zero rpm. Depending on the test conditions selected, the flow curve may gradually change from one region to the other. The transition from a solid gel to an easy-flowing liquid may

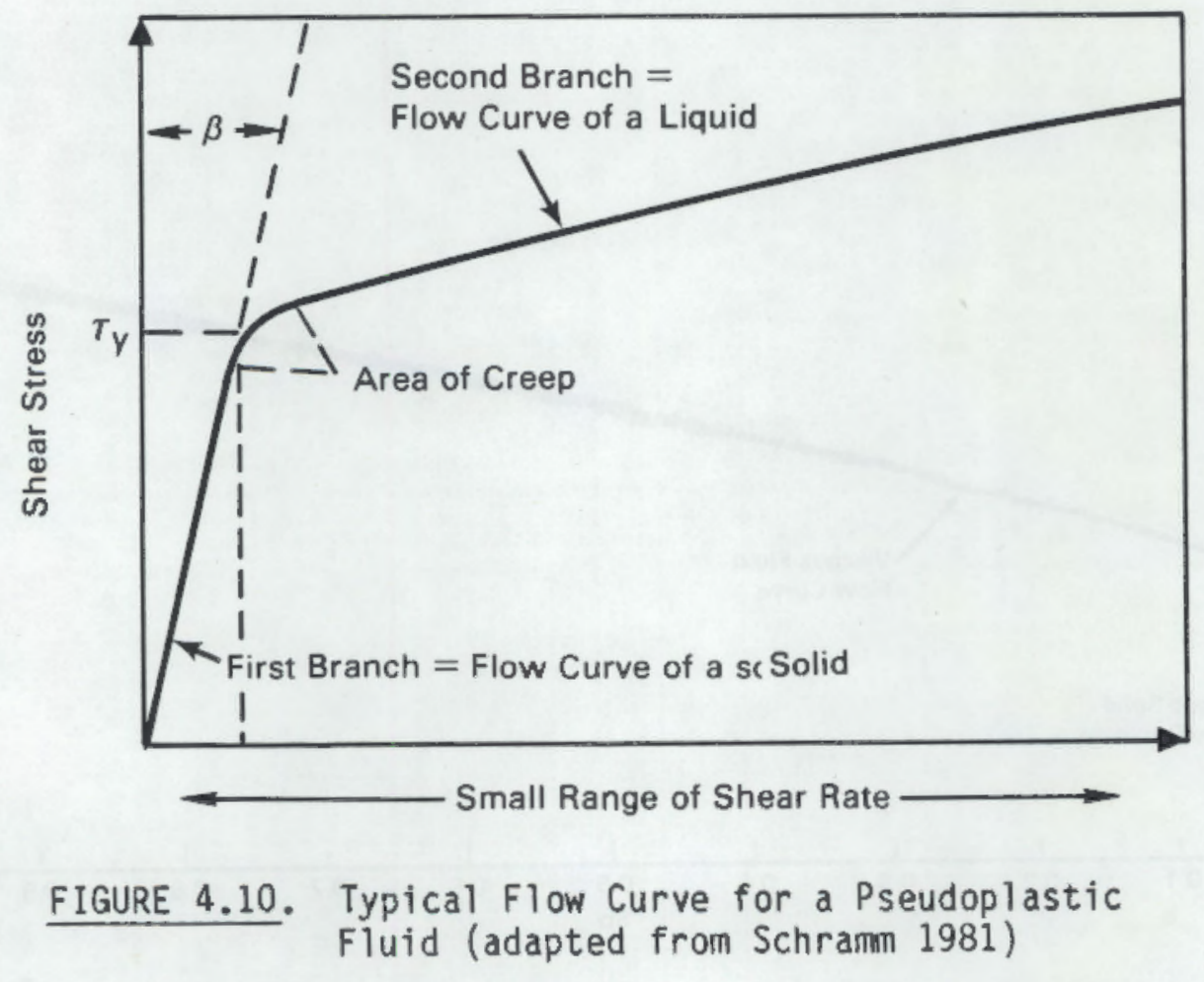


include a phase of creep, which makes the turning point less clear. Under these conditions the yield point is determined by the crossing point of the tangents of the elastic and viscous branches of the rheogram.

If a Brookfield-type concentric cylinder arrangement is used to produce a flow curve, yield stress is calculated by

$$
\tau_{y}=\frac{T}{2 \pi R_{b}^{2} L}
$$

where $T=$ torque measured by instrument, dyne $-\mathrm{cm}$

$L=$ effective length of spindle, $\mathrm{cm}$

$R_{b}=$ radius of spindle, $\mathrm{cm}$.

The torque corresponding to the point of flow curve deflection is calculated by Brookfield Engineering Laboratories (1984) as

$$
T=F \cdot \frac{R_{t}}{100}
$$

where $F=$ spring factor associated with viscometer, dyne-cm

$R_{t}=$ viscometer torque reading, 0 to 100 full-scale, dimensionless.

Values of $\mathrm{F}$ for Brookfield and Haake viscometers are listed in Table 4.2. If a Haake viscometer is used, the torque at the point of flow curve deflection is calculated as

$$
T=F \cdot S_{\tau} \cdot \frac{\% \tau}{100}
$$

where $S_{\tau}=$ viscometer torque scale reading, 0 to 1 full-scale, dimensionless. (a)

$\% \tau=$ torque reading scale factor, 1 to 100 , dimensionless. (a)

(a) Note that $S_{\tau} \cdot \%_{\tau}=R_{t}=$ torque reading (regardless of viscometer used), 0 to 100 full scale, dimensionless. 
TABLE 4.2. Viscometer Spring Constants

\begin{tabular}{lc} 
Torque Sensor System & $F$ (dyne-cm) \\
\cline { 1 - 2 } Brookfield RVDT & 7,187 \\
Brookfield LVDT & 673.7 \\
Haake M1500 & $1,470,000$ \\
Haake M500 & 590,000 \\
Haake M150 & 147,000 \\
Load Cell Torque & $\begin{array}{l}\text { Torque corresponding to } \\
\text { full-scale }\left(R_{t}=100\right) \\
\text { Apparatus }\end{array}$ \\
deflection
\end{tabular}

If a Haake concentric cylinder apparatus is used to produce the rheogram, the yield stress can be calculated directly (without having to calculate torque) via

$$
\tau_{y}=S_{\tau} \cdot \tau_{\max } \cdot 10, \text { dyne } / \mathrm{cm}^{2}
$$

where $\tau_{\max }=$ full-scale shear stress, Pa.

values of $\tau_{\max }$ and $\% \tau$ are indicated on the $S_{\tau}$ scale of Haake rheograms. (a)

If a miniature shear vane is used, in conjunction with a Brookfield or Haake viscometer, torque at the point of flow curve deflection is calculated by Equations (4.10 or 4.11), respectively. The following equation is then used to calculate yield stress (ASTM 1963):

$$
\tau_{y}=\frac{T}{\pi}\left[\frac{H_{v} D_{v}^{2}}{2}+\frac{0_{v}^{3}}{6}\right]^{-1}
$$

where $T_{v}=$ torque applied to shear vane, dyne $-\mathrm{cm}$

$\mathrm{H}_{\mathrm{v}}=$ shear vane blade height, $\mathrm{cm}$

$D_{v}=$ shear vane blade diameter, $\mathrm{cm}$.

(a) In Figure 4.9 for example, $\tau_{\text {max }}=14.49 \mathrm{~Pa}\left(=144.9 \mathrm{dyne} / \mathrm{cm}^{2}\right.$, and $\% \tau=15$ as written in the upper left corner of the plot. 


\subsubsection{Optimizing the Extrapolation Method}

If the presence of a yield stress is detected on a steady-state flow curve such as Figure 4.9, the following procedure can be used to obtain a more accurate value of $\tau_{y}$.

Using a Haake viscometer equipped with a concentric cylinder spindle arrangement or a miniature shear vane, shear the sludge sample at a constant spindle speed (around $5 \mathrm{rpm}$ or lower) until a constant (steady-state) reading is achieved. Then run a down-curve (from 5 to $0 \mathrm{rpm}$ ). If the flow curve plot is expanded in the low rpm range, the point of flow curve deflection is less ambiguous. For example, in Figure 4.11 (a flow curve of the sample represented in Figure 4.9), the low shear rate range is expanded, and the point of

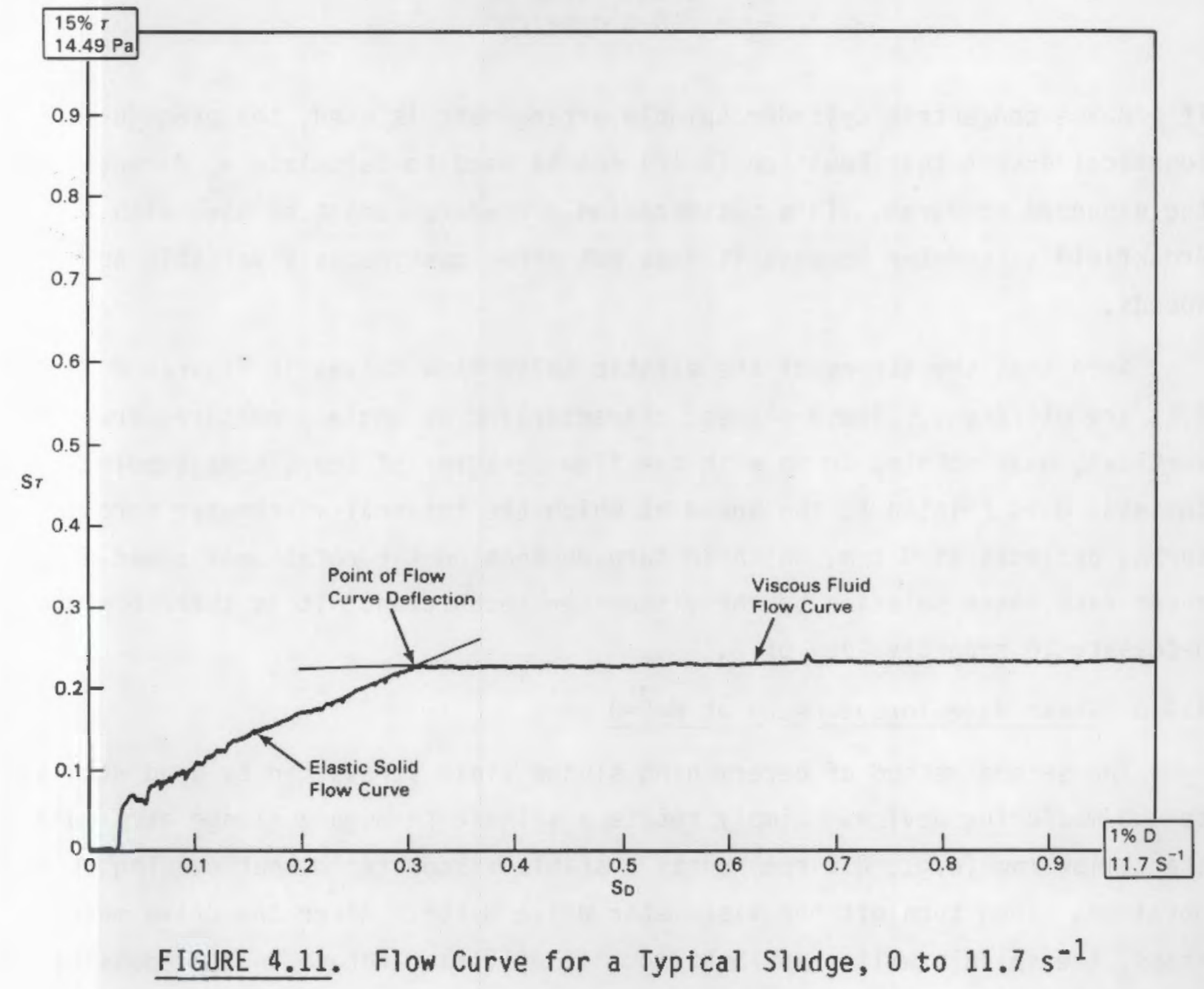


deflection occurs at $S_{\tau}=0.227, R_{t}=3.41$. Using Equations (4.11 and 4.13), and assuming that a shear vane having $H_{v}=D_{v}=2.220 \mathrm{~cm}$ was used to make the measurement, one can calculate yield stress as $\tau_{y}=220 \mathrm{dyne} / \mathrm{cm}^{2}$. The results of this calculation using Option 4 of the calculator program VANE-2 (described in Appendix B) are shown below.

$$
\begin{aligned}
F & =147000.0 \text { dyne }-\mathrm{cm} \\
D_{v} & =2.220 \mathrm{~cm} \\
R_{c} & =3.000 \mathrm{~cm} \\
R_{s} & =0.1588 \mathrm{~cm} \\
T_{c} & =0.000 \text { dyne }-\mathrm{cm} \\
R_{t} & =3.410 \\
H_{v} & =2.220 \mathrm{~cm} \\
T_{v} & =5012.7 \text { dyne }-\mathrm{cm}^{2} \\
\tau_{s} & =218.8 \text { dyne } / \mathrm{cm}^{2}
\end{aligned}
$$

If a Haake concentric cylinder spindle arrangement is used, the procedure is identical except that Equation (4.12) can be used to calculate $\tau_{y}$ directly from the expanded rheogram. This optimization procedure cannot be used with a Brookfield viscometer because it does not offer continuously variable spindle speeds.

Note that the slopes of the elastic solid flow curves in Figures 4.9 and 4.11 are different. These slopes, characterized by angle $\beta$ measured from the vertical, have nothing to do with the flow behavior of the sludge sample. Instead, $\beta$ is related to the speed at which the internal viscometer torque spring deflects at $0 \mathrm{rpm}$, which in turn depends on the rotational speed or shear rate range selected by the viscometer technician. It is therefore not necessary to report values of $\beta$.

\subsubsection{Shear Vane Torque Decay at $N=\dot{S}=0$}

The second method of determining sludge yield stress can be used with any torque-measuring device. Simply rotate a spindle through a sludge at a constant, low rpm (e.g., $0.5 \mathrm{rpm}$ ) until a stable viscometer output reading is obtained. Then turn off the viscometer drive motor. After the drive motor stops, the spindle will stop rotating. It will then rotate in the opposite direction, because of a force imposed by an internal viscometer spring as it 
relaxes to zero deflection. If a yield stress exists, the sludge will clamp the spindle at a finite spring deflection corresponding to a finite torque reading. To calculate $\tau_{y}$ from this reading, Equations (4.9) through (4.13) can be used as appropriate, depending on the viscometer (Brookfield or Haake) and spindle (shear vane or concentric cylinder arrangement). Should the viscometer output signal decay to a torque output reading of zero, then the test material will not exhibit a true yield stress but may instead exhibit creeping (highly viscous) flow at very low shear rates. In cases where a sample fluid exhibits creep at constant stress, the final viscometer output will rapidly reach a certain value and then slowly reach zero as time goes to infinity. Figure 4.12 illustrates the difference in the two sets of behavior and indicates how $\tau_{y}$ should be specified in the case of plastic creep.

\subsection{DETERMINING POWER LAW COEFFICIENTS FROM RHEOGRAMS}

Power law parameters $k$ and $n$ are determined by plotting shear stress versus shear rate in terms of $\log \left(\tau-\tau_{y}\right)$ versus $\log (\dot{S})$. The slope of such a plot is equivalent to $n$. The intercept (at $\log \dot{S}=0$ ) is equivalent to $\log k$. To prepare such a plot requires at least 5 and preferably 10 to 20 viscometer torque readings at as many spindle rotational speeds. The torque reading/rpm

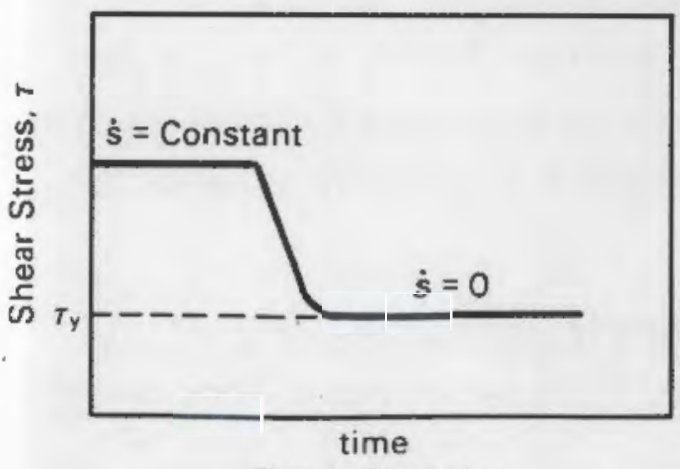

Elastic Behavior

(a)

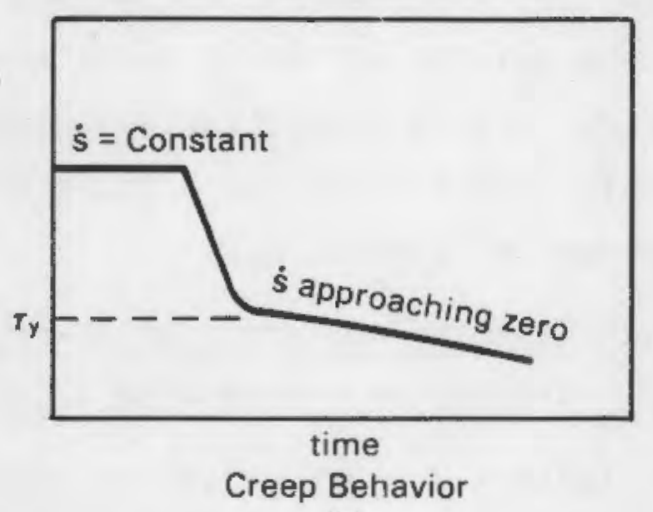

(b)

FIGURE 4.12. Comparison of Elastic and Creep Behaviors as Shear Rate Approaches Zero 
data are then reduced to shear-stress/shear-rate data by using the appropriate equations (depending on the viscometer/spindle arrangement) as described in Sections $4.1,4.2$, and 4.3 .

When a Haake viscometer is used, shear the sample at a constant spindle rotational speed equal to $\mathrm{N}_{\max }$ until a steady state-output is produced. Then ramp spindle rpm from $\mathrm{N}_{\max }$ down to 0 over a period of at least 10 min ( $\operatorname{set} t_{2}=$ $10 \mathrm{~min}$ ). Allow more time if the sample is very thixotropic and appears to require 5 min or more to achieve a steady-state output at $N_{\max }$. Down-curve time can be set at as little as 5 min if the sample is considered not very thixotropic or reaches steady state at $N_{\max }$ in less than $30 \mathrm{~s}$. Read the values of $S_{\tau}$ and $S_{D}$ off of the down-curve--between 10 and 20 points should be read at regularly spaced intervals. If a shear vane is used as the test spindle, convert values of $S_{\tau}$ to values of $R_{t}$ by multiplying by $\% \tau$ (between 1 and 100). Convert values of $S_{D}$ to rpm by multiplying by $N_{\max }$ (maximum shear vane rpm during the test). Then use VANE-2 (Appendix B) to calculate values of shear stress versus shear rate.

If a Brookfield viscometer is used, only eight discrete rotational speeds are available. To obtain a sufficient number of data points (between 10 and 20) use either one spindle with both an LVDT and an RVDT or two different spindles with one viscometer to obtain a maximum of 16 data points. Both Brookfield viscometers can be used with two different spindles for a total of 32 data points. If shear vanes are used, analyze the $R_{t}$ versus $N$ data using VANE-2. The following two examples pertain to cylindrical spindles. An example illustrating how $n$ and $k$ are determined from shear vane data is provided in Appendix B.

4.5.1 Example: Determining Power Law Coefficients with a Brookfield Viscometer Fitted with a Concentric Cylinder Spindle Arrangement

Table 4.3 shows values of shear stress and shear rate obtained for a sludge sample. A Brookfield RVDT viscometer was fitted with the concentric cylinder UL adapter. This sludge was found to exhibit a yield stress (estimated by the torque decay method described in Section 4.4.3) of 2.66 dyne $/ \mathrm{cm}^{2}$. Several replicate measurements were made by rotating the UL spindle at $0.3 \mathrm{rpm}$ until the viscometer output reached a stable reading. The 
TABLE 4.3. Values of Shear Stress and Shear Rate Obtained by Using a Brookfield RV Viscometer with a Brookfield UL Adapter

\begin{tabular}{ccc} 
Shear Rate $\left(\mathrm{S}^{-1}\right)$ & Shear Stress (dyne $\left./ \mathrm{cm}^{2}\right)$ & Viscosity $(\mathrm{CP})$ \\
\cline { 2 - 2 } 0.0 & $2.66(\mathrm{a})$ & -- \\
0.61 & 9.21 & 1510.0 \\
1.22 & 10.31 & 844.8 \\
3.05 & 11.48 & 376.3 \\
6.12 & 12.61 & 206.1 \\
12.24 & 14.10 & 115.2 \\
24.47 & 15.66 & 64.0 \\
61.18 & 18.78 & 30.7 \\
122.36 & 23.00 & 18.8
\end{tabular}

(a) Yield stress value measured using procedure described in Section 4.4 .3 .

spindle motor was then turned off, and the final viscometer output, $R_{t}$, was read. In all tests, $R_{t}$ was found to be $3.40 \pm 0.10$ and $\tau_{y}$ was calculated by Equations (4.9) and (4.10) as

$$
\tau_{y}=\frac{(7187)(3.40 / 100)}{2 \pi(1.258)^{2}(9.239)}=2.66 \text { dyne } / \mathrm{cm}^{2}
$$

The values in Table 4.3 were plotted as $\log \left(\tau-\tau_{y}\right)$ versus $\log (\dot{S})$, and produced a straight line. From the slope and intercept of this plot, the power law parameters in Equation (3.2) were calculated as $n=0.19$ and $k=$ 7.27 dyne $/ \mathrm{cm}^{2}$. Since $\mathrm{n}<1$, this melter feed is considered a pseudoplastic power law fluid. Because this sludge sample exhibits a finite $\tau_{y}$, and $n<1$, it demonstrates yield-pseudoplastic behavior and is described, in cgs units, by

$$
\tau=2.66+7.27 \dot{s}^{0.19}
$$

4.5.2 Example: Determining Power Law Coefficients with a Haake Rotovisco Viscometer Fitted with a Concentric Cylinder Spindle Arrangement

Laboratory rheological data were also obtained for the same sludge as used in the previous example, except that measurements were made with a Haake 
viscometer equipped with an M150 measuring/drive head and the MV II concentric cylinder spindle system. The resulting rheogram is shown in Figure 4.13. The yield-pseudoplastic model for this melter feed, based on the Haake rheogram, was calculated as

$$
\tau=2.54+7.74 \dot{S}^{0.17}
$$

Comparison of Equations (4.15) and (4.16) verify that data from both viscometers provide similar results. Table 4.4 shows values of shear stress and shear rate taken from the Haake rheogram.

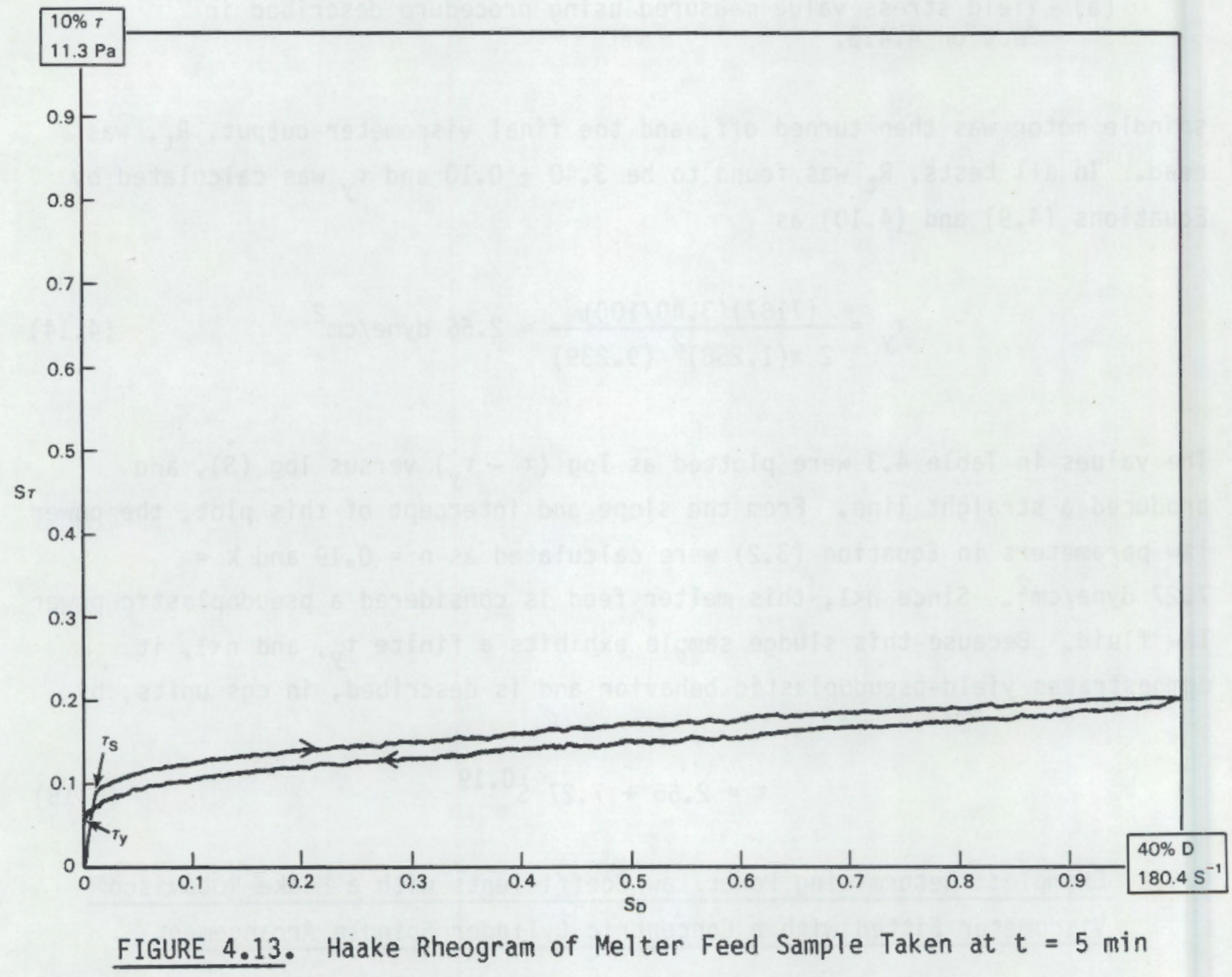


TABLE 4.4. Values of Shear Stress and Shear Rate Obtained by Using a Haake Rotovisco RV-100 Viscometer with System M150, Sensor System MV II

$\begin{array}{ccc}\text { Shear Rate }\left(\mathrm{S}^{-1}\right) & \text { Shear Stress }\left(\text { dyne } / \mathrm{cm}^{2}\right) & \text { Viscosity }(\mathrm{CP}) \\ 0.0 & 2.54(\mathrm{a}) & -- \\ 3.61 & 10.2 & 283.0 \\ 7.22 & 11.3 & 157.0 \\ 10.82 & 12.1 & 112.0 \\ 14.43 & 12.8 & 88.7 \\ 18.04 & 13.2 & 73.2 \\ 36.08 & 15.0 & 41.6 \\ 54.12 & 16.3 & 30.1 \\ 72.16 & 17.7 & 24.5 \\ 90.20 & 18.8 & 20.84 \\ 108.2 & 19.9 & 18.39 \\ 126.3 & 30.9 & 16.55 \\ 144.3 & 21.7 & 15.04 \\ 162.4 & 23.1 & 14.22\end{array}$

(a) Estimated from Haake rheogram.

Note that in Figure 4.13, there are two shear stress deflection points near zero shear rate. The start-up deflection point is related to shear strength, $\tau_{s}$, which (as discussed in Section 3.3) is time-dependent for gelforming materials. The deflection point on the lower curve is related to the steady-state yield stress, $\tau_{y}$, and corresponds to the value of $\tau_{y}$ used in the power law Equation (4.16). Although the fluid represented in Figure 4.13 exhibits both, many fluids exhibit a $\tau_{s}$ but not a $\tau_{y}$, indicating that once the gel structure is broken, these fluids obey the pseudoplastic model rather than the yield-pseudoplastic model.

\subsection{TESTS FOR DETECTING TIME-DEPENDENT (THIXOTROPIC OR RHEOPECTIC) BEHAVIOR}

There are two general methods for detecting time-dependent flow behavior in sludges. These methods are described below in Sections 4.6.1 and 4.6.2. 4.6.1 Constant Shear Rate Method

The first method is to run a spindle at a constant rpm for 5 to $10 \mathrm{~min}$. Any viscometer/spindle arrangement may be used. If a sludge is thixotropic, 
the viscometer torque reading will initially reach a maximum and with time will gradually fall off to a lower, steady-state value. A semi-quantitative method for reporting this type of data is to calculate a thixotropic breakdown coefficient, $T_{B R}$, defined by Brookfield Engineering Laboratories (1984) as

$$
T_{B R}=\frac{\eta_{a p p_{1}}-\eta_{a p p_{2}}}{\ln \left[\frac{t_{2}(\min )}{t_{1}(\min )}\right]}
$$

where $\eta_{\mathrm{app}}=$ apparent sludge viscosity at time $1\left(t_{1}\right)$

$\eta_{\mathrm{app}_{2}}=$ apparent sludge viscosity at time $2\left(t_{2}\right)$.

When reporting values of $T_{B R}$, pre-shear conditions should be described. If readings at constant rotational speed increase with time, then the sludge sample is rheopetic. Equation (4.17) can be used to report negative values of $T_{B R}$ for rheopectic samples. A more-detailed quantitative method for describing time-dependent behavior is available (Ford and Steffe 1986).

\subsubsection{Variable Shear Rate Flow Curve Hysteresis}

The second method of characterizing time-dependent behavior is to measure spindle torque while ramping spindle rpm from 0 to $N_{\text {max }}$, holding at $N_{\max }$ until a steady-state torque reading is achieved, and then ramping shear vane rpm back down from $\mathrm{N}_{\max }$ to 0 . If a Haake viscometer is used, the test data will have the general appearance of Figure 4.14. The area of hysteresis between the upand down-curves provides a semi-quantitative measure of time-dependent flow behavior. If the down-curve falls below the up-curve, the sample is thixotropic. If the down-curve rises above the up-curve, the sample is rheopectic.

The Haake-derived curves in Figure 4.14 are smooth because shear vane rpm during the test is varied continuously between 0 and $N_{\max }$. By contrast, a Brookfield viscometer has discrete speeds that must be manually increased and decreased, resulting in a stepped output having the general appearance of Figure 4.15.

Since thixotropic behavior is time-dependent, the amount of time expended in ramping shear vane rpm up and down will influence the test results. If a 


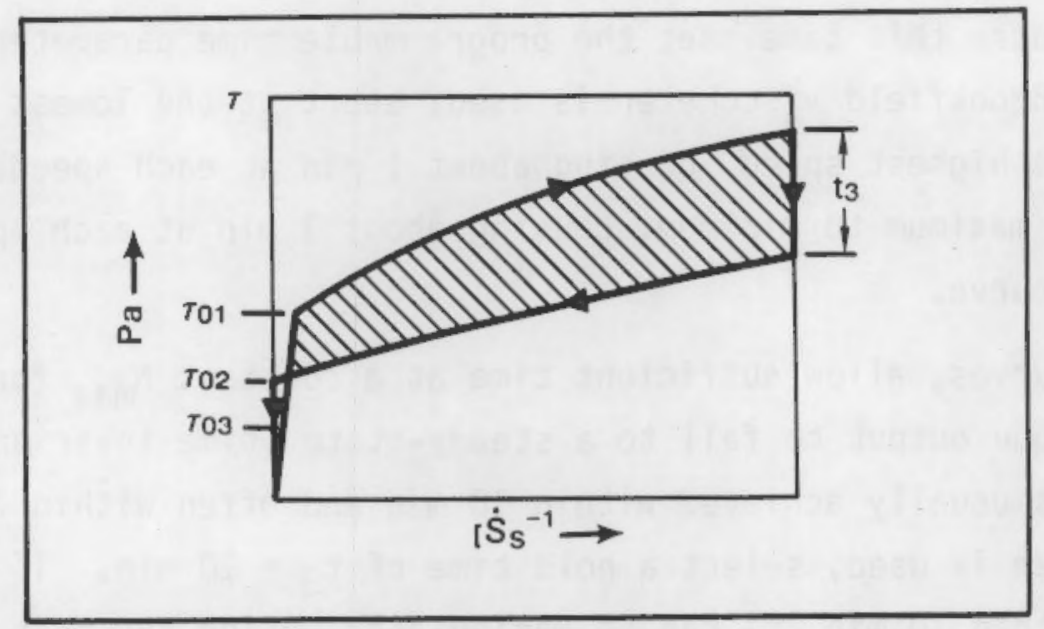

FIGURE 4.14. Flow Curve Hysteresis Indicating Sludge Thixotropy (adapted from Schramm 1981)

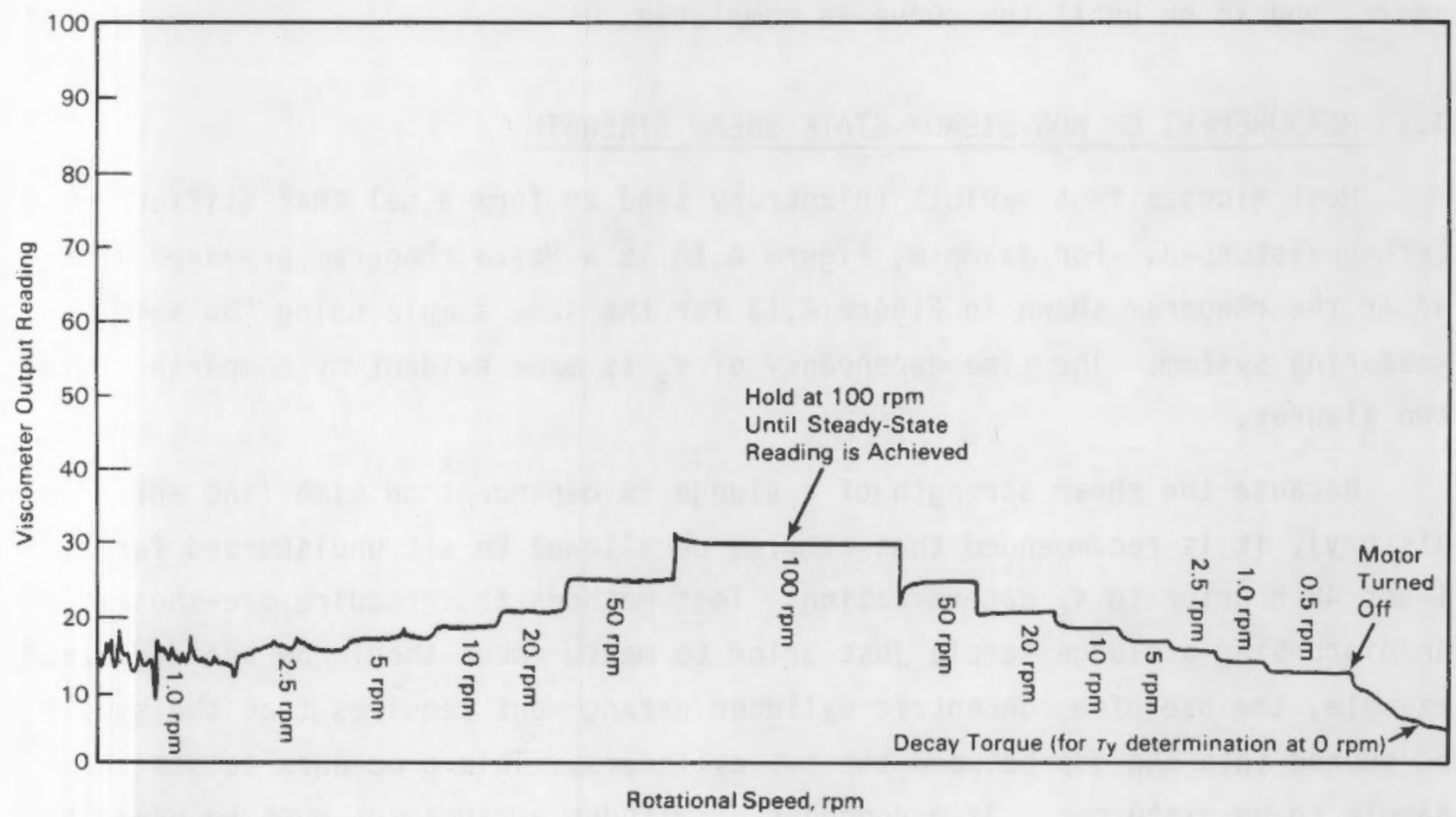

FIGURE 4.15. Up and Down Flow Curves Produced with Brookfield RVDT Viscometer 
Haake viscometer is used, it is recommended that each curve be completed in $10 \mathrm{~min}$. To ensure this time, set the programmable time parameters to $t_{1}=t_{2}=$ $10 \mathrm{~min}$. If a Brookfield viscometer is used, start at the lowest speed and progress to the highest speed, pausing about $1 \mathrm{~min}$ at each speed. Then, reduce the speed from maximum to minimum, pausing about 1 min at each speed, to produce the down-curve.

Between curves, allow sufficient time at a constant $N_{\max }$ for the viscometer torque output to fall to a steady-state (time invariant) value. Steady state is usually achieved within $10 \mathrm{~min}$ and often within $2 \mathrm{~min}$. If a Haake viscometer is used, select a hold time of $t_{3}=10 \mathrm{~min}$. If steady state occurs sooner than $10 \mathrm{~min}, \mathrm{t}_{3}$ can be manipulated during the test to allow production of the down-curve without the full 10 -min wait at $\mathrm{N}_{\max }{ }^{*}$ If a Brookfield viscometer is used, wait until the torque reading at Max reaches a constant value, then shift to the next lowest speed, wait $1 \mathrm{~min}$, shift down again, and so on until the curve is completed.

\subsection{MEASUREMENT OF NON-STEADY-STATE SHEAR STRENGTH}

Most sludges that exhibit thixotropy tend to form a gel that stiffens when left undisturbed. For example, Figure 4.16 is a Haake rheogram prepared $18.5 \mathrm{~h}$ after the rheogram shown in Figure 4.13 for the same sample using the same measuring system. The time dependency of $\tau_{s}$ is made evident by comparing these two figures.

Because the shear strength of a siudge is dependent on time (and shear history), it is recommended that samples be allowed to sit undisturbed for at least $48 \mathrm{~h}$ prior to $\tau_{\mathrm{s}}$ determination. Test methods that require pre-shearing or disturbing a sludge sample just prior to measurement should be avoided. For example, the use of a concentric cylinder arrangement requires that the sample be poured into the gap between the two cylinders. This procedure causes the sample to be disturbed. If a concentric cylinder arrangement must be used, the sample should be loaded and then left undisturbed for $48 \mathrm{~h}$. 


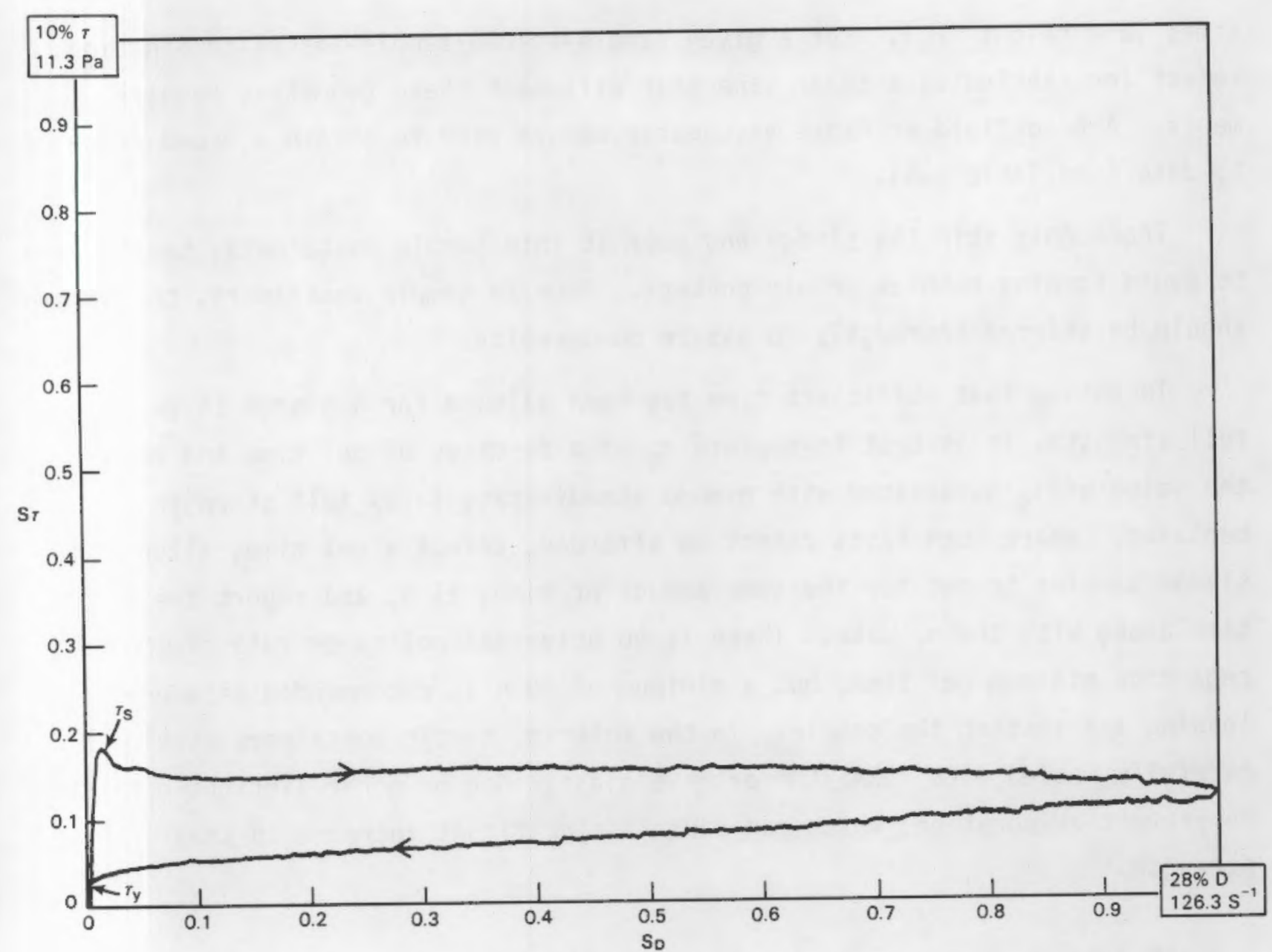

FIGURE 4.16. Haake Rheogram of Melter Feed Sample Taken at $t=18.5 \mathrm{~h}$

Miniature shear vanes provide an alternative method for shear strength determination because a shear vane is designed to be lowered into a sample without causing significant disturbance. The following sections describe the use of miniature shear vanes in conjunction with either Haake or Brookfield viscometers, in order to accurately measure $\tau_{s}$, and the preparation of sludge samples for $\tau_{s}$ determination.

\subsubsection{Sample Preparation}

First, determine the volume of each sludge sample that will be required. Up to five replicate sludge samples should be examined to obtain a statistically meaningful body of data. Next, select sample vessels with inner diameters $\left(2 R_{C}\right)$ at least three times vane diameter $\left(D_{v}\right)$, and with depths at least three 
times vane height $\left(H_{v}\right)$. For a given sample-volume/sample-vessel combination, select (or fabricate) a shear vane that will meet these geometric requirements. A Brookfield or Haake viscometer can be used to obtain a broad range of $t_{s}$ data (see Table 4.5).

Thoroughly stir the sludge and pour it into sample containers, taking care to avoid forming bubbles or air pockets. Once in sample containers, the sludge should be stirred thoroughly to assure homogeneity.

To ensure that sufficient time has been allowed for a sludge to gel to full strength, it is best to measure $\tau_{s}$ as a function of gel time and report the value of $\tau_{s}$ associated with pseudo steady-state (>95\% full strength) behavior. Where such tests cannot be afforded, select a gel time, allow all sludge samples to set for the same amount of time, $t l \mathrm{~h}$, and report the gel time along with the $\tau_{s}$ data. There is no universal policy or rule of thumb regarding minimum gel time, but a minimum of $48 \mathrm{~h}$ is recommended between loading and testing the sample. In the interim, sample containers should be carefully sealed with PARAFILM or in a plastic bag or other airtight enclosure to prevent evaporation, which can cause a significant increase in shear strength.

TABLE 4.5. Viscometer/Shear Vane Selection for Shear Strength Measurements

\begin{tabular}{|c|c|c|c|}
\hline Torque Sensor System & $\begin{array}{l}\text { Shear Vane } \\
\text { Diameter }(\mathrm{cm})\end{array}$ & $\begin{array}{c}\text { Maximum } \\
\text { Measurable } \\
\text { Torque } \\
\text { (dyne-cm) } \\
\end{array}$ & $\begin{array}{c}\text { Maximum } \\
\text { Measurable } \\
\text { Shear } \\
\text { Strength } \\
\left.\text { (dyne/ } \mathrm{cm}^{2}\right) \\
\end{array}$ \\
\hline Brookfield LVDT & $\begin{array}{l}0.975 \\
2.220\end{array}$ & $\begin{array}{l}673.7 \\
673.7\end{array}$ & $\begin{array}{r}350 \\
30\end{array}$ \\
\hline Brookfield RVDT & $\begin{array}{l}0.975 \\
2.220\end{array}$ & $\begin{array}{l}7187 \\
7187\end{array}$ & $\begin{array}{r}3700 \\
320\end{array}$ \\
\hline Haake RV-100/M150 & $\begin{array}{l}0.975 \\
2.220\end{array}$ & $\begin{array}{l}147,000 \\
147,000\end{array}$ & $\begin{array}{r}75,730 \\
6,420\end{array}$ \\
\hline Haake RV-100/M500 & $\begin{array}{l}0.975 \\
2.220\end{array}$ & $\begin{array}{l}490,000 \\
490,000\end{array}$ & $\begin{array}{r}252,420 \\
21,380\end{array}$ \\
\hline
\end{tabular}

Trademark of American Can Company, Greenwich, Connecticut. 


\subsubsection{Test Method for a Miniature Shear Vane}

Once the shear vane is installed on the viscometer, obtain a medium sized laboratory apparatus support jack. Put a sludge sample on the jack; center the jack and sample directly under the shear vane. Zero the viscometer and recorder. Do not readjust them at any point during the test.

For best results, carefully raise the lab jack until the shear vane shaft is, immersed to a depth, L, equivalent to the vane height, $H_{v}$. The blades will be fully immersed. It is best to pre-mark the shaft at $L=H_{v}$ and then submerge the shaft to the mark; otherwise, it will be difficult to judge immersion depth.

Determine the speed, $\mathrm{N}$, at which the shear vane should be rotated by selecting $\mathrm{N}$ from Table 4.6 relevant to the shear vane/viscometer combination used. As discussed later in Section 5.1.1, measured values of shear strength depend on shear vane rpm. With drive motor off, set the viscometer to a rotational speed selected from Table 4.6. When the viscometer drive motor is turned on, the shear vane will initially remain stationary as the internal viscometer torque spring gradually deflects, causing a steadily increasing torque output. As the torque increases, the shear vane should slowly, sometimes erratically, begin to turn. In the ensuing few seconds, the torque

\section{TABLE 4.6. Viscometer RPM for Shear Strength Determination}

\begin{tabular}{|c|c|c|}
\hline Viscometer & Di ameter $(\mathrm{cm})$ & Suggested Test rpm (a) \\
\hline Brookfield LVOT & $\begin{array}{l}0.975 \\
2.220\end{array}$ & $\begin{array}{l}0.3 \\
0.3\end{array}$ \\
\hline Brookfield RVDT & $\begin{array}{l}0.975 \\
2.220\end{array}$ & 0.5 \\
\hline Haake RV-100/M150 & $\begin{array}{l}0.975 \\
2.220\end{array}$ & $\begin{array}{l}0.3 \\
0.2\end{array}$ \\
\hline Haake RV-100/M500 & $\begin{array}{l}0.975 \\
2.220\end{array}$ & $\begin{array}{l}0.3 \\
0.2\end{array}$ \\
\hline
\end{tabular}

(a) Based on a vane tip speed of 0.015 to $0.030 \mathrm{~cm} / \mathrm{s}$. 
output should level off and begin to drop. Record the peak torque output reading as $R_{t}(\max )$. If a Brookfield viscometer is used, $R_{t}$ will be between 0 and 100. If a Haake is used, record the peak value of $S_{\tau}$ (between 0 and 1.0) and the output scale factor, \% $\tau$ (between 1 and 100). Multiply $S_{\tau}$ by $\% \tau$ and record their product as $R_{t}(\max )$, which should be between 0 and 100 . Figures 4.17 and 4.18 are typical Brookfield and Haake viscometer output plots obtained for $\tau_{s}$ determinations with shear vanes.

After peaking, the torque output should fall off to a lower, pseudosteady-state value. The strength (dyne/ $\mathrm{cm}^{2}$ ) associated with this metastable output is known as the remolded strength; it may be worth recording but is optional. The phenomenon is fully discussed by Abdelhamid (1982).

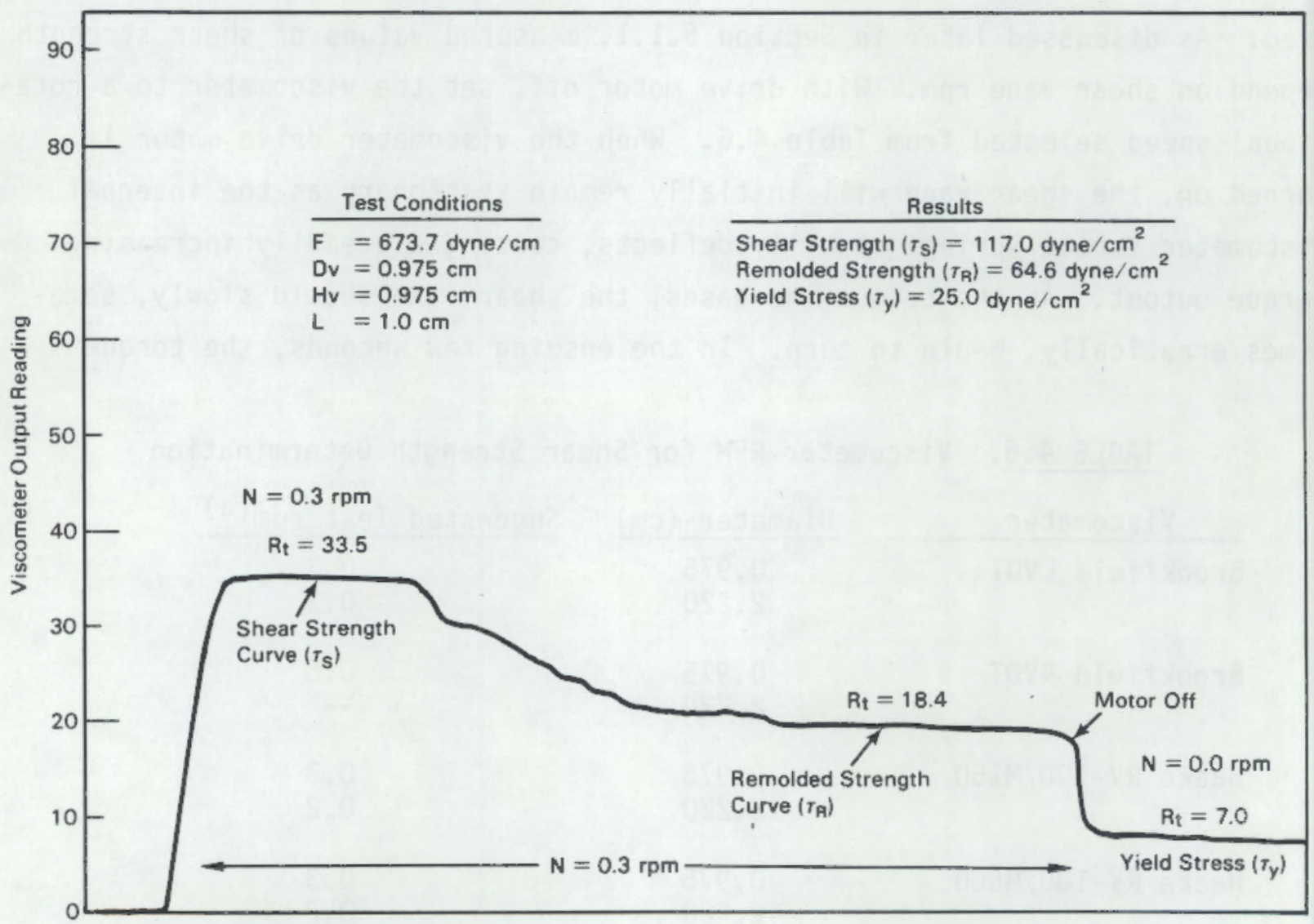

FIGURE 4.17. Plot of Viscometer Output Versus Time at a Constant Shear Vane Rotation $(0.3 \mathrm{rpm})$ for a Sample of Slurry 


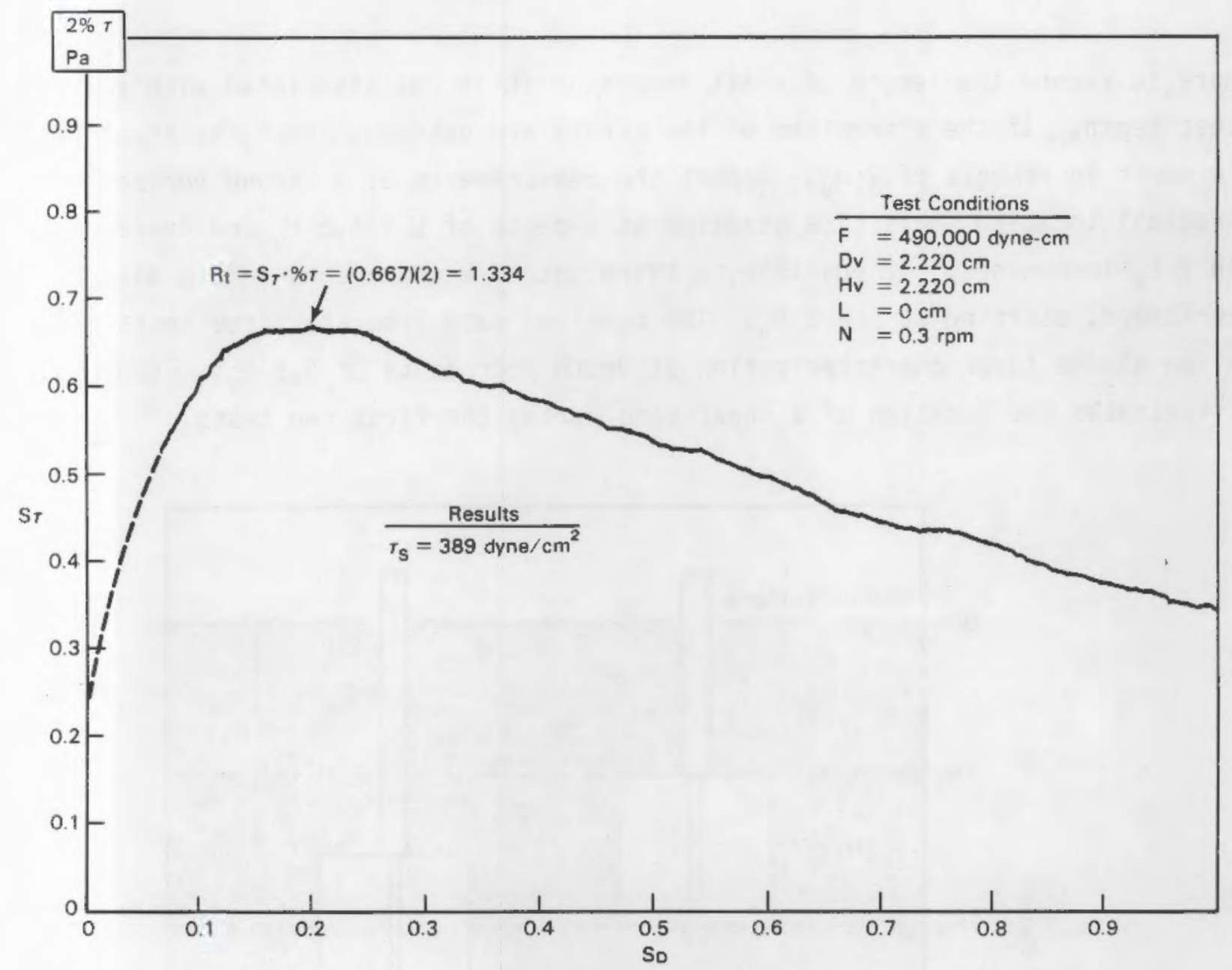

FIGURE 4.18. Plot of Viscometer Output Versus Time at a Constant Shear Vane Rotation $(0.3 \mathrm{rpm})$ for a Sample of Radioactive NCRW Sludge

To analyze the $R_{t}(\max )$ test data in terms of $\tau_{s}$, refer to the procedure in Appendix B. Use the torque correction for shaft friction if the apparent viscosity of the sludge exceeds approximately 10,000 CPs at very low shear rates $\left(\dot{S}<0.1 \mathrm{~s}^{-1}\right)$. A method for calculating shaft friction is presented later in Section 5.2.3.

If a stratified sludge (containing multiple layers) is tested, the shear vane should be lowered to a depth that centers it in each layer during each test. Start with the uppermost layer and work vertically downward at the same horizontal (radial) location. For best results, the shear vane blade height should be smaller than the thickness of the smallest layer to be tested. Be 
sure to record the length of shaft immersion ( $L$ in $\mathrm{cm}$ ) associated with each test depth. If the dimensions of the strata are unknown, lower the shear vane in depth increments of $2 \mathrm{H}_{\mathrm{v}}$. Repeat the measurements at a second horizontal (radial) location, this time starting at a depth of $L=1.5 \mathrm{H}_{v}$ and descending in $2 \mathrm{H}_{\mathrm{v}}$ increments. If possible, a third set of measurements should also be performed, starting at $L=2 H_{v}$. The combined data from all three tests will allow sludge layer characterization at depth increments of $0.5 \mathrm{H}_{\mathrm{v}}$. Figure 4.19 illustrates the location of a shear vane during the first two tests.

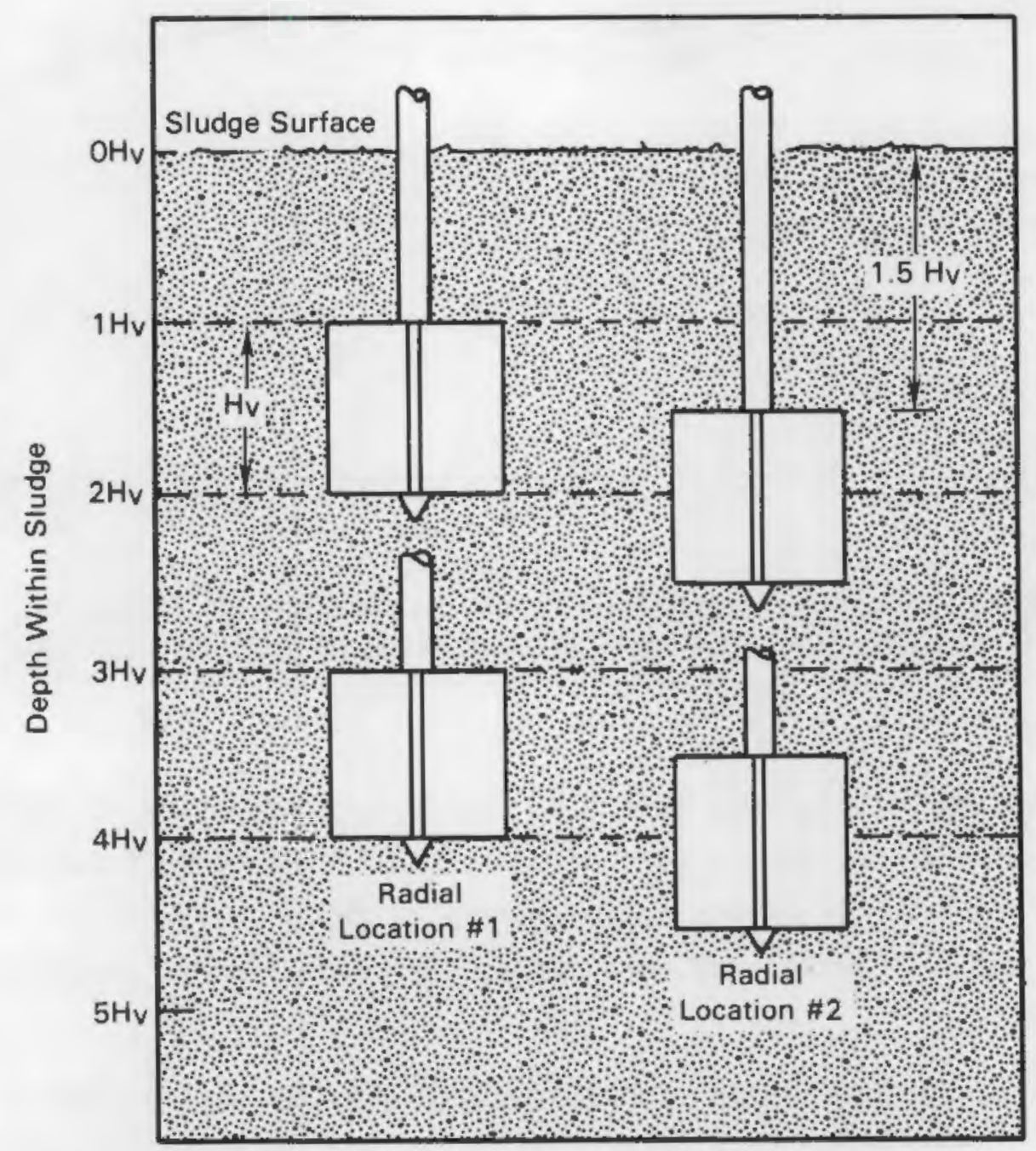

FIGURE 4.19. Location of Shear Vane During Determinations of Sludge Shear Strength 
From one depth to the next, any residual torque (with viscometer drive motor off) should be dissipated by perturbing the sample up and down about $1 \mathrm{~mm}$ (use the lab jack). Take care to avoid sideways motion. It is usually possible to remove $50 \%$ to $80 \%$ of residual torque this way, but some will probably remain. Under no circumstances is it appropriate to readjust a viscometer or chart/pen recorder zero setting to achieve zero output in the middle of a test. Such adjustments can cause larger errors than those associated with undissipated residual torque.

\subsubsection{Effect of Pore Pressure on Laboratory Shear Strength Measurements}

When shear vane tests are conducted in soils, a correction usually must be made for pore pressure (Mesri and Godlewski 1977; British National Society 1961), also referred to as "capillary pressure" (van 01phen 1977). Capillary pressure occurs when water present in the soil is forced to flow through interparticle interstices (pores), creating a pressure drop because of surface tension at air/water interfaces. The net results can be erroneously high estimates of shear strength, depending on the soil's water content, void fraction and pore dimensions. In most in situ tank tests, capillary pressures will not occur because there are no air/water interfaces in the submerged sludge. However, laboratory tests may represent different conditions. It is therefore recommended that a liquid cover be placed over laboratory samples during miniature shear vane tests.

A word of caution: the sample cover liquid should have nearly the same chemistry and/or electrolytic strength as the real cover liquid (tank supernatant), to avoid peptization of the sample. Peptization, which can result in loss of cohesiveness and consequent reduction in shear strength of a sample, is discussed frequently in the literature of colloidal science, for example by van 0lphen (1977). 



\subsection{DEVELOPMENT OF A SHEAR VANE METHOD FOR IN-TANK MEASUREMENT OF SLUDGE FLOW PARAMETERS}

A shear vane used in conjunction with torque instrumentation provides a convenient and reliable means of measuring the shear strength of cohesive materials (Terzaghi and Peck 1948; Krynine 1947; Pyles 1984; ASTM 1978). Shear vanes have been used by soil scientists (ASTM 1978) because they offer the advantage of allowing soil shear strengths to be measured in the field. This obviates the need to remove core samples and subject them to laboratory testing. This removal step is undesirable because physical disturbances caused by the sampling operation tend to stress and weaken the samples. Consequently, shear strengths measured in the laboratory are often lower than the actual, in situ shear strength of the intact soil. Since shear vanes are designed to be positioned without causing disturbance along the cylindrical shearing surface (see Figure 4.6), they provide in situ soil strength data with engineering significance.

Shear, vanes offer similar advantages for in-tank testing of high-level liquid waste (HLLW) sludges. The first use of shear vanes for measuring the shear strength of an HLLW tank sludge was described by Abdelhamid (1982). A shear vane of 3-in. dia, mounted on a shaft $40 \mathrm{ft}$ long was lowered to different depths within the tank sludge and rotated at $0.017 \mathrm{rpm}$ (one revolution per hour) as stated in the above-mentioned ASTM procedure. The amount of torque required to initiate vane rotation (start-up torque, $T_{\text {max }}$ ) was used to calculate sludge shear strength via Cadling's Equation (ASTM 1963):

$$
T_{\max }=\pi\left[H_{v} \frac{D_{v}^{2}}{2}+\frac{D_{v}^{3}}{6}\right] \tau_{s}
$$

Following this initial extension of the shear vane method to the measurement of the shear strength of tank sludges, PNL embarked on a WVNS-sponsored program to further develop the use of shear vanes for in situ sludge testing. 
The next three sections summarize the developments made during this program. Section 5.1 discusses scale-up of shear strength data. Section 5.2 focuses on the development of a method for measuring apparent viscosity using shear vanes. Section 5.3 describes attempts to correlate shear vane rpm with shear rate.

\subsection{SCALE-UP OF SHEAR VANE SHEAR STRENGTH DATA}

Shear vanes can be used to evaluate the shear strength, $\tau_{s}$, of a sludge by submerging the vane portion in the sludge, rotating it at a constant speed, and measuring the amount of torque required to initiate vane rotation. Equation (5.1) is used to relate the measured start-up torque to sludge shear strength.

The procedure $(\$ 4.7)$ for using the PNL miniature shear vanes to measure the shear strength of laboratory sludge samples differs from the ASTM soil test procedure in both the the size of shear vane used and the rotational speed during testing. The ASTM procedure D2573-72/78 (ASTM 1978) specifies the use of shear vanes having diameters between 3.8 and $9.2 \mathrm{~cm}$, whereas the two miniature shear vanes used at PNL (tank sludge testing) have diameters of $0.975 \mathrm{~cm}$ and $2.220 \mathrm{~cm}$. The ASTM procedure also specifies an upper limit in the rate of vane rotation during testing of $0.017 \mathrm{rpm}$ (one revolution per hour). In contrast, most viscometers have a minimum rotational speed of 0.3 to $0.5 \mathrm{rpm}$.

During initial testing at PNL, it was determined that when rotated at $0.05 \mathrm{rpm}$, several measurements of sludge start-up torque using the differentsized miniature shear vanes all resulted in the same values of shear strength as calculated by Equation (5.1.) Measured values of shear strength are apparently independent of shear vane diameter within the range of $0.975 \mathrm{~cm}<0 v$ $<2.220 \mathrm{~cm}$. The following section describes tests that were conducted to determine whether measured values of sludge shear strength are dependent on the rotational speed of the shear vanes. From these tests, a vane tip speed criterion was developed to allow in-tank shear vane data to be compared directly with laboratory-scale, miniature shear vane data. 
Effect of Vane RPM on Shear Strength Measurement. To investigate the effect of vane rotational speed on shear strength measurements, the two miniature shear vanes were rotated at various speeds through iron-based and silicabased tank sludge simulants. The range of speed investigated was $0.017 \mathrm{rpm}$ to $0.5 \mathrm{rpm}$, corresponding to the maximum speed recommended by ASTM (1978) for soil shear strength testing and the minimum speed available on a Brookfield RVDT viscometer. A Haake viscometer, capable of a minimum speed of $0.05 \mathrm{rpm}$, was used in conjunction with the two shear vanes to perform the shear strength measurements. The results for the $0.975-\mathrm{cm}$ shear vane are shown in Figure 5.1 . Each plotted point represents the average of one to three data points, exhibiting minimal scatter.

As can be seen from the plotted test data, shear strength appears to be independent of shear vane rotational speed in the range of $0.3 \mathrm{rpm}$ to $0.5 \mathrm{rpm}$. Below this range, shear strength appears to vary as a function of vane rpm as well as test material (as evidenced by the two differently shaped curves). An initial conclusion might be that the in-tank and in-cell shear vanes should be rotated at the same speed to ensure that the two procedures generate directly comparable data. However, an assumption implicit in shear vane testing is that the material behaves as an elastic solid being sheared along the outer edges of the vane. The rate of elastic strain is related to vane tip speed, suggesting that vane tip speed may be a more appropriate test parameter to hold constant in the in-tank and in-cell tests. This rationale suggests that an in-tank shear vane of $8.9 \mathrm{~cm}(3.5 \mathrm{in.})$ dia should be rotated at $0.032 \mathrm{rpm}$ (1.9 revolutions per hour) during shear strength testing to achieve the same tip speed $(0.015 \mathrm{~cm} / \mathrm{s})$ as that of a $0.975-\mathrm{cm}$ viscometer shear vane rotated at $0.3 \mathrm{rpm}$. Furthermore, rotation at this higher speed should produce data that are less sensitive to small variations in the rate of shear vane rotation. On the basis of available test data, therefore, it is recommended that the in-tank shear vane be rotated at $0.032 \mathrm{rpm}$. However, this recommendation should be verified during additional laboratory- and field-scale tests. 


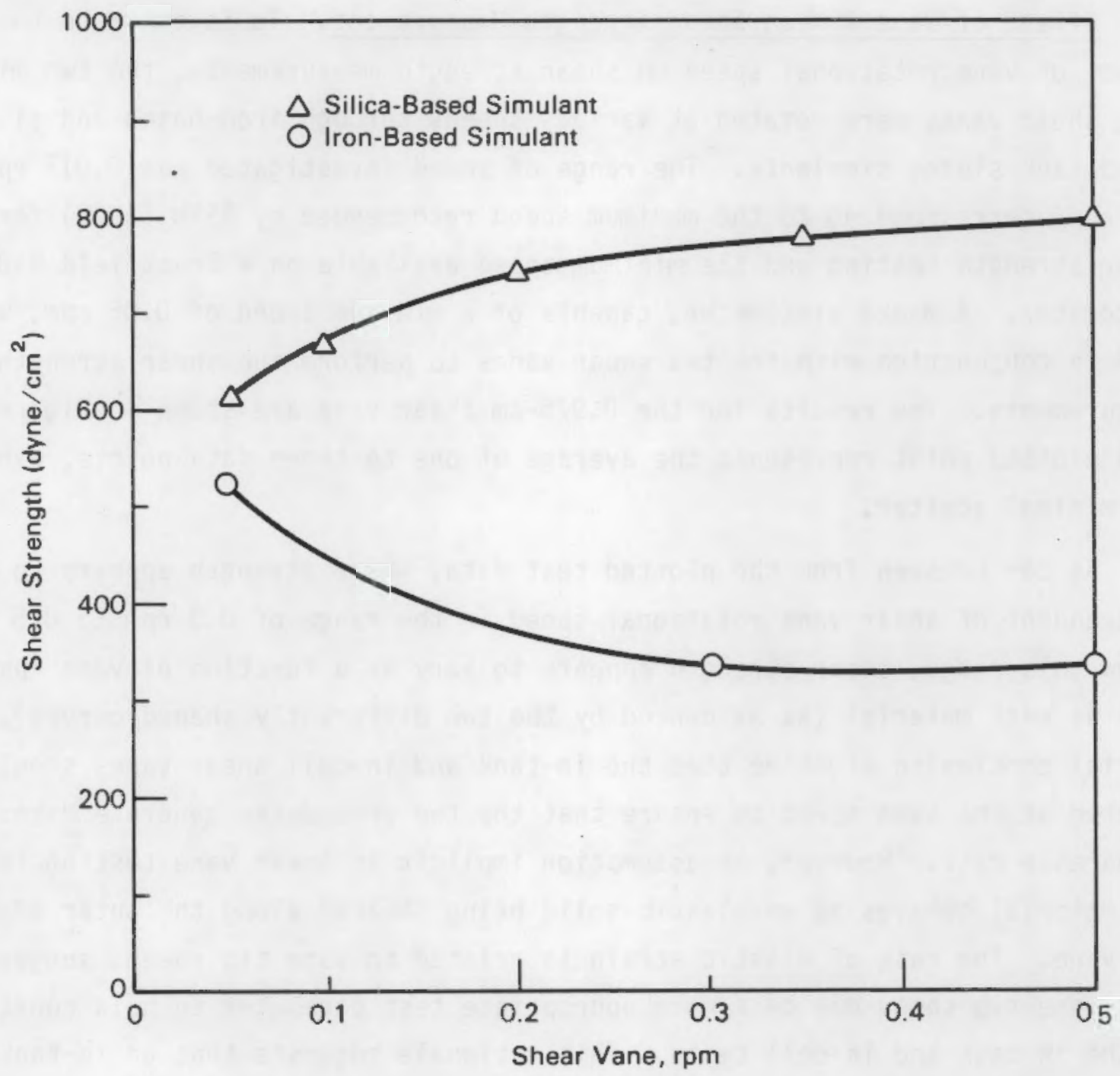

FIGURE 5.1. Effect of Shear Vane RPM on Sludge Shear Strength Measurement

\subsection{MEASUREMENT OF APPARENT VISCOSITY USING SHEAR VANES}

The main uncertainty associated with use of a shear vane to obtain viscosity data is whether the measured variable, shear vane torque, will vary as a predictable function of shear vane rate of revolution. To investigate the torque versus $\mathrm{rpm}$ response of a shear vane over a wide set of operating conditions encompassing both laboratory-scale and full-scale (in-tank) testing, the effects of following variables were studied: 
- shear vane diameter, $D_{v}$

- test fluid viscosity, $\eta$

- test vessel radius, $R_{C}$.

The following sections describe the equipment, procedure, calculations, and results of this experiment.

\subsubsection{Test Equipment}

Three shear vanes were tested; their diameters were $0.975 \mathrm{~cm}$ (shear vane No. 1), $2.220 \mathrm{~cm}$ (shear vane No. 2), and $7.557 \mathrm{~cm}$ (shear vane No. 3). All three vanes heights $\left(H_{v}\right)$ equaled the overall diameters $\left(D_{v}\right)$. All fluids used, except glycerol and corn syrup, were Brookfield viscosity standards, having the stated viscosity $\pm 1 \%$ at $25^{\circ} \mathrm{C}$. The viscosities of corn syrup and glycerol were determined with a Haake rotovisco viscometer, Model RV-100, fitted with sensor system $M-150$. The densities of the test fluids were measured as $1.26 \mathrm{~g} / \mathrm{cm}^{3}$ for glycerol, $1.41 \mathrm{~g} / \mathrm{cm}^{3}$ for corn syrup, and 0.97 for all of the Brookfield viscosity standards. The test fluids were poured into containers of various radii for shear vane testing. Table 5.1 lists the specific configurations tested.

\section{TABLE 5.1. Shear Vane/Tank/Test Fluid Configurations Investigated}

\begin{tabular}{|c|c|c|c|c|c|c|c|}
\hline \multirow[b]{2}{*}{ Tank Radius } & \multicolumn{3}{|c|}{ Shear Vanes } & \multirow[b]{2}{*}{ Test Fluids CP } & \multicolumn{3}{|c|}{ Shear Vanes } \\
\hline & No. 1 & No. 2 & No. 3 & & No. 1 & No. 2 & No. 3 \\
\hline 1.68 & $x$ & $x$ & & 5.4 & & $x$ & \\
\hline 2.95 & $x$ & $x$ & & 50.5 & & $x$ & \\
\hline 4.20 & $x$ & $x$ & & 475 & $x$ & $x$ & \\
\hline 14.0 & & & $x$ & 1,037 (a) & & & $x$ \\
\hline & & & & 1,237 & $x$ & $x$ & \\
\hline & & & & 12,000 & $x$ & $x$ & \\
\hline & & & & $14,650^{(b)}$ & $x$ & $x$ & $x$ \\
\hline & & & & 29,700 & & & \\
\hline
\end{tabular}

(a) Glycerol at test conditions $\left(15^{\circ} \mathrm{C}\right)$. (b) Corn syrup at test conditions $\left(12^{\circ} \mathrm{C}\right)$. 


\subsubsection{Experimental Procedure}

In a procedure common to all test configurations, a measured volume of test fluid was carefully poured into a test container to avoid bubbles; the test fluid temperature was monitored and in most cases remained constant, $\pm 1^{\circ} \mathrm{C}$; a test shear vane was installed and rotated at several rpm; and torque readings were recorded at each rpm setting.

The torque required to rotate shear vanes 1 and 2 was measured with two Brookfield viscometers, an LVDT model and an RVDT model. The viscometer output reading is related to shear vane torque in dyne-cm by Equation 4.4 .

Shear vane 3 was tested in conjunction with a 0.25 -hp agitator motor mounted on a freely swiveling base that was prevented from rotating by a metal rod linked to a strain gauge load cell device for torque instrumentation. The load cell readings in grams were converted to values of torque in dyne-cm via the following expression (Haliday and Resnik 1981): (a)

$$
T_{0}=(a)\left(R_{t}-R_{0}\right)(r)(\sin \theta)
$$

where: $T_{0}=$ overall shear vane torque, dyne $-\mathrm{cm}$

$R_{t}=$ load cell reading, $g$

$R_{0}=$ constant subtracted from load cell reading to account for agitator motor torque (constant), equal to $13.25 \mathrm{~g}$ for glycerol

tests and $16.5 \mathrm{~g}$ for corn syrup tests

$r=$ length of metal rod linking freely rotating agitator motor base to fixed-mounted load cell, 10 in.

$\theta=$ angle between metal linkage rod and line drawn radially from center of agitator shaft, $90^{\circ}$

$a=$ conversion factor equal to $2.49 \times 10^{3} \mathrm{~cm}^{2} / \mathrm{s}^{2} \mathrm{in}$.

$$
\left(\frac{980 \mathrm{~cm}}{\mathrm{~s}^{2}} \times \frac{2.54 \mathrm{~cm}}{i \mathrm{in} .}\right)
$$

(a) P. 179, Equation 12.2a, where $F=(a)\left(R_{\tau}-R_{0}\right)$ 
This test apparatus was used to vary the rotational speed of shear vane No. 3 continuously from $40 \mathrm{rpm}$ to $300 \mathrm{rpm}$. Values of rpm were recorded by a digital tachometer, accurate to the nearest $0.5 \mathrm{rpm}$.

\subsubsection{Shaft Friction Correction}

The overall torque data, $T_{0}$, for each test was corrected to account for shaft torque, $T_{s}$, caused by frictional losses to the test fluid. The following expression for a cylinder rotating within a cylindrical container was used to calculate the shaft torque (Brookfield 1984): (a)

$$
T_{s}=n \cdot R_{b}^{2} \cdot L \cdot \frac{8 \pi^{2}}{60} \cdot \frac{N_{c}^{2}}{R_{c}^{2}-R_{b}^{2}}
$$

where $T_{s}=$ torque caused by shaft friction, dyne-cm

$\eta=$ fluid viscosity, Poise $(1$ Poise $=100 \mathrm{cP}$ )

$R_{b}=$ shaft radius, $\mathrm{cm}$

$\mathrm{L}=$ shaft length, $\mathrm{cm}$

$\mathrm{N}=$ rate of shaft rotation, $\mathrm{rpm}$

$R_{c}=$ radius of mixing vessel, $\mathrm{cm}$.

This expression does not account for shaft end effects, which can be assumed to be negligible.

The calculated values of shaft torque were subtracted from the overall torque measurements to yield values of vane torque, $T_{v}$, or

$$
T_{v}=T_{0}-T_{s}
$$

Values of $T_{v}$, not $T_{0}$, are used in all subsequent calculations.

(a) Page 18: Combine Equations 5.4, 5.5, and 5.6 and solve for $M$ where $M$ is equivalent to $T_{s}$. 


\subsubsection{Correlation of Test Data Via Reynolds Number/Power Number Relationship}

Based on common industrial practices (Bates, Fondy and Fenic 1966;

Calderbank and Moo-Young 1961; Metzner and Otto 1957), the test data values of $T_{v}$ and $N$ were plotted in terms of the dimensionless groups $N_{R E}$ and $N_{p}$ :

$$
\begin{aligned}
& N_{R E}=\frac{\rho D^{2} N}{\eta} \\
& N_{P}=\frac{P}{\rho D^{5} N^{3}}
\end{aligned}
$$

where $N_{R E}=$ Reynolds number, ratio of inertial forces to viscous forces, dimensionless

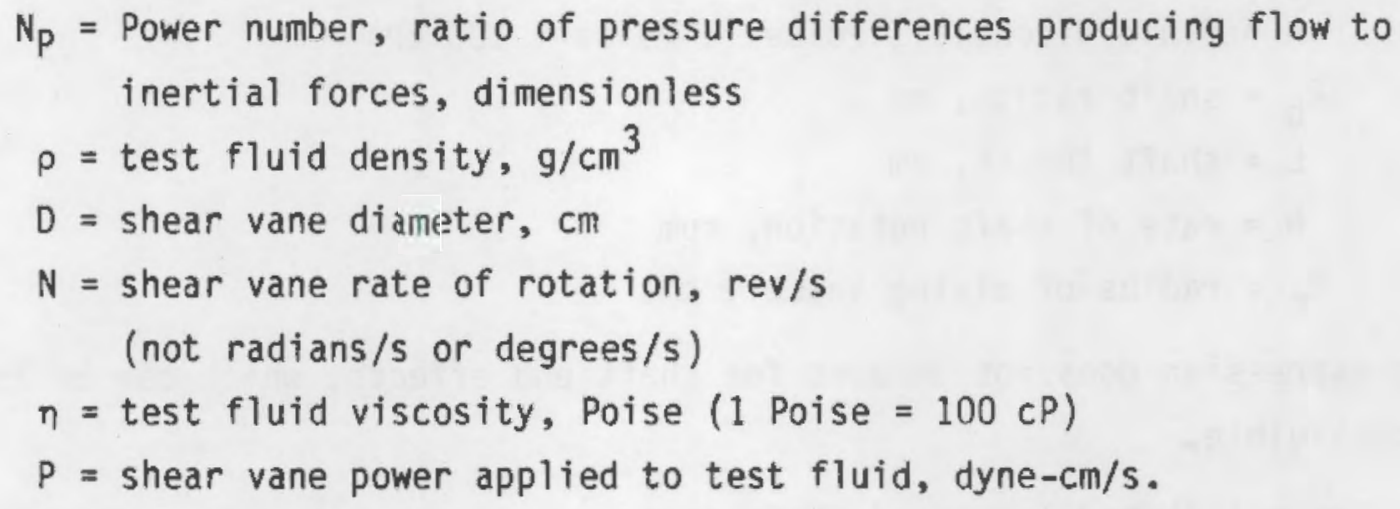

Shear vane power, P, is calculated as (Halliday and Resnick 1981).

$$
P=T_{v} \cdot \omega
$$

where $T_{v}=$ vane torque, dyne-cm

$$
\omega=\text { vane angular velocity, radians/s }
$$

Using the relation

$$
\omega=\frac{2 \pi}{60} \cdot N
$$


Equation 5.7 becomes

$$
P=T_{v} \cdot \frac{2 \pi}{60} \cdot N \text {, dyne-cm/s }
$$

An example of plots of $\mathrm{N}_{p}$ versus $\mathrm{N}_{\mathrm{RE}}$ for various turbine agitator geometries is provided in Figure 5.2, which is abstracted from Bates, Fondy and Fenic (1966). Note that the plots are approximately linear in the laminar flow regime, defined by Bates, Fondy and Fenic as $N_{R E}<10$, and by 01 dshue (1983) as $\mathrm{N}_{\mathrm{RE}}<15$.

Figure 5.3 is a plot of the PNL shear vane test data in terms of $N_{p}$ versus $N_{R E}$. A11 of the test data are plotted. As can be seen, there is remarkably little scatter in the data, which indicates a linear relationship between $\mathrm{N}_{p}$ and $N_{R E}$ independent of test fluid viscosity from 5.4 to $29,700 \mathrm{CP}$, independent of shear vane diameter from $0.975 \mathrm{~cm}$ to full scale, and independent of

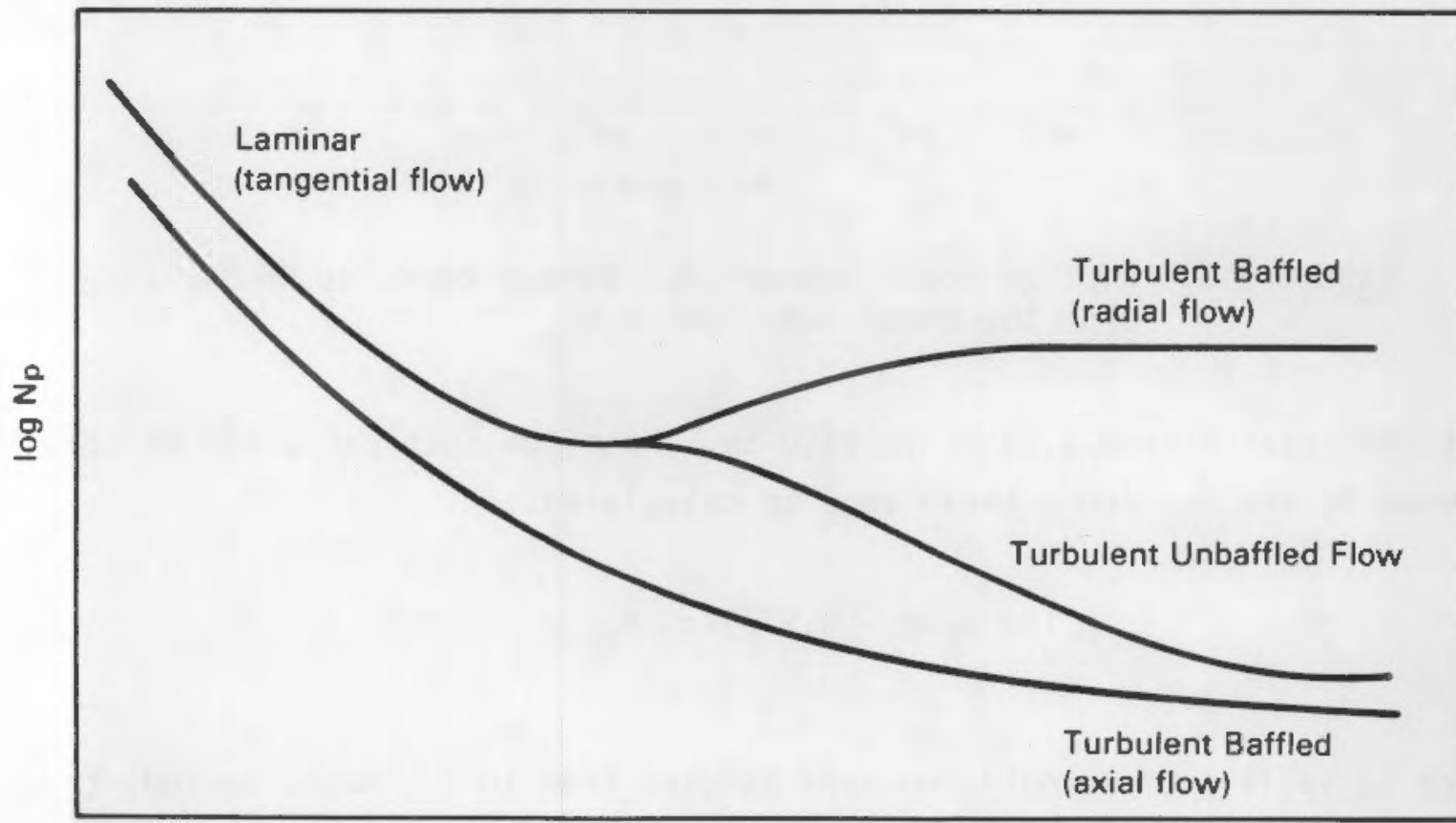

$\log$ NRe

FIGURE 5.2. Plots of $N_{p}$ and $N_{R E}$ for Some Turbine Agitator Geometries 


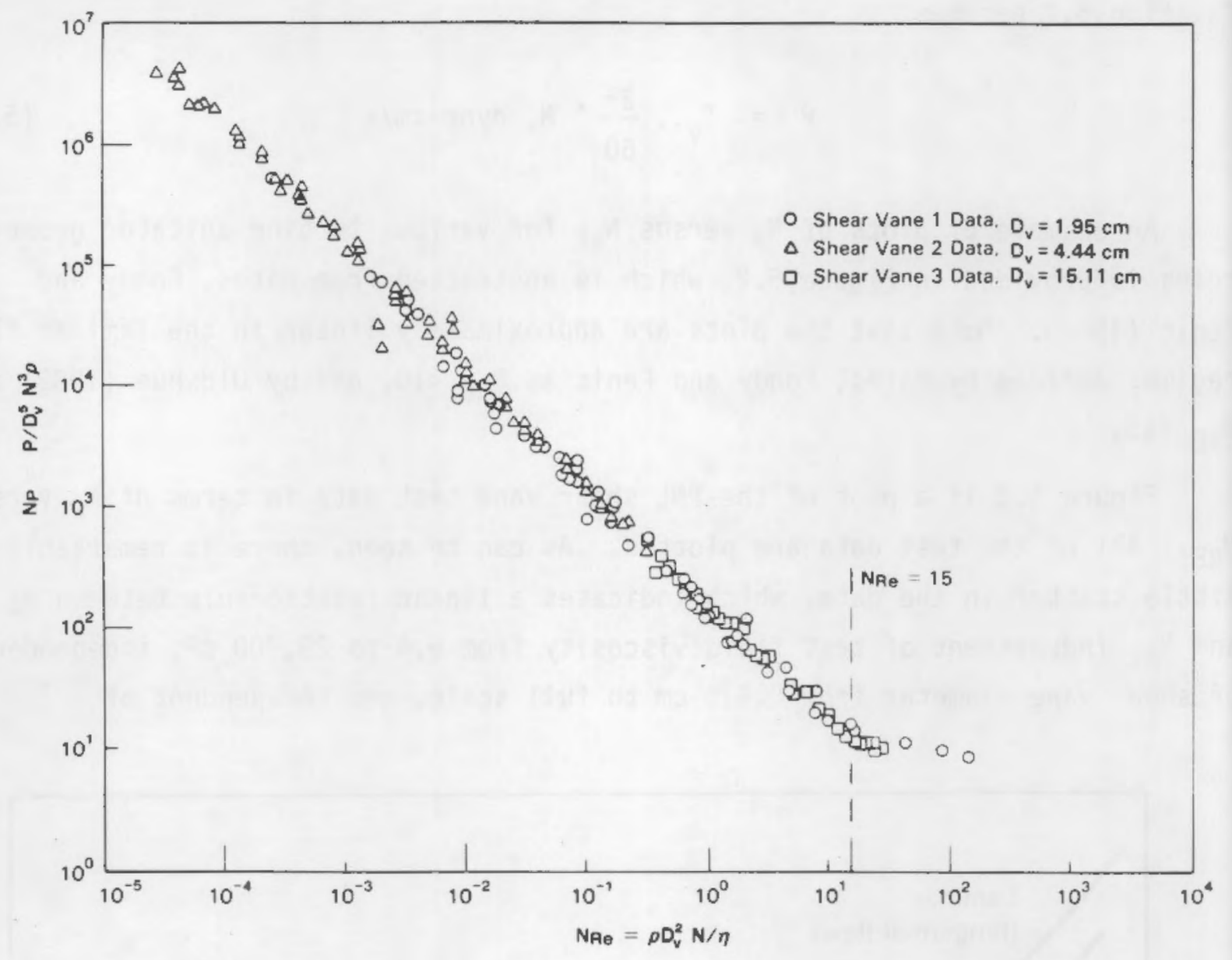

FIGURE 5.3. Plot of Power Number $\left(N_{p}\right)$ Versus Reynolds Number $\left(N_{R E}\right)$ from the Shear Vane Test Data

container radius from $1.68 \mathrm{~cm}$ to $14.0 \mathrm{~cm}$. From the test data, the relationship between $N_{p}$ and $N_{R E}$ for a shear vane is calculated as

$$
\log N_{P}=-(0.977) \log N_{R E}+(2.190)
$$

which is valid from Reynolds numbers ranging from $10^{-5}$ (10west tested) to about 10. The viscosity of a fluid can be measured with a shear vane by calculating a power number based on torque measurements, identifying the corresponding Reynolds number (from Figure 5.3), and back-calculating the viscosity, $\eta$. 


\subsubsection{Discussion of Experimental Results}

The data presented in Figure 5.3 indicate that the torque-versus-rpm response of a shear vane such as that planned for use in both scale-model and full-scale, in-tank tests is a predictable function of two dimensionless groups, the Reynolds number, $\mathrm{N}_{\mathrm{RE}}$, and the power number, $\mathrm{N}_{\mathrm{p}}$. For a shear vane operated in the laminar regime $\left(N_{R E}<10\right)$, the relationship between $\log N_{R E}$ and $\log N_{p}$ is linear as described by Equation 5.10.

Plots of $\log N_{p}$ versus $\log N_{R E}$ for all types of turbine agitators have been found (Bates, Fondy and Fenic 1966) to have a slope equal to -1 , which compares favorably to PNL's empirically determined slope of -0.977 . This is as expected: a shear vane can be categorized as a turbine agitator by its geometry.

The Froude number,

$$
N_{F R}=\frac{D N^{2}}{g} \text {, }
$$

representing the ratio of inertial to gravitational forces, can also be important in describing mixing phenomenon and can be factored in by plotting log $N_{p} / N_{F R}$ versus $N_{R E}$. However, the Froude number is considered insignificant in mixing power correlations for baffled tanks, and also for unbaffled tanks except when an appreciable vortex is formed (Bates, Fondy and Fenic 1966). In PNL tests, vortex formation was not appreciable; therefore, $N_{F R}$ was not factored into the data correlation.

The utility of the $N_{R E}-N_{p}$ correlation developed for the shear vane is that with this correlation, shear vane torque measurements can be used to estimate tank sludge viscosity, both in the scale model and in the full-scale tank.

\subsection{RELATIONSHIP BETWEEN VANE RPM AND SHEAR RATE}

As described in Section 5.2.4, shear vanes were found to exhibit $N_{R E}-N_{P}$ behavior representative of impeller mixers operated at Reynolds numbers in the laminar range. The most generally accepted empirical correlation between rate of revolution and shear rate for impellers has the form $\dot{S}=K N$, where $\dot{S}$ is 
shear rate in $\mathrm{s}^{-1}$ and $\mathrm{N}$ is rotational speed in revolutions per second. The proportionality constant, $K$, is usually assigned a numerical value of 10 (Bates, Fondy and Fenic 1966), although a value of 13 is recommended by some authors (01dshue 1983).

To investigate the relationship between $N$ and $\dot{S}$, shear vanes were used to measure the apparent viscosity of two non-Newtonian (pseudoplastic) liquids at several rpms. The fluids were also tested with a Hake viscometer to produce rheograms. The rheogram viscosities were compared with those calculated by using the $\mathrm{N}_{\mathrm{RE}} / \mathrm{Np}$ correlation. Then, the shear rates corresponding to those viscosities were determined from the rheogram. This procedure was based on the general method developed by Metzner and 0tto (1957). The results are presented in Table 5.2. The data were all taken at a shear vane rotational speed of $100 \mathrm{rpm}$.

If the values of shear rate are averaged as they appear in the table, $k$ is calculated to be 11.1. Note that this value falls within the range of values recommended in the literature (10 to 13 ).

TABLE 5.2. Shear Rate Oata (at $100 \mathrm{rpm}$ ) as a Function of Shear Vane Diameter and Sludge Type

\begin{tabular}{llccc}
\multicolumn{1}{c}{ Sample Material } & & $\begin{array}{c}\text { Shear Vane } \\
\text { Diameter }(\mathrm{cm})\end{array}$ & $\begin{array}{c}\text { Shear Rate } \\
\left(\mathrm{s}^{-1}\right)\end{array}$ \\
\cline { 1 - 1 } Iron-based sludge simulant \#1 & & 2.220 & & 19.7 \\
Iron-based sludge simulant \#1 & & 2.220 & 20.8 \\
Iron-based sludge simulant \#1 & & 0.975 & 15.6 \\
Silica-based sludge simulant \#1 & & 0.975 & 32.4 \\
Silica-based sludge simulant \#2 & & 0.975 & 17.8 \\
Silica-based sludge simulant \#4 & 0.975 & 5.5
\end{tabular}

On the basis of the data in Table 5.2, it is recommended that the following equation be used to estimate shear rates:

$$
S=(11.1) \mathrm{N}
$$




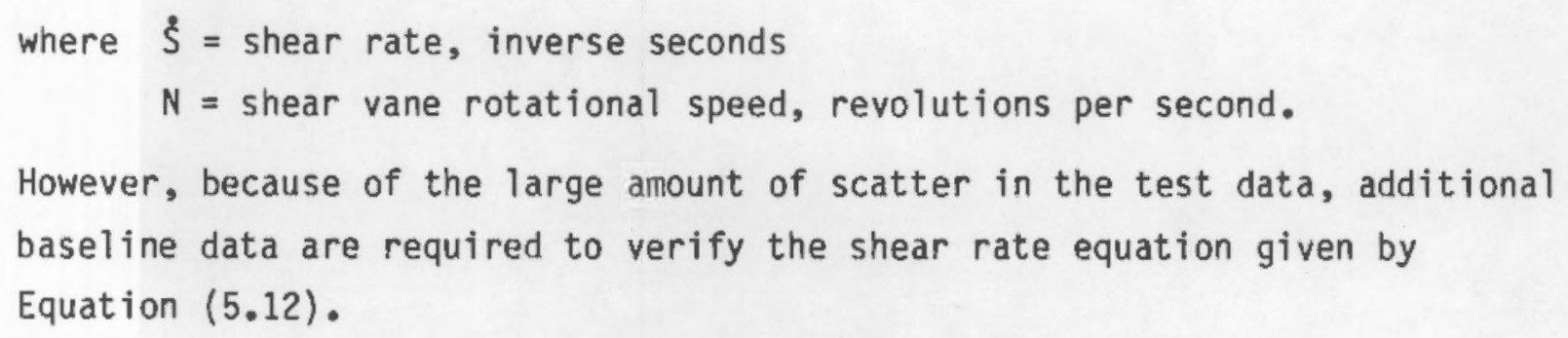




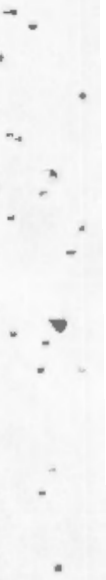




\subsection{CONCEPTUAL DESIGN OF FULL-SCALE IN-SITU SHEAR VANE DEVICE}

An objective of the current DST Sampling and Analysis program is to design an apparatus for performing in-situ tank sludge rheology characterization. Chapter 6 presents a conceptual design for a modified shear vane device and describes how it can be used to accomplish in-tank rheological characterization of DST sludge.

Figure 6.1 shows the conceptual design of a shear vane device recommended for in-tank use. An engineering sketch is provided in Appendix $A$. The device is designed to be installed, as shown, through an existing tank riser having inner diameter of $10 \mathrm{~cm}(4 \mathrm{in.)}$ or greater. To allow operation at up to $300 \mathrm{rpm}$, an outer shaft support structure was designed. This structure, consisting of a fixed $3-i n$. schedule 80 pipe, imparts sufficient rigidity to prevent the inner, rotating shear vane shaft from whipping at high rates of rotation. Spherical bearings and roller bearing bushings (not shown) permit the inner shaft to rotate within the fixed support structure. Spherical bearings were used rather than thrust bearings (employing roller bearings) because the former can better tolerate small shaft deflections, providing better stability at high speeds.

To simplify installation, removal, and decontamination, the shear vane shaft was designed to be disassembled in 3-m sections. The couplers used to attach the sections are designed to be easy to engage and disengage for minimal personal exposure or even adaptation to entirely remote handling. These couplers are off-the-shelf items that are slightly modified to clear the inner diameter of the tank riser. The polar moment of inertia associated with rotation at $300 \mathrm{rpm}$ is calculated to be insufficient to cause the couplers to disengage during testing.

The shear vane at the bottom of the rotating shaft has a vane diameter and height equal to $8.9 \mathrm{~cm}(3.5 \mathrm{in.})$ and is of the same general shape as those used in testing at PNL. The recommended material of construction is carbon steel, the same material used to fabricate the tank. 


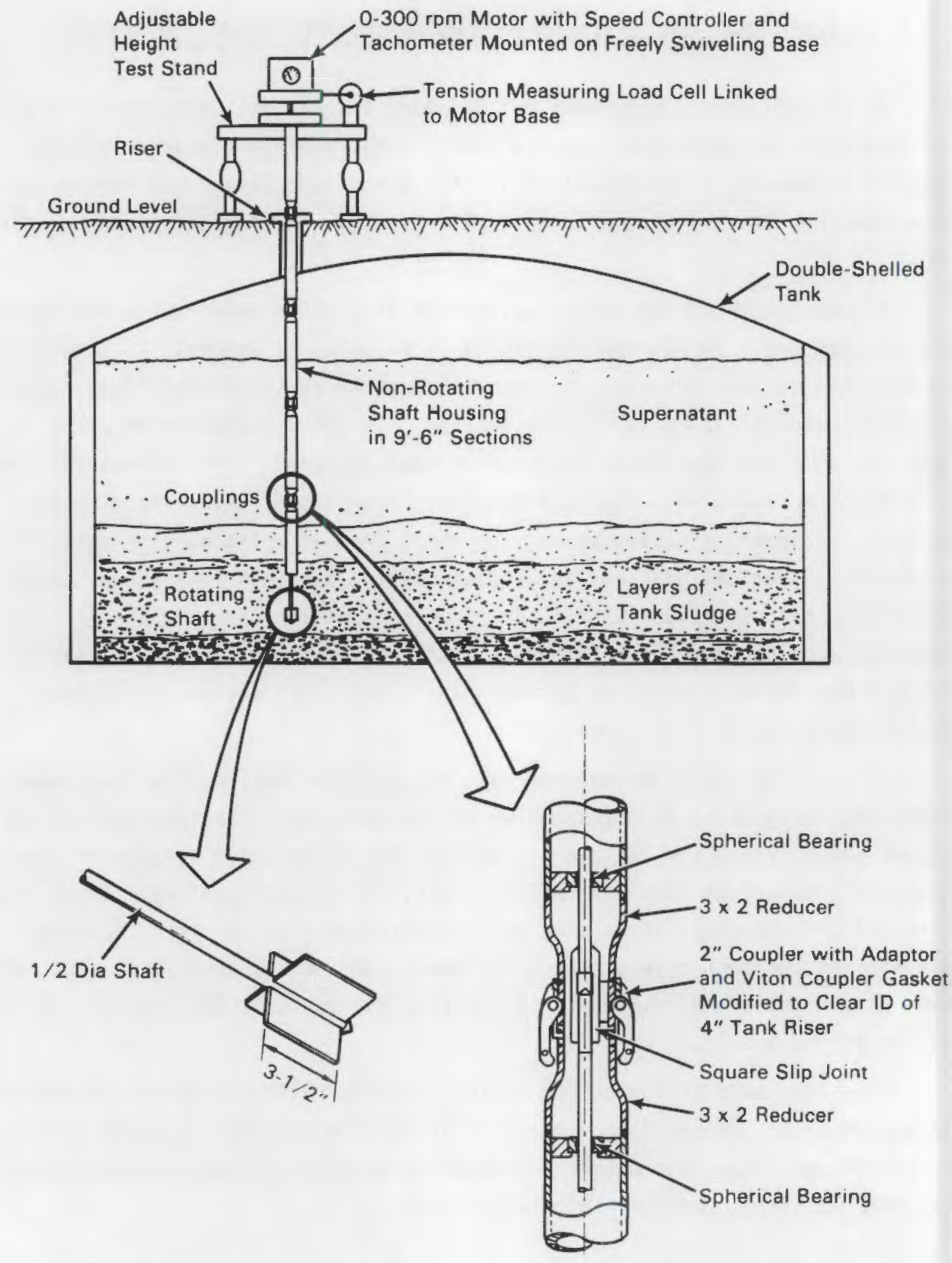

FIGURE 6.1. Conceptual Design of a Shear Vane Installed in a Double-Shell Tank 
Instrumentation requirements consist of a tachometer to measure shear vane rpm (0-300) and a load cell to measure shear vane torque (a measuring capability of 0 to $20 \mathrm{ft}-1 b_{f}$ should be adequate). The load cell is linked to the shear vane drive motor, which must be mounted on a freely swiveling base. If the load cell is mounted on a fixed platform and linked to the motor, the torque applied to the motor can be measured. This measured torque, $\mathrm{T}_{0}$, is the sum of three torques:

- $T_{v}$, torque applied directly to the rotating vanes

- $T_{s}$, torque applied to the exposed rotating shaft portion of the shear vane

- $T_{C}$, torque associated with frictional losses within the shaft structure.

The torque applied to the vanes, $T_{y}$, is calculated as

$$
T_{v}=T_{0}-\left(T_{s}+T_{c}\right)
$$

Values of $T_{s}$ can be calculated via Equation (5.3). The correction torque, $T_{C}$, must be empirically determined prior to testing by rotating the shear vane in air and calculating a correction torque from the in-air readings. This calculated value, usually approximately independent of rotational speed, is then subtracted, along with calculated values of $T_{s}$ (rpm dependent), from each overall shear vane torque measurement (Equation 6.1).

\subsection{CONDUCTING IN-TANK SHEAR VANE MEASUREMENTS}

The use of shear vanes to make in-situ rheological measurements of sludge in underground HLLW storage tanks involves procedures similar to those described in Chapter 4 for miniature shear vanes. Characterization of tank sludge rheology should proceed, as closely as is possible or practicable, as follows: 
1. The location of the sludge layer/supernatant interface should be accurately measured with respect to a reference point above the tank riser. [An in-tank density probe (Abdelhamid 1982) can be used to locate this interface.]

2. The shear vane segments should be assembled, positioned above the tank riser, and rotated at several rpms in air. Use the in-air torque readings to calculate $T_{C}$, which is caused by internal friction in the shear vane shaft and drive motor.

3. Carefully (slowly) lower the shear vane shaft through the riser and into the tank until the bottom of the shear vane shaft is immersed in sludge to a depth of $8.9 \mathrm{~cm}$. (3.5 in.), equivalent to $1 \mathrm{H}_{\mathrm{v}}$ (see Figure 4.20).

4. Initiate vane rotation at $0.032 \mathrm{rpm}$. A plot of torque versus time should be produced, having the general appearance of Figure 3.3. Use the peak value of the torque reading $\left[R_{t}(\max )\right]$ to calculate sludge shear strength $\left(\tau_{S}\right)$ using option \#4 of VANE-2 (Appendix B).

5. Prepare an "up-curve" and a "down-curve" by ramping vane speed from $0.032 \mathrm{rpm}$ to $50 \mathrm{rpm}$, holding at $50 \mathrm{rpm}$ until a steady-state reading is achieved, and then ramping back down to 0 rpm. Hold at $0 \mathrm{rpm}$ until the torque reading decays to a steady-state value. At each rpm, hold for approximately 1 min before proceeding to the next rpm. Ramping in increments of 2 to $3 \mathrm{rpm}$ is recommended so that 15 to 25 data points are obtained on the up- and down-curves. A maximum speed of $50 \mathrm{rpm}$ is recommended because axial mixing set up by the rotating vane is negligible at this speed. Axial mixing, which becomes appreciable at around $100 \mathrm{rpm}$, should be avoided during initial rheological measurements.

6. Compare the up- and down-curves to determine whether time-dependent behavior (thixotropy or rheopexy) is exhibited (see Sections 3.2 .3 and 4.6 ).

7. Using Option \#1 of VANE-2, analyze the down-curve data in terms of shear stress versus shear rate as discussed in Section 4.3 and in Appendix B. 
8. Determine whether a yield stress exists by the final torque reading at $0 \mathrm{rpm}$ at the conclusion of the down-curve test. Using the torque decay method presented in Section 4.4 .3 , calculate the yield stress based on the final torque decay reading. Option \#4 of VANE-2 can also be used to calculate $\tau_{y}$.

9. Fit the steady-state down-curve data, analyzed in steps 7 and 8 , to the yield-pseudoplastic power law equation discussed in Section 4.5 and in Appendix B.

10. Lower the shear vane shaft an additional $18 \mathrm{~cm}$ to a shaft depth of $L=3 H_{v}=26.7 \mathrm{~cm}$. Repeat steps 4 through 9 at this depth. (A depth increment equal to $2 \mathrm{Hv}$ provides a vertical distance of $1 \mathrm{Hv}$ between tests. This is recommended to minimize the effect of disturbances on subsequent tests. Because $\mathrm{Hv}$, in this case, equals $8.9 \mathrm{~cm}(3.5 \mathrm{in.})$, a depth increment of $18 \mathrm{~cm}$ ( $7 \mathrm{in.)}$ is recommended between tests.)

11. Repeat step 10 at lower depths in depth increments of $18 \mathrm{~cm}$.

12. Complete the analysis of the data (can be done in 1 or 2 d) to determine whether further tests at the current tank riser location are warranted.

13. Slowly raise the shear vane shaft up through the tank sludge. It is a good idea to pause at various heights, separated by a vertical distance of $18 \mathrm{~cm}$ ( $7 \mathrm{in.})$, and run high-rpm tests, for instance at 100 , 150,200 and $250 \mathrm{rpm}$. Do not exceed $300 \mathrm{rpm}$, or excessive shaft whipping could cause damage. Incorporate the high-rpm shear vane data in the analyses done in steps 7, 8, and 9 for low-rpm data taken at the same or similar sludge depths.

14. Carefully raise the shear vane assembly completely out of the tank. Partial decontamination can be accomplished by rinsing the assembly with water as it raised. If this is an acceptable approach, a jig (involving spray nozzles) may be required to assure that the contaminated rinse water drains into the tank.

15. If possible, lower the shear vane assembly through other risers to obtain sludge data at other locations within the same tank. 
16. Disengage the shaft couplers and place the disassembled shaft portions in a 10-ft cask. Transport the shaft sections in the cask to a decontamination facility, or to a suitable burial site for final disposal.

If these steps are followed, it should be possible to conduct all tests necessary to characterize the rheology of a tank sludge within a 1-week period. It is important, of course, that the entire operation be thoroughly planned and test personnel have the opportunity to acquire experience through cold testing with appropriate mock-ups of a tank, shear vane, shear vane handling equipment, and so on. The following example shows how measured values of shear vane torque and rotational speed are analyzed to determine the apparent viscosity of a tank sludge. The example uses one data point for torque versus rpm.

\subsection{EXAMPLE CALCULATION: ESTIMATION OF SLUDGE VISCOSITY FROM IN-TANK SHEAR VANE DATA}

Assume that a stable (steady-state) shear vane torque of approximately

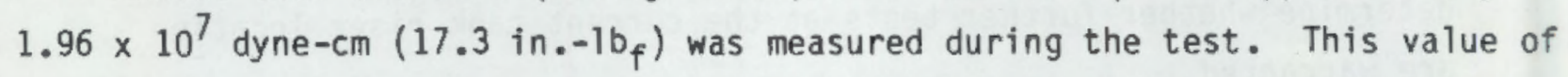
$T_{0}$ will be used in this example. Assume further that the torque associated with shaft motor-bearing friction was measured, by rotating the shear vane in air, as $9.0 \times 10^{5}$ dyne-cm $\left(0.8 \mathrm{in.}-1 b_{f}\right)$. Finally, assume that the shear vane has diameter and vane height equal to $8.89 \mathrm{~cm}(3.5 \mathrm{in.})$ and that the shear vane rate of rotation was held constant at approximately $50 \mathrm{rpm}$ throughout the test. Figure 6.2 illustrates the placement of such a shear vane in the sludge layer at the bottom of a tank.

First, the component of overall shear vane torque attributable to the portion of the shear vane shaft contacting the tank supernatant is calculated as $T_{s}=400$ dyne $-c m\left(3.5 \times 10^{-4}\right.$ in. $\left.-1 b_{f}\right)$ via Equation (5.3):

$$
T_{s}=\eta \cdot R_{b}^{2} \cdot L \cdot \frac{8 \pi^{2}}{60} \cdot \frac{N R_{c}^{2}}{R_{c}^{2}-R_{b}^{2}}
$$




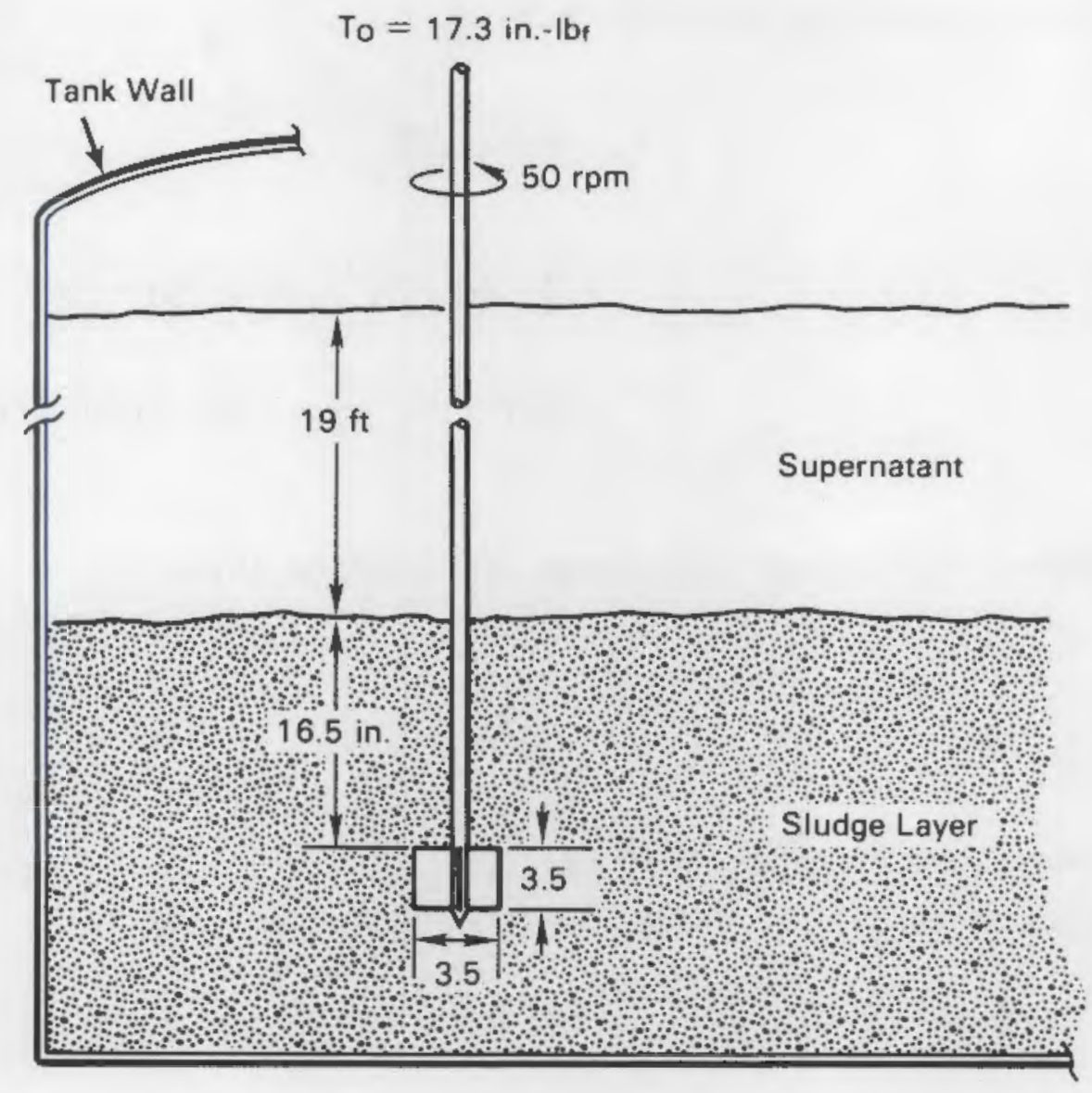

\section{FIGURE 6.2. In-Tank Test Configuration Assumed in Example Calculation}

where $\eta=$ assumed supernatant viscosity, $2.6 \mathrm{cP}=0.026$ Poise

$R_{b}=$ shear vane shaft radius, $1 / 4-i n .=0.635 \mathrm{~cm}$

$L=$ length of shaft immersed in supernatant, $19 \mathrm{ft}=580 \mathrm{~cm}$

$\mathrm{N}=$ shear vane rate of rotation, $50 \mathrm{rpm}$

$R_{C}=$ tank radius, $35 \mathrm{ft}=1069 \mathrm{~cm}$.

In this case, $T_{s}$ is negligible and $T_{v}=T_{0}-T_{C}=16.5 \mathrm{in.}-1 b_{f}$. Next, the power number, $N_{p}$, is calculated. To convert the units of $T_{v}$ from in.-lbf to dyne-cm,

$$
\begin{aligned}
T_{v}= & 16.5 \mathrm{in.}-1 b_{f} \times \frac{32.171 b_{m}-f t}{1 b_{f} \cdot s^{2}} \times \frac{2.54 \mathrm{~cm}}{i n .} \times \frac{30.5 \mathrm{~cm}}{\mathrm{ft}} \\
& \times \frac{453.6 \mathrm{~g}}{1 b_{m}}=1.86 \times 10^{7} \text { dyne }-\mathrm{cm}
\end{aligned}
$$


Power, $P$, is calculated via Equation (5.9) as

$$
\begin{aligned}
P & =T_{v} \times \frac{2 \pi N}{60} \\
& =\left(1.86 \times 10^{7}\right)\left(\frac{2 \pi}{60}\right)(50) \\
& =9.7 \times 10^{7} \text { dyne }-\mathrm{cm} / \mathrm{s}\left(1.30 \times 10^{-2} \mathrm{H}_{\mathrm{P}}\right)
\end{aligned}
$$

The power number, $N_{p}$, is then calculated via Equation (5.6) as

$$
N_{P}=\frac{P}{D^{5} N^{3} \rho}
$$

where $D=$ shear vane diameter, $8.89 \mathrm{~cm}(3.5 \mathrm{in.})$

$\rho=$ assumed hard layer sludge density, $2.49 \mathrm{~g} / \mathrm{cm}^{3}$

and

$$
N_{p}=\frac{\left(9.7 \times 10^{7}\right) \text { dyne-cm } / \mathrm{s}}{(8.89 \mathrm{~cm})^{5}(50 \mathrm{rpm})^{3}\left(\frac{1 \mathrm{~min} \cdot{ }^{3}}{60 \mathrm{sec}}\right)^{3}\left(2.49 \mathrm{~g} / \mathrm{cm}^{3}\right)}=1.22 \times 10^{3}
$$

Using Equation (5.10), developed empirically as described in Section 5.2.4, estimate the Reynolds number associated with this shear vane test case by

$$
\log \left[1.217 \times 10^{3}\right]=-0.977 \log \left[\mathrm{N}_{\mathrm{RE}}\right]+2.190
$$

$N_{R E}=1.214 \times 10^{-1}$, which is well into the laminar regime. The definition of the Reynolds number is then used to estimate the sludge viscosity at $50 \mathrm{rpm}$ :

$$
N_{R E}=\frac{\rho D^{2} N}{\eta}
$$


or

$1.21 \times 10^{-1}=\frac{\left(2.49 \mathrm{~g} / \mathrm{cm}^{3}\right)(8.89 \mathrm{~cm})^{2}(50 \mathrm{rpm})\left(\frac{1 \mathrm{~min}}{60 \mathrm{sec}}\right)}{\eta(\text { Poise })}$

and $n=1.35 \times 10^{3}$ Poise or roughly $135,000 \mathrm{cP}$.

By this initial calculation, the apparent viscosity of the sludge layer is large enough that the portion of the shear vane shaft submerged in the sludge layer may experience a large friction loss which should be considered. The average depth of the shear vane during the test is such that about $41.9 \mathrm{~cm}$ (16.5 in.) of the shaft was submerged in sludge. Assuming the sludge layer to be homogeneous--not a generally valid assumption but made to simplify this example calculation--a new estimate of $T_{S}$ is made, this time using $L=41.9 \mathrm{~cm}$ and $\eta=135,000 \mathrm{cP}$. Now $T_{S}$ is calculated as $1.50 \times 10^{6}$ dyne-cm, resulting in a corrected $T_{v}$ of $1.71 \times 10^{7}$ dyne-cm. Based on this value of $T_{v}$, a new, overall sludge viscosity (average viscosity of sludge layer) is calculated as $124,000 \mathrm{cP}$. Iterative calcutations are then performed in which the average sludge viscosity is guessed, and new values of $T_{s}$ and $T_{v}$ are calculated. New values of $P, N_{p}$, and $N_{R E}$ are also calculated, as is a new estimate of the average sludge viscosity. The iterations are performed until the estimated and calculated values of viscosity converge. In this case, after three iterations the values of sludge viscosity converge at a value of $126,000 \mathrm{cP}$.

Further, more-detailed examples are provided in Appendix $B$ along with a calculator program for quickly analyzing the raw torque and rotational speed shear vane data. 
c. 


\subsection{NOMENCLATURE}

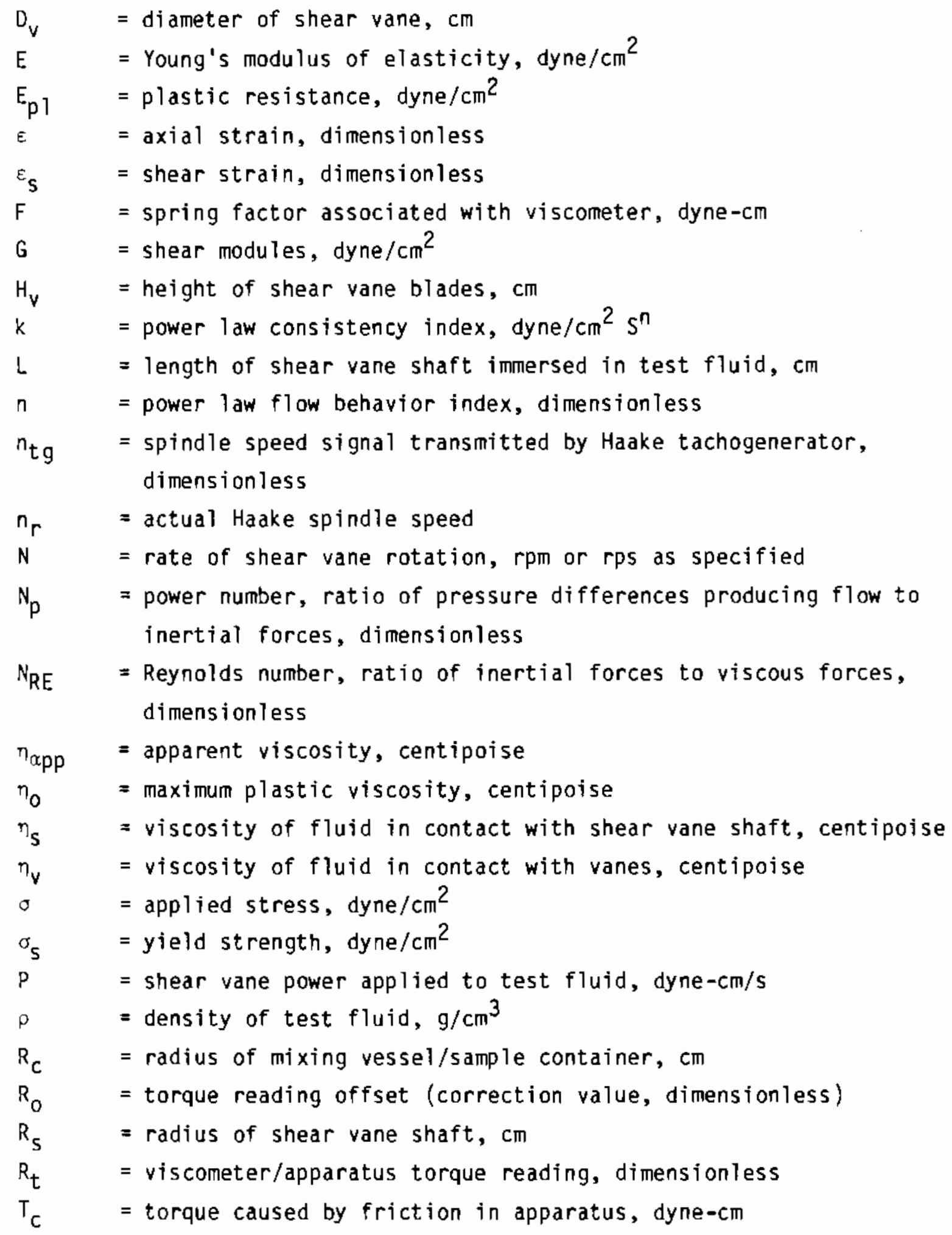




$$
\begin{array}{ll}
\dot{S} & =\text { shear rate, } \mathrm{s}^{-1} \\
T_{0} & =\text { overall shear vane torque, dyne-cm } \\
T_{s} & =\text { torque caused by shaft friction, dyne-cm } \\
T_{v} & =\text { net torque applied by vane, dyne-cm } \\
\tau & =\text { shear stress, dyne } / \mathrm{cm}^{2} \\
\tau_{s} & =\text { shear strength, dyne } / \mathrm{cm}^{2} \\
\tau_{y} & =\text { yield stress, dyne } / \mathrm{cm}^{2}
\end{array}
$$




\subsection{REFERENCES}

Abdelhamid, M. S. 1982. "Test Results and Evaluation Tank 8D-2 Siudge Characterization Study West Valley Demonstration Project." Job No. 10805108-23, West Valley Nuclear Services Company.

American Society for Testing and Materials (ASTM). 1963. Laboratory Shear Testing of Soils. ASTM STP No. 316, pp. 377-385, PhiladeTphia, Pennsylvania.

Anerican Society for Testing and Materials (ASTM). 1978. Standard Test Method for Field Vane Shear Test in Cohesive Soil. ASTM D2573-72778, Phitadelphia, Pennsylvania.

Athanasopoutous, G. A., and F. E. Richart, Jr. 1983. "Effect of Creep on Shear Modulus of Clays." J. Geotech. Eng. 109(10):1217-1232.

Bates, R. L., P. L. Fondy and J. G. Fenic. 1966. "Impeller Characteristics and Power," pp. 111-175, Mixing Theory and Practice, Academic Press

Publications Co., New York.

Blair, G. W. S. 1949. A Survey of General and Applied Rheology. Sir Isaac Pitman and Sons, Ltd., London.

British National Society of the International Society of Soil Mechanics and Foundation Engineering. 1961. Conference on Pore Pressure and Suction in Soils at the Institution of CiviT Engineers, held on March 30-31, 1960. Butterworths, London.

Brookfield Engineering Laboratories, Inc. 1982. UL Adapter Assembly and Operating Instructions. Brookfield Engineering Laboratories, Inc., Stoughton, Massachusetts.

Brookfield Engineering Laboratories, Inc. 1984. More Solutions to Sticky Problems - A Guide to Getting More From Your Brookfield Viscometer. Brooxfield Engineering Laboratories, Inc., Stoughton, Massachusetts, pp. 17-25.

Calderbank, P. H. and M. B. Moo-Young. 196l. Transactions of the Institution of Chemical Engineers. (London), 39(22).

Denn, M. M. 1980. Process Fluid Mechanics. Prentice-Hall, Inc., Englewood Cliffs, New Jersey.

Evans, D. J., H. J. M. Hanley, and S. Hess. 1984. "Non-Newtonian Phenomena in Simple Fluids." Phys. Today $37(1): 26-33$.

Ford, E. W. and J. F. Steffe. 1986. "Quantifying Thixotropy in StarchThickened, Strained Apricots Using Mixer Viscometry Techniques." J. Texture Stud. 17:71-85. 
Govier, G. W., and K. Aziz. 1972. The Flow of Complex Mixtures in Pipes. Robert E. Krieger Publishing Company, Malabar, Florida.

Halliday, D. and R. Resnick. 1981. Fundamentals of Physics, 2nd Edition, Extended Version. John Wiley and Sons, New York.

Krynine, D. P. 1947. Soil Mechanics - Its Principles and Structural Applications. McGraw-HitT Book Company, Inc., New York.

McCarthy, D., M. K. C. Chan and R. 0. Lokken. 1985. Rheological Evaluation of Pretreated Cladding Removal Waste. PNL-5589, Pacific Northwest Laboratory, Richiand, washington.

Merrington, A. C. 1949. Viscometry. Arnold Publishers, London.

Mesri, G., and P. M. Godlewski. 1977. "Time- and Stress-Compressibility Interrelationship." J. Geotech. Eng. Div. 103:417-435

Metzner, A. B. and R. E. Otto. 1957. "Agitation of Non-Newtonian Fluids," AIChE $3: 1,3$.

0ldshue, J. Y. 1983. Fluid Mixing Technology. McGraw-Hill Publications Company, New York.

Pyles, M. R. 1984. "Vane Shear Data on Undrained Residual Strength." J. Geotech. Eng. 110(4):543-547.

Rehbinder, P. 1954. "Coagulation and Thixotropic Structures." Discuss. Faraday Soc. 18:151-160.

Reiner, M. 1949. Deformation and Flow - An Elementary Introduction to Theoretical Rheology. H. K. Lewis, Co. Ltd., London.

Schramm, G. 1981. Optimization of Rotovisco Tests. Gebrader Haake GmbH, Karlsruhe, West Germany.

Tanner, R. I. 1983. "Recent Progress in Rheology." J. of Appl. Mech. $50: 1181-1190$.

Terzaghi, K., and R. B. Peck. 1948. Soil Mechanics Engineering Practice. John Wiley and Sons, Inc., New York.

vaid, Y. P., and R. G. Campanella. 1977. "Time-Dependent 8ehavior of Undisturbed Clay." J. Geotech. Eng. Div. 103:693-709.

Van 01phen, H. 1977. An Introduction to Clay Colloid Chemistry. 2nd ed. John Wiley and Sons, New York.

Van VIack, L. H. 1975. Elements of Materials Science and Engineering, 3rd edition. Addison-Wesley Publishing Company, Reading, Massachusetts. 
APPENDIX A

CONCEPTUAL DESIGN OF FULL SCALE, IN-SITU SHEAR VANE DEVICE 


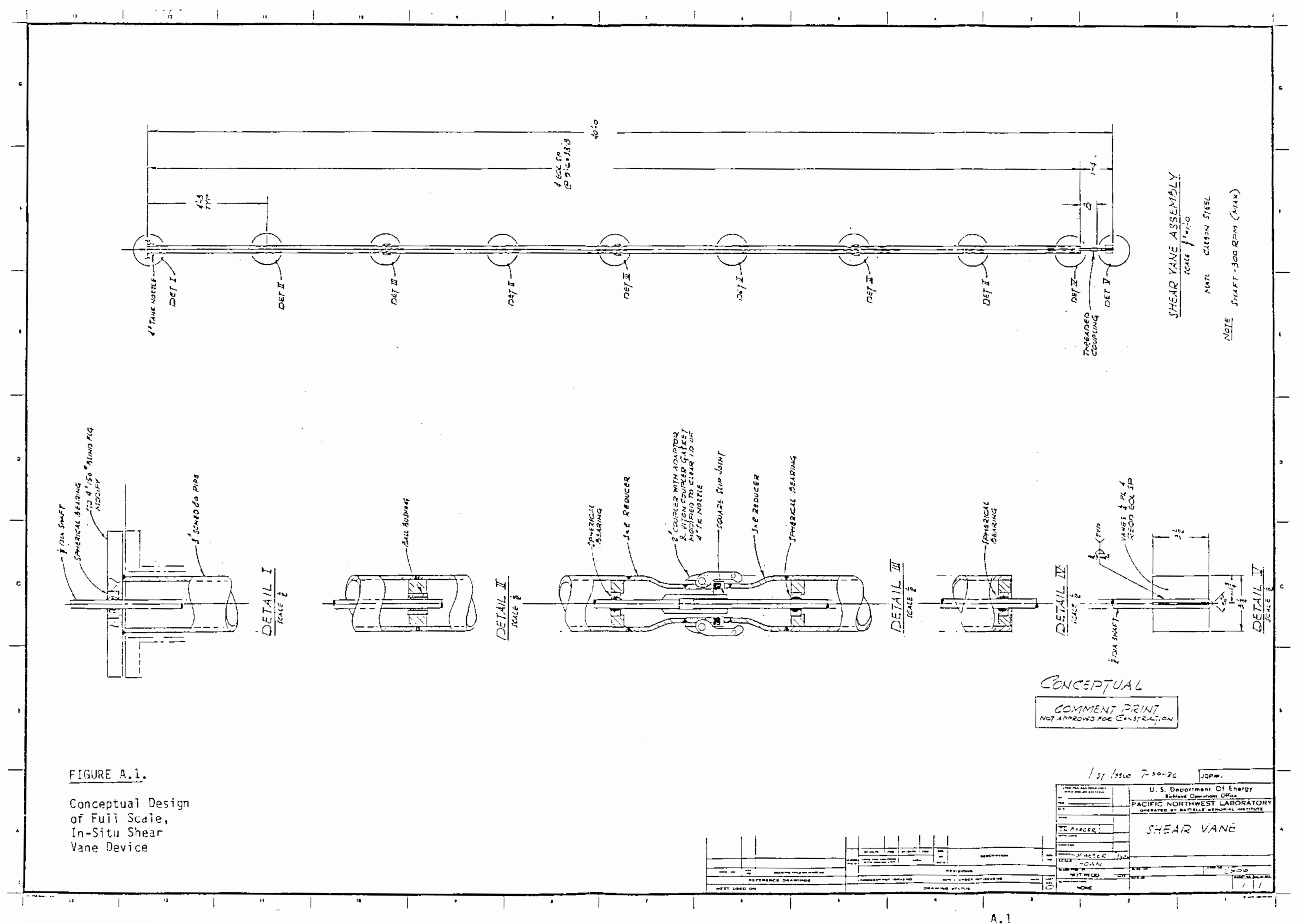




\section{APPENDIX B}

PROCEDURE FOR USING CALCULATOR PROGRAM "VANE-2"

FOR REDUCING SHEAR VANE SLUDGE AND SLURRY DATA 


\section{CONTENTS OF APPENDIX B}

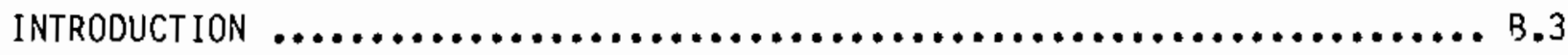

SETTING UP THE CALCULATOR AND PRINTER $\ldots \ldots \ldots \ldots \ldots \ldots \ldots \ldots \ldots \ldots \ldots \ldots . . \ldots$

INPUTTING INITIAL DATA AND STARTING THE PROGRAM $\ldots \ldots \ldots \ldots \ldots \ldots \ldots \ldots . . . \ldots$

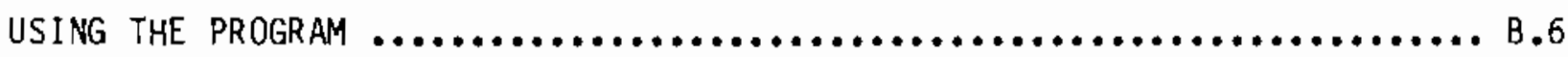

INPUTTING TORQUE READING AND SHEAR VANE RPM DATA $\ldots \ldots \ldots \ldots \ldots \ldots \ldots \ldots \ldots .6$

INPUTTING REMAINING TEST PARAMETERS $\ldots \ldots \ldots \ldots \ldots \ldots \ldots \ldots \ldots \ldots \ldots \ldots . ., 8.7$

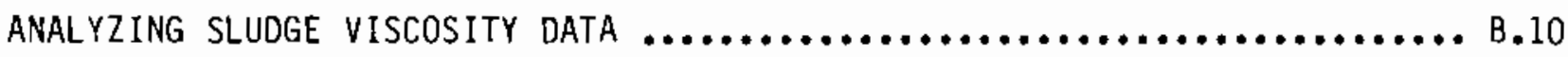

Procedure when vanes and Shaft Are in

Contact with the Same Fluid $\ldots \ldots \ldots \ldots \ldots \ldots \ldots \ldots \ldots \ldots \ldots \ldots \ldots \ldots . . .11$

Procedure when Vanes and Shaft Are in Contact

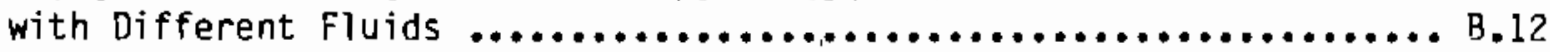

Using Option \#2 to Save Time when Shaft

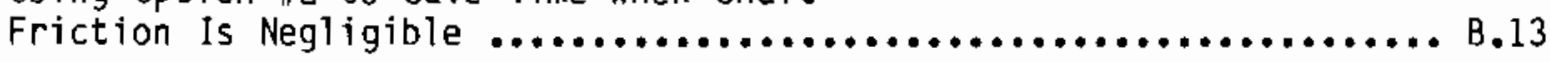

Using Option \#5 to Save Time when

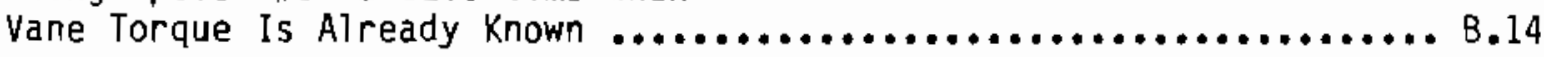

FITTING NON-NEWTDNIAN VISCOSITY DATA TO THE POWER LAW MODEL FOR

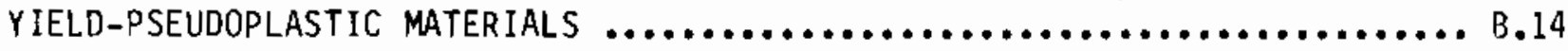

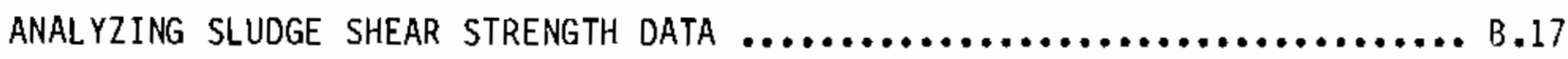

"vane-2" Program listing and StORAge Register Description ............. B.19 
$\therefore$ 
APPENDIX B

PROCEDURE FOR USING CALCULATOR PROGRAM "VANE-2" FOR REDUCING SHEAR VANE SLUDGE AND SLURRY DATA

\section{INTRODUCTION}

This procedure employs an HP-4l calculator program for analyzing sludge shear strength and apparent viscosity data obtained using shear vanes. This program, VANE-2, was developed to simplify the calculations and to allow shear vane data to be rapidly analyzed as it becomes available. This program will provide feedback to test personnel while they are performing in-tank and laboratory shear vane tests. It should result in better and more informed responses to decisions that arise during testing, and more assurance that sufficient data are obtained. Siudge shear strength and viscosity data can be obtained using shear vanes in conjunction with a torque-measuring device, such as a viscometer, by following procedures outlined in Chapters 4 and 5 .

VANE-2 is a user-interactive calculator program that asks the user questions and then performs the desired calculations. Familiarity with an HP-41 calculator is not required to use this program. Before proceeding, however, it is best to obtain an HP-41 calculator loaded with VANE-2 and an HP 82143A printer.

For VANE-2 to calculate sludge/slurry shear strength, the following data must be input by the user: $F, D_{v}, R_{c}, R_{s}, T_{c}, R_{t}$, and $H_{v}$. The program then calculates $T_{0}, T_{v}$, and $\tau_{s}$. For the program to calculate s?udge/slurry viscosity, the following input data are required: $F, D_{v}, R_{c}, R_{S}, T_{c}, R_{t}$, $N, L, \eta_{s}$, and $\rho$. The program then calculates $T_{0}, T_{s}, T_{v}, P, N_{p}, N_{R E}, \eta_{v}$, $\dot{S}$ and $\tau$.

The following instructions explain how to use VANE-2 for analyzing shear vane data. 
SETTING UP THE CALCULATOR AND PRINTER

First, hook up the HP $82143 \mathrm{~A}$ printer by plugging the printer cable into one of four ports at the front of the MP-41 calculator. Assure that calculator and printer are off during the hook up. Turn on the calculator and set it in "user mode" by pushing the user switch until the word "USER" shows up in the lower left corner of the calculator display. Each time the program is restarted, User mode must be reactivated. The calculator must not be in "program mode" (the phrase "PRGM" shows up in the lower right corner of the calculator display). Get out of it by pushing the "PRGM" switch, which is to the right of the "ON" switch. Next, assure sufficient storage register space by performing the following keystrokes: press "XEQ"; press "ALPHA"; press the buttons " 8 ," "COS," " 1 ," "LN" to spell the word "SIZE"; press "ALPHA"; key in "030." There are now 30 storage registers available for program use. Now turn on the printer and set the mode switch to "MAN." Calculator and printer are now on and ready to go.

INPUTTING INITIAL DATA AND STARTING THE PROGRAM

With the calculator in User mode, press the " $\Sigma+$ " button (top left button on calculator keypad). This starts the program. The phrase "FACTOR=?" should appear on the calculator display. The program is asking for a spring factor, which corresponds to the full-scale torque, in dyne-cm, that the viscometer (or load cell) is capable of measuring. Select the appropriate spring factor from Table $B .1$ and key it into the calculator. Use the "+" button to correct any incorrect digits. After the correct spring factor is keyed in, press "R/S," which advances the program to the next step.(a)

(a) Whenever the "R/S" button is pushed, the phrase "PRGM" will appear in the lower right corner of the calculator display, indicating that the program is running. Pushing any button on the calculator keypad will interrupt (stop) the program. Program operation can be resumed by pushing "R/S." When the program has finished running, the phrase "PRGM" will disappear. 
TABLE B.1. Viscometer Spring Factor

\begin{tabular}{l} 
Torque Sensor System \\
\hline Brookfield RVDT \\
Brookfield LVDT \\
Haake M1500 \\
Haake M500 \\
Haake M150 \\
Load Cell
\end{tabular}

\begin{tabular}{l}
$\mathrm{F}$ (dyne-cm) \\
\hline 7,187 \\
673.7 \\
$1,470,00$ \\
490,000 \\
147,000 \\
Torque corresponding to \\
full-scale $\left(R_{t}=100\right)$ \\
deflection
\end{tabular}

The calculator display now asks for the diameter, $D_{v}$, of the shear vane. Input $D_{V}$ in $C m$ and press "R/S" to proceed.

The program now asks for the radius, $R_{C}$, of the test container. Input $R_{C}$ in $\mathrm{Cm}$ and press " $\mathrm{R} / \mathrm{S}$ " to proceed.

The program now asks for the radius, $R_{s}$, of the shaft portion of the shear vane. The miniature shear vanes used in lab testing have a shaft radius of $0.1588 \mathrm{~cm}$. Input $\mathrm{R}_{\mathrm{S}}$ (in $\mathrm{cm}$ ) and push "R/S" to proceed.

The program now asks for $T_{c}$ (correction for torque zero offset caused by bearing friction, etc. in torque instrumentation). If the shear vane data were obtained using a Brookfield or Haake viscometer, $T_{c}=0$. If other torque instrumentation was used, such as an agitator motor linked to a load cell, a nonzero value for $T_{c}$ must be determined empirically. This is done by rotating the shear vane in air at the test rpm, reading the load cell output, and calculating the torque associated with the in-air reading. Input this zero offset torque in dyne-cm and press " $\mathrm{R} / \mathrm{S}$ " to proceed.

The program has now received all initial data and automatically prints out a list of the input values as they were keyed in, as shown in Figure B.1. If an error occurs in the printout, start over by pushing the USER switch and then " $\Sigma+, "$ and input the correct values. After the program becomes familiar, all of these steps will take less than one minute. 
$F=4,990.8$ JYHE - CH

$D-Y=2.228$ CH

$R-C=3.880$ Cn

$R-S=8.1589 \mathrm{CH}$

$T-C=8.800$ DYHE $-\mathrm{CH}$

FIGURE B.1. Printout of Initial Value Data

USING THE PROGRAM

VANE-2 contains several subroutines for calculating various parameters pertaining to sludge flow properties and shear vane test conditions. Which subroutines are used depends on what parameters are to be calculated. The input values of the four variables $F, L, R_{t}$, and $N\left(L, R_{t}\right.$, and $N$ are described later) control the calculation process and determine the parameters to be calculated. Depending on whether each variable is input as zero or some nonzero value, different subroutines are activated and different parameters are calculated. By controlling the values for $F, L, R_{t}$, and $N$, six different calculation options are avajlable. Table B.2 describes these options and indicates how they are selected by appropriate zero or non-zero inputs of $F, L$, $R_{t}$, and N. Use Table B.2 to select the appropriate option on the basis of the parameters to be calculated. Figure $B .2$ is a flow chart of VANE-2 that illustrates how the program uses this initial value data to determine which subroutines are activated. The equations employed by VANE-2 are listed in Table B.3. The following sections provide general information on how and when to use the six available calculation options.

INPUTTING TORQUE READING AND SHEAR VANE RPM DATA

After the initial values for $F, D_{v}, R_{c}, R_{s}$, and $T_{c}$ are keyed in and printed out as described earlier, the program asks for a viscometer/load cell torque reading $\left(R_{t}\right)$. If a Brookfield viscometer (digital or dial reading) was used, $R_{t}$ is equivalent in magnitude to the viscometer output signal that varies from 0 to 100. If a Haake Rotovisco viscometer was used, $R_{t}$ equals the torque output reading, $S_{\tau}$, which varies from 0 to 1.0 , multiplied by an output scale factor, $\%$, which varies from 0 to 100 . For example, if the Haake output $\left(S_{\tau}\right)$ reads 0.8 and the scale factor $(\% \tau)$ is $50 \%, R_{t}=(0.8)(50)=40.0$. 
TABLE B.2. VANE-2 Subroutine Options and How to Control Them

$$
\begin{aligned}
& \frac{\text { Option \# }}{1} \frac{\text { Conditions }}{F \neq 0} \frac{\text { Inputs Required }}{F, D_{v}, R_{c}, R_{s}, T_{c}, R_{t}, N,} \frac{\text { Calculated Parameters }}{T_{0}, T_{s}, T_{y}, P, N_{p},} \\
& R_{t} \neq 0 \quad L, n_{s}, \rho \quad N_{R E}, n_{v}, S, \tau \\
& \mathrm{N} \neq 0, \mathrm{~L} \neq 0 \\
& 2 \quad F \neq 0 \quad F, D_{v}, R_{c}, R_{s}, T_{c}, R_{t}, N, T_{0}, T_{s}=0, T_{v}, P, N_{p}, \\
& R_{\mathrm{t}} \neq 0 \quad L=0, \rho \quad N_{\mathrm{RE}}, \eta_{\mathrm{v}}, \dot{S}, \tau \\
& \mathrm{N} \neq 0, \mathrm{~L}=0 \\
& 3 \quad F \neq 0 \\
& R_{t}=0 \\
& \mathrm{~N}=0 \\
& 4 \quad F \neq 0 \\
& R_{\mathrm{t}} \neq 0 \\
& \mathrm{~N}=0 \\
& 5 \quad \mathrm{~F}=0 \\
& \mathrm{~N} \neq \mathrm{D}, \mathrm{L} \neq 0 \\
& 6 \quad F=0 \\
& \mathrm{~N}=0 \\
& F, D_{v}, R_{c}, R_{s}, T_{c}, N, L \quad T_{s} \\
& n_{S} \\
& F, D_{v}, R_{c}, R_{s}, T_{c}, R_{t}, \quad T_{0}, T_{v}, \tau_{s} \\
& \mathrm{H}_{v} \\
& D_{v}, N, T_{v}, \rho \\
& P, N_{p}, N_{R E}, \eta_{v}, \dot{S}, \tau
\end{aligned}
$$

If other torque instrumentation is used, such as a load cell connected to a free-swiveling motor base, $R_{t}$ equals the torque output reading expressed as a percentage of full-scale output. For example, if the output scale reads from 0 to 1000 , and a particular reading is 469.0 , then $R_{t}=(469 / 1000) \times(10 D)=$ 46.9. After inputting an appropriate value of $R_{t}$, press "R/S" to proceed.

The program now asks for the rate of shear vane rotation, $N$, in revolutions per minute. Key in rpm and press "R/S" to proceed. 


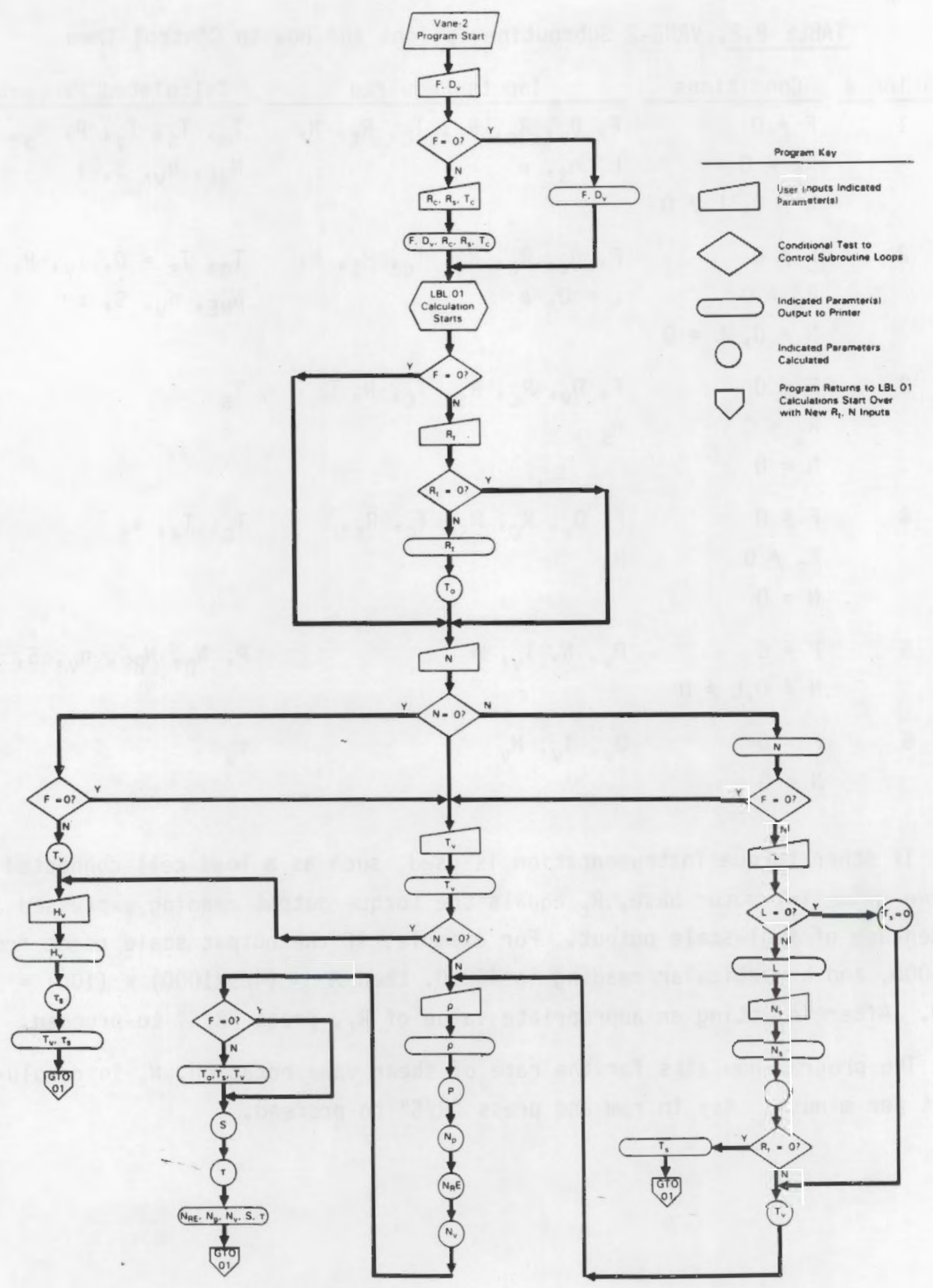

FIGURE B.2. VANE-2 Flow Chart 
TABLE B.3. Equations Employed by VANE-2(a)

$$
\begin{aligned}
& T_{0}=F \cdot \frac{R_{t}}{100} \\
& T_{s}=\frac{n_{s}}{100} \cdot R_{s}^{2} \cdot L \cdot \frac{8 \pi^{2}}{60} \cdot \frac{N R_{c}^{2}}{R_{c}^{2}-R_{s}^{2}} \\
& T_{v}=T_{0}-T_{s}-T_{c} \\
& P=T_{v} \cdot \frac{2 \pi}{60} \cdot N \\
& N_{p}=\frac{P}{\rho D_{v}^{5}(N / 60)^{3}} \\
& \log N_{p}=-(0.977) \log N_{R E}+(2.190) \\
& N_{R E}=\frac{P D_{v}^{2}(N / 60)}{\left(\eta_{v} / 100\right)} \\
& \dot{S}=(11.1) \frac{N}{60} \\
& \tau=\left(n_{v} / 100\right)(s) \\
& \tau_{s}=\frac{T_{v}}{\pi}\left[\frac{H_{v} D_{v}^{2}}{2}+\frac{D_{v}^{3}}{6}\right]-1
\end{aligned}
$$

(a) All of these equations are obtained from the literature except for (6), and (9), which are developed by Heath in unpublished documents. 
The program now asks for the length, $L$, of the shaft portion of the shear vane (above the blades) that was submerged in the test fluid during the test. Input $L($ in $\mathrm{cm}$ ) and press "R/S" to proceed. If no part of the shaft was submerged, input $L=0$.

If $F, R_{t}, N$, and $L$ were all assigned nonzero values (Option \#1) or if $R_{t}=0$ (Option \#3), the program now asks for the viscosity $(n)$ of the fluid in contact with the shaft portion of the shear vane. The input value of $n_{s}$ is used to calculate a correction for shaft friction, $T_{s}$. Enter $n_{s}$ in centipoise and press "R/S" to proceed.

The program now asks for the density of the sludge in $\mathrm{g} / \mathrm{cm}^{3}$. Input sludge density and press "R/S" to proceed.

\section{ANALYZING SLUDGE VISCOSITY DATA}

In analyzing sludge viscosity data, Options \#1, \#2, \#3, and \#5 are involved. For tests in which the vanes and part of the shaft are immersed in the same test fluid (sludge), use Option \#l of Table B.2. In this case, first input the initial data ( $F$ through $T_{C}$ ) as described in preceding section. Then input $R_{t}, N$, and $L$ as described above. The program now asks for the viscosity, $n_{s}$, of the fluid in contact with the shaft portion of the shear vane. Generally, $n_{s}$ will not be known beforehand, so estimate a value, enter $i t$, and press "R/S" to proceed. Now input $\rho$ in $\mathrm{g} / \mathrm{cm}^{3}$ and press "R/S" to proceed. The program will now calculate and print out the parameters listed in Table B.2 under Option \#1.

Following this step, the program is ready to analyze additional data, having new values for $R_{t}, N, L, n_{s}$, and $\rho$, but with the same initial values for $F, D_{v}, R_{c}, R_{s}$, and $T_{c}$. The program will request new values for $R_{t}, N, L, n_{s}$, and $\rho$, which should be input as described above. If one or more of the initial values of $F, D_{v}, R_{c}, R_{s}$, or $T_{c}$ change, start the program over by pressing "USER" and " $\Sigma+$ ", and input the new initial value data. 
Procedure When Vanes and Shaft Are in Contact with the Same (Unknown) Fluid

In cases where the fluid contacting the shear vane shaft is the same as that contacting the blades, $\eta_{v}$ must, by definition, be equivalent to $\eta_{s}$. In general, the estimated value of $n_{s}$ used to calculate shaft friction will differ from the value of $\eta_{v}$ calculated by VANE-2. Since $n_{s}=\eta_{v}$ is known, an iterative procedure must be followed wherein the calculated value of $\eta_{v}$ is used as a better estimate of $n_{s}$, allowing a new value of $n_{s}$ to be calculated. This procedure is repeated until the values of $n_{s}$ and $n_{v}$ converge such that $n_{s}=n_{v}=n_{a p p}$, where $n_{a p p}$ is the apparent viscosity of the sludge in centipoise. The calculation shown in Figure B.3 illustrates this iterative procedure.

Even though the initial estimated value of $n_{5}$ in the sample calculation was low by a factor of 50 , note that only three iterations were required for $n_{s}$ and $n_{y}$ to converge. The procedure does not generally require a large number of iterations.

$F=4,998.6$ DYHE - CM

$\mathrm{D}-\mathrm{V}=2.220 \mathrm{~cm}$

$R-C=3.989 \mathrm{CH}$

$R-S=0.1589 \mathrm{CH}$

$T-C=9.890$ DYHE $-C M$
$R T=48.9$

$H=19.6 \mathrm{RPH}$

$L=1.999 \mathrm{CM}$

YISC $-S=19$. 0 C.PS

DEHS $=1.258 \mathrm{G} / \mathrm{CH}+3$

$T-0=1,969.0$ DYNE-CH

$T-S=9.3$ DYNE $-C$ H

$T-Y=1,959.7$ DYNE-CH

$\mathrm{RE}=2.159 \mathrm{E}-2$

$N P=6.594 E 3$

$Y I S C, Y=4,774.9$ CPS

RATE $=1.850$ INY SEC

$T A U=89.34 \mathrm{BYHE} / \mathrm{CH}+2$
$R T=48.9$

$N=19.8 \mathrm{RPH}$

$L=1.898 \mathrm{CH}$

YISC $-S=4,775.8$ CPS

DENS $=1.258$ G/CHI 3

$T-0=1,969.8$ DYHE-CH

$T-5=15.9$ DYHE-CH

$T-Y=1,944.1$ BYHE-CH

$\mathrm{RE}=2.169 \mathrm{E}-2$

$M P=6.542 E 3$

YISC $Y=4,736.1$ CPS

RATE $=1.858$ INY SEC

TAU $=87.62$ DYME/CH+2
$R T=49.8$

$H=19.8 \mathrm{RPH}$

$L=1.898 \mathrm{CH}$

VISC $-S=4,736.5$ CPS

DENS $=1.259 \mathrm{G} / \mathrm{CH}+3$

$T-0=1,969.0$ DYHE-CH

$T-S=15.8$ BYHE-CH

$T-Y=1,944.2$ DUNE-CH

$\mathrm{RE}=2.168 \mathrm{E}-2$

$M P=6.542 E 3$

VISC $-Y=4,736.5$ CPS

RATE $=1.859$.INY SEC

$T A U=87.62$ DYNE/CH+2

\section{(a)}

(c)

FIGURE B.3. Example Calculation of Apparent Sludge Viscosity from Shear Vane $R_{t}$ Versus $N$ Data.

(a) Initial value data

(b) Iteration $\# 1, n_{s}$ guessed as $100 \mathrm{cP}, n_{v}$ calculated as $4775 \mathrm{cP}$

(c) Iteration $\# 2, \eta_{v}$ used as new estimate for $n_{s}$

(d) Iteration \#3, values of $n_{s}$ and $n_{v}$ converge; $n_{a p p}=n_{s}=n_{v}=4740 \mathrm{cP}$. 
Procedure when Vanes and Shaft Are in Contact with Different (Unknown) Fluids

A similar but somewhat more involved procedure must be used to calculate the apparent sludge viscosity $\left(n_{a p p}\right)$ when the fluid contacting the shaft is different from that contacting the vanes. For example, when tests are conducted in multi-layered sludges, it is possible for the shaft to be in contact with several fluids where flow properties all differ from those of the material in contact with the vanes. In this case, a shaft friction loss torque correction $\left(T_{S}\right)$ must be calculated for each layer, using 0ption \#3 in Table B.2. As an example, consider a three-layered sludge in which the apparent viscosities of the top two layers have been determined, but that of the bottom layer is unknown. Refer to Figure B.4, which provides a basis for an illustrative example calculation.

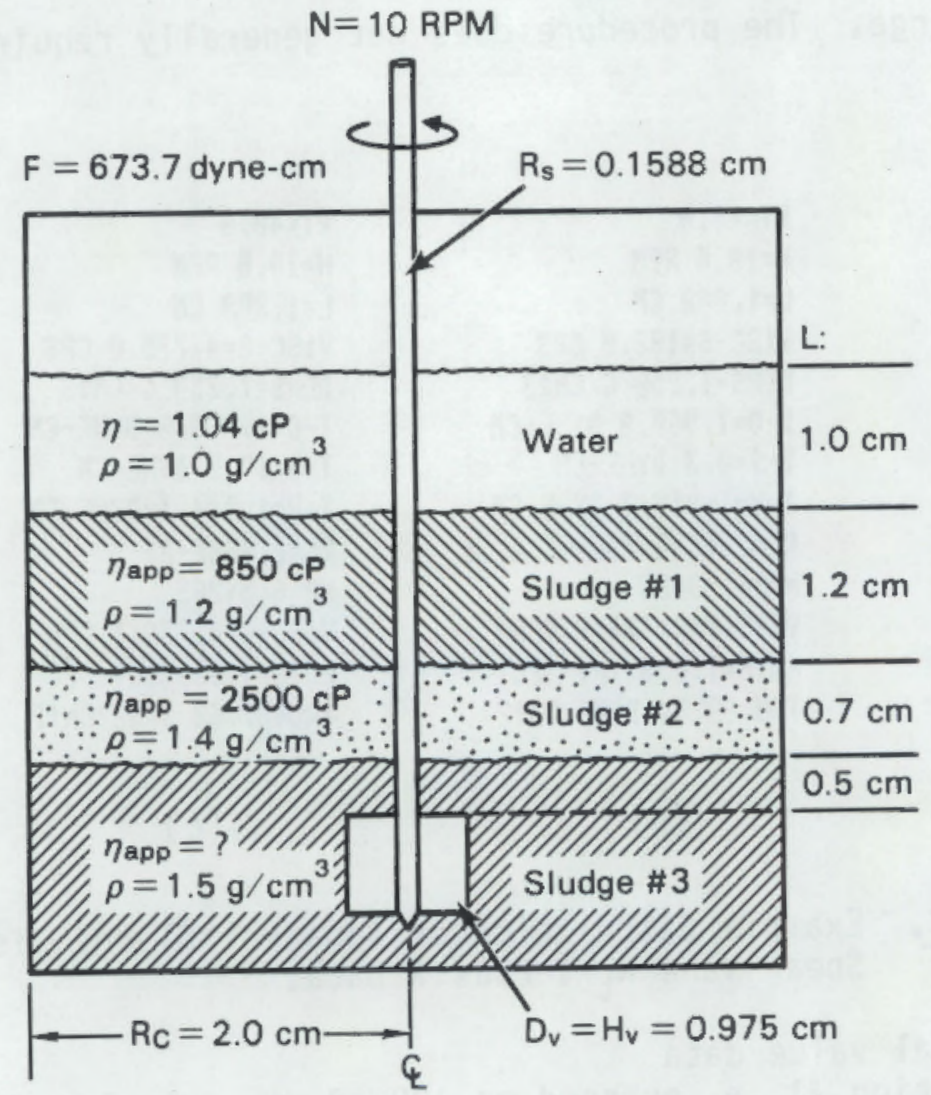

FIGURE B.4. Example Calculation Test Configuration 
First, press "USER" and " $\Sigma+$," and input $F=673.7$ dyne-cm, $D_{v}=0.975 \mathrm{~cm}$, $R_{c}=2.0 \mathrm{~cm}, R_{S}=0.1588 \mathrm{~cm}$, and $T_{C}=0.0$ dyne $-c m$, which are the values indicated in Figure B.4. Calculate the shaft torque associated with friction losses to the water layer by keying in $R_{t}=0$ (to activate Option \#3), $N=10 \mathrm{rpm}, L=1.0 \mathrm{~cm}$, and $\eta_{s}=1.04 \mathrm{cp}$. Shaft torque $\left(\tau_{s}\right)$ due to friction losses in the top water layer is calculated as $3.5 \times 10^{-3}$ dyne-cm. To calculate $T_{s}$ for sludge $\# 1$, key in $R_{t}=0, N=10 \mathrm{rpm}, L=1.2 \mathrm{~cm}$, and $n_{s}=850 \mathrm{cp}$, resulting in $T_{s}=3.4$ dyne-cm. The frictional losses for sludge \#2 are similarly calculated as $T_{s}=5.8$ dyne-cm. The total shaft friction losses above the bottom sludge layer, at $10 \mathrm{rpm}$, are $\left(3.5 \times 10^{-3}\right)+3.4+$ $5.8=9.204$ dyne $-\mathrm{cm}$.

Now, the apparent viscosity of the bottom sludge layer can be calculated by pressing " $\Sigma+, "$ which starts the program over, and inputting the appropriate values of $F, D_{v}, R_{c}$, and $R_{s}$. This time, instead of keying in $T_{c}=0.0$, key in $T_{c}=9.204$ dyne-cm. This correction torque, in this case attributed to shaft friction losses in the top layer of the sample, will be used to adjust the overall torque, $T_{p}$, in calculating the net torque applied by the vanes, $T_{v}$. Input $R_{t}=63.7, N=10 \mathrm{rpm}$, and $\mathrm{L}=0.5 \mathrm{~cm}$ corresponding to the length of the shaft submerged in sludge $\# 3$ at the bottom of the test container. As described earlier, use an iterative procedure to guess $\eta_{s}$; calculate $\eta_{v}$; use $\eta_{v}$ as a better guess for $\eta_{s}$; and so on until $\eta_{s}=\eta_{v}=\eta_{a p p}$. In each case, input $\rho=1.5 \mathrm{~g} / \mathrm{cm}^{3}$. The final value of $\eta_{\text {app }}$ is calculated as $12,150 \mathrm{cPs}$ at $10 \mathrm{rpm}$, corresponding to a shear rate $(\dot{S})$ of $1.850 \mathrm{~s}^{-1}$. With an initial estimate of $n_{s}=1200 \mathrm{cPs}$, four iterations were required for $\eta_{s}$ and $\eta_{v}$ to converge. Using Option \#2 to Save Time when Shaft Friction Is Negligible

In cases where shaft friction is negligible $\left(T_{S}=0\right)$, use Option $\# 2$ by keying in $\mathrm{L}=0$. Option \#2 can also be used in cases where $T_{S}$ is known beforehand by inputting $L=0$ and $T_{c}=T_{s}$. The option is further useful for obtaining a quick estimate of apparent sludge viscosity without accounting for shaft friction losses. For the three-layered sludge data depicted in Figure B.4, an apparent viscosity of 13,065 cP is calculated using Option \#2. As expected, this value is higher than the more-accurate value of $12,150 \mathrm{cP}$, which took shaft friction into account. 
Using Option \#5 to Save Time when Vane Torque Is Al ready Known

Option \#5 (Table B.2) is provided to save time when a value of $T_{v}$ is already known. This would occur, for example, if Option \#2 were used to calculate $T_{v}$ and the other parameters neglecting shaft friction losses, and if Option \#3 were used to calculate only the shaft friction losses. In this case $T_{s}$ of Option \#3 would be subtracted from $T_{v}$ of 0ption \#2; and the resulting $T_{v}$, corrected for shaft friction losses, would be input directly by using Option \#5. Repeated use of VANE-2 will demonstrate the practicality of these options.

FITTING NON-NEWTONIAN VISCOSITY OATA TO THE POWER LAW MOOEL FOR YIELDPSEUOOPLASTIC MATERIALS

The preceding section described how data for shear vane torque, $T_{v}$, versus rotational speed, $\mathrm{N}$, can be reduced to data for shear stress, $\tau$, versus shear rate, $\dot{S}$, by means of VANE-2. The relationship between $\tau$ and $\dot{S}$ uniquely defines the flow behavior of viscous fluids.

For Newtonian fluids the ratio $\tau / \dot{S}$ is constant over all shear rates and is

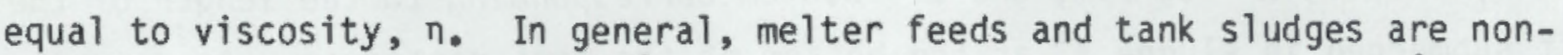
Newtonian in that the ratio $\tau / \dot{S}$ is not constant over all values of $\dot{S}$. The shear stress-shear rate behavior of these fluids has been successfully described by the power law Equation 4:

$$
\tau=k \dot{S}^{n}
$$

where $k=$ consistency index, dynes $/ \mathrm{cm}^{2}$

$n=$ flow behavior index, dimensionless.

This expression can be used to calculate values of shear stress as a function of shear rate. Values of apparent viscosity, $\eta_{\text {app }}$ in centipoise, can then be calculated by the expression

$$
\eta_{\text {app }}=\frac{\tau}{\dot{S}}
$$


The values of $k$ and $n$ for a given fluid are determined experimentally by measuring shear stress at several different shear rates and plotting the data as $\log \tau$ vs $\log \dot{S}$. The slope and intercept of such a plot, which is usually approximately linear, correspond to values of $n$ and $k$, respectively. The significance of the flow behavior index is that if $n=1$, the fluid is Newtonian; if $n<1$, the fluid is "shear thinning" or pseudoplastic; and if $n>1$, the fluid is shear thickening or dilatent. Melter feeds and sludges are typically found to be pseudoplastic as $n$ is usually less than unity. Note that sludges and slurries must be pseudoplastic (not dilatent) in order for the shear vane method to work properly. If a pseudoplastic is found to exhibit a yield stress, $\tau_{y}$, then it is termed a "yield-pseudoplastic" and is described by

$$
\tau-\tau_{y}=k \dot{S}^{n}
$$

Figure B.5 schematically represents the various types of rheological behavior in qualitative shear stress and shear rate curves.

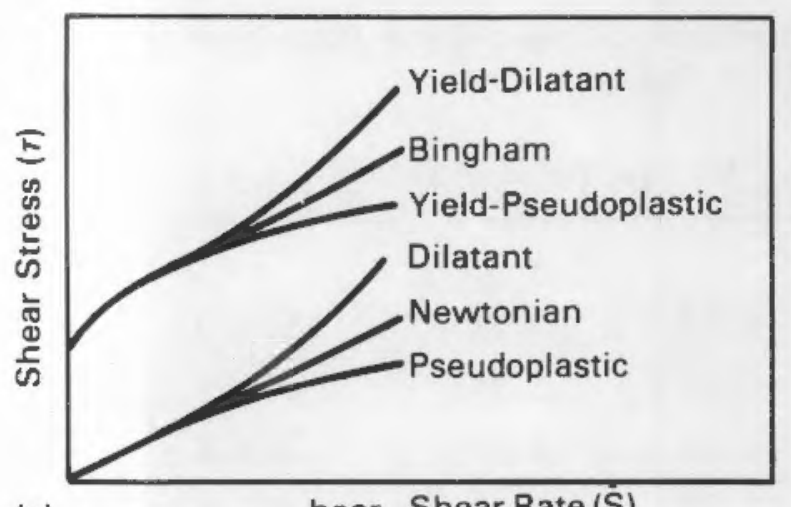

(a) hear Shear Rate (S)

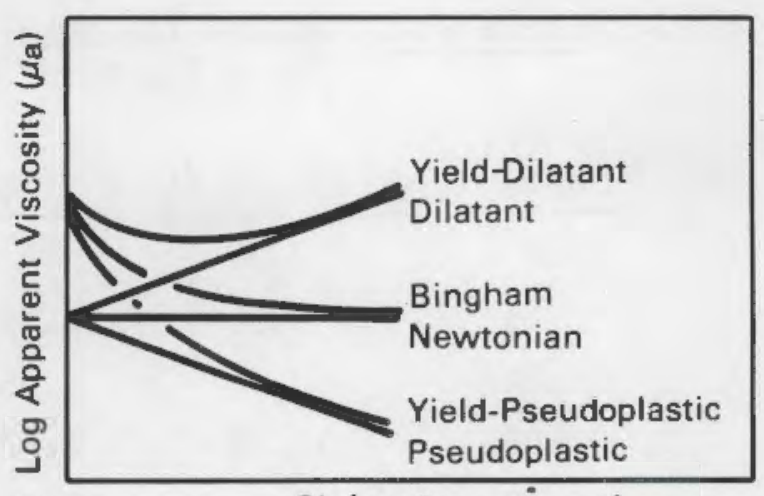

(b) g ShıLog Shear Riate (S)

FIGURE B.5. Rheograms for Time-Independent Non-Newtonian Fluids 
Example: Determining Power Law Parameters from Shear Vane Data. By operating a viscometer equipped with a shear vane at different rates of vane rotation, sufficient data to produce a rheogram or plot of shear stress versus shear rate can be obtained. Measurements of shear vane torque must be made at several rotational speeds (e.g., more than 5) to provide sufficient data to analyze the power law coefficient, $k$, and exponent, $n$.

Table 8.4 shows values of shear stress and shear rate that represent data obtained for a "typical" melter feed slurry. Each row in Table 8.4 represents a single data point for shear vane torque versus rpm. Note that this melter feed was found to exhibit a yield stress of 2.66 dyne $/ \mathrm{cm}^{2}$ (estimated by the torque decay method described in Section 4.4.3). To determine $k$ and $n$, first plot the $\dot{S}$ vs $\tau$ data (first two columns of Table B.4 in terms of $\ln (\dot{S}$ ) versus In $\left(\tau-\tau_{y}\right)$ as shown in Figure B.6. For this data, the plot intercepts the line $\dot{S}=1(\ln \dot{S}=0)$ at a value of $\ln k=1.98$. The power law coefficient $k$ is thus $\exp (1.98)=7.24$ dyne $/ \mathrm{cm}^{2}$. The slope of the plot, $n$, is found to be 0.19. Because $n<1$, this melter feed is considered a pseudoplastic power law fluid. Therefore, this melter feed slurry exhibits yield-pseudoplastic behavior and is described by the following power law expression, in cgs units:

TABLE B.4. Values for Shear Stress and Shear Rate Obtained for a Sample of Melter Feed Slurry

\begin{tabular}{|c|c|c|c|c|c|}
\hline$\dot{\mathrm{s}}\left(\sec ^{-1}\right)$ & $\tau\left(\right.$ dyne $\left./ \mathrm{cm}^{2}\right)$ & $\tau-\tau y$ & $\ln \dot{S}$ & $\ln (\tau-\tau y)$ & $\eta_{\text {app }}(c P)$ \\
\hline 0.0 & 2.66 & 0 & -- & -- & -- \\
\hline 0.61 & 9.21 & 6.55 & -0.49 & 1.87 & 1510.0 \\
\hline 1.22 & 10.31 & 7.65 & 0.20 & 2.04 & 844.8 \\
\hline 3.05 & 11.48 & 8.82 & 1.12 & 2.18 & 376.3 \\
\hline 6.12 & 12.61 & 9.95 & 1.81 & 2.30 & 206.1 \\
\hline 12.24 & 14.10 & 11.44 & 2.51 & 2.44 & 115.2 \\
\hline 24.47 & 15.66 & 13.00 & 3.20 & 2.57 & 64.0 \\
\hline 61.18 & 18.78 & 16.12 & 4.11 & 2.78 & 30.7 \\
\hline
\end{tabular}




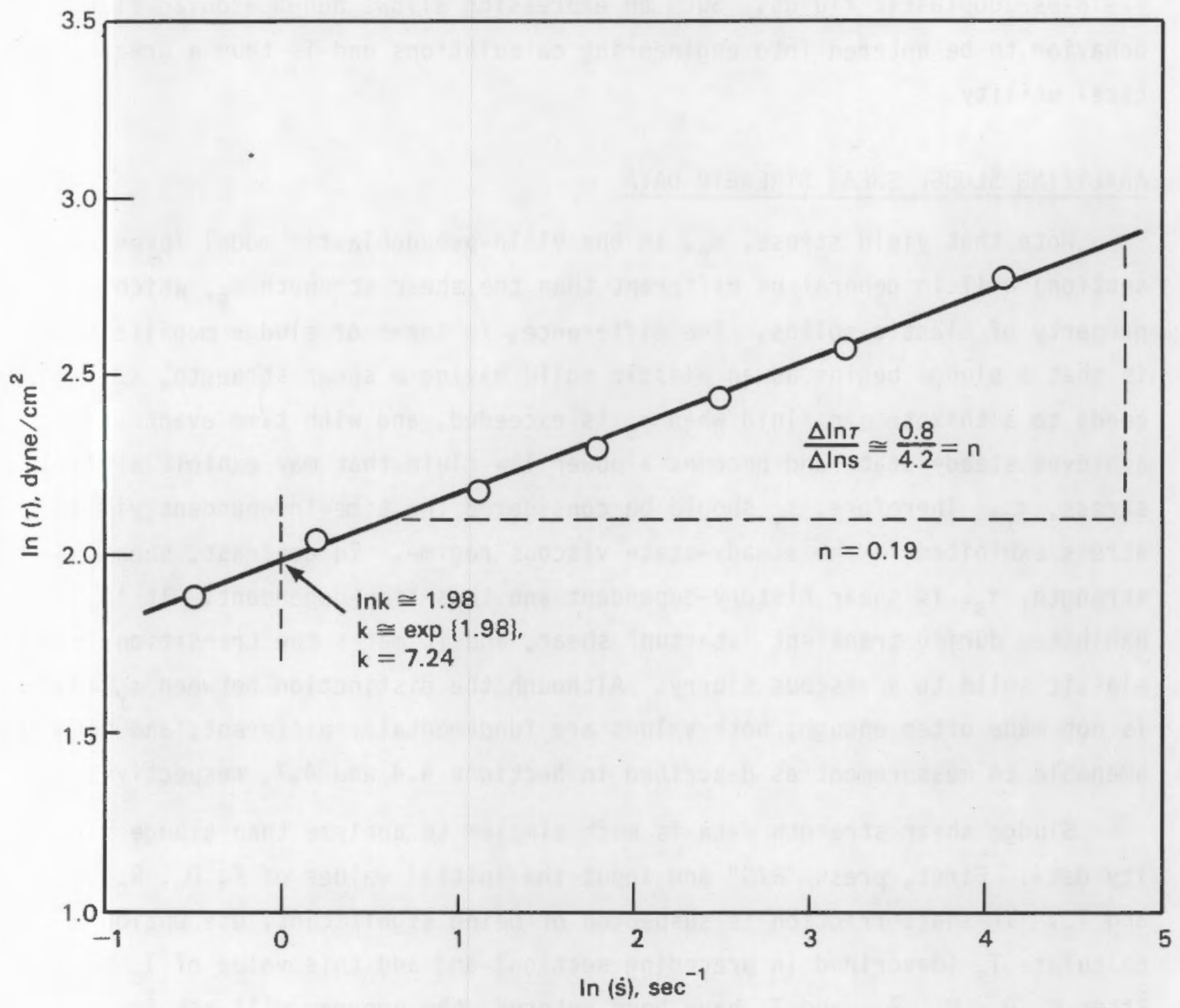

FIGURE B.6. Plot of $\log \dot{S}$ Versus $\log \tau$ for Typical Melter Feed

$$
\tau-2.66=7.2 \dot{S}^{0.19}
$$

Apply this same procedure for calculating the power law coefficient $k$ and exponent $-n$ regardless of whether the $\tau$ versus $\dot{S}$ data of interest were obtained using a shear vane or any other viscometric method. The resultant power law expression adequately describes the flow behavior of pseudoplastic $\left(\tau_{y}=0\right)$ and 
yield-pseudoplastic fluids. Such an expression allows non-Newtonian flow behavior to be entered into engineering calculations and is thus a great practical utility.

\section{ANALYZING SLUDGE SHEAR STRENGTH DATA}

Note that yield stress, $\tau_{y}$, in the yield-pseudoplastic model (previous section) will in general be different than the shear strength $\tau_{s}$, which is a property of elastic solids. The difference, in terms of sludge mobilization, is that a sludge begins as an elastic solid having a shear strength, $\tau_{s}$, proceeds to a thixotropic fluid when $\tau_{s}$ is exceeded, and with time eventually achieves steady state and becomes a power law fluid that may exhibit a yield stress, $\tau_{y}$. Therefore, $\tau_{y}$ should be considered the time-independent yield stress exhibited in the steady-state viscous regime. In contrast, shear strength, $\tau_{s}$, is shear history-dependent and thus time-dependent. It is exhibited during transient "startup" shear, and it marks the transition from an elastic solid to a viscous slurry. Although the distinction between $\tau_{y}$ and $\tau_{s}$ is not made often enough, both values are fundamentally different, and both are amenable to measurement as described in Sections 4.4 and 4.7 , respectively.

Sludge shear strength data is much simpler to analyze than sludge viscosity data. First, press "R/S" and input the initial values of $F, D_{v}, R_{c}, R_{S}$, and $T_{c}$. If shaft friction is suspected of being significant, use Option \#3 to calculate $T_{S}$ (described in preceding section) and add this value of $T_{S}$ to $T_{C}$. After $F, D_{v}, R_{c}, R_{s}$, and $T_{c}$ have been entered, the program will ask for $R_{t}$. Enter $R_{t}$ as described in preceding sections and press "R/S." The program now asks for $\mathrm{N}$. For shear strength calculations, key in a value of 0.0 for $\mathrm{N}$ and press "R/S" to proceed. (The parameter $\mathrm{N}$ does not enter into shear strength calculations.) This initializes 0ption \#4. The program now asks for the height, $H_{v}$, of the shear vane blades submerged in the slurry during the tests. Input $H_{v}$ (in $\mathrm{cm}$ ) and press "R/S" to proceed. The program now calculates vane torque and sludge shear strength. 
Using Option $\# 6$ to Save Time when Vane Torque Is Already Known. If $T_{v}$ is known ahead of time, use Option \#6 as described in Table B.2 to speed up the calculation process. To use option $\# 6$, input $F=0$, input $D_{v}$, input $N=0$, input $T_{v}$, input $H_{v}$, and the program will calculate $\tau_{s}$.

"VANE-2" PROGRAM LISTING AND STORAGE REGISTER DESCRIPTION

Table B.5 provides a description of the contents of the storage registers used in VANE-2. Table B.6 provides a program listing of VANE-2. Both tables are provided for the reader's use.

TABLE B.5. Storage Register Description

\begin{tabular}{|c|c|}
\hline Parameter & Register Number \\
\hline$\rho$ & 04 \\
\hline$D$ & 05 \\
\hline$\eta_{s}$ & 06 \\
\hline $\mathrm{N}$ & 07 \\
\hline $\mathrm{R}_{\mathrm{E}}$ & 08 \\
\hline$T_{0}$ & 09 \\
\hline $\mathrm{Np}$ & 10 \\
\hline$R_{c}$ & 11 \\
\hline$L$ & 12 \\
\hline $\mathrm{R}_{\mathrm{b}}$ & 14 \\
\hline$T_{s}$ & 15 \\
\hline$T_{V}$ & 16 \\
\hline$P$ & 17 \\
\hline $\mathrm{H}_{\mathrm{v}}$ & 18 \\
\hline$\tau$ & 19 \\
\hline $\mathrm{R}_{\mathrm{t}}$ & 20 \\
\hline$S$ & 21 \\
\hline$\pi \mathrm{v}$ & 22 \\
\hline$F$ & 23 \\
\hline$T_{c}$ & 24 \\
\hline$\tau_{S}$ & 25 \\
\hline
\end{tabular}


TABLE B.6. VANE-2 Program Listing

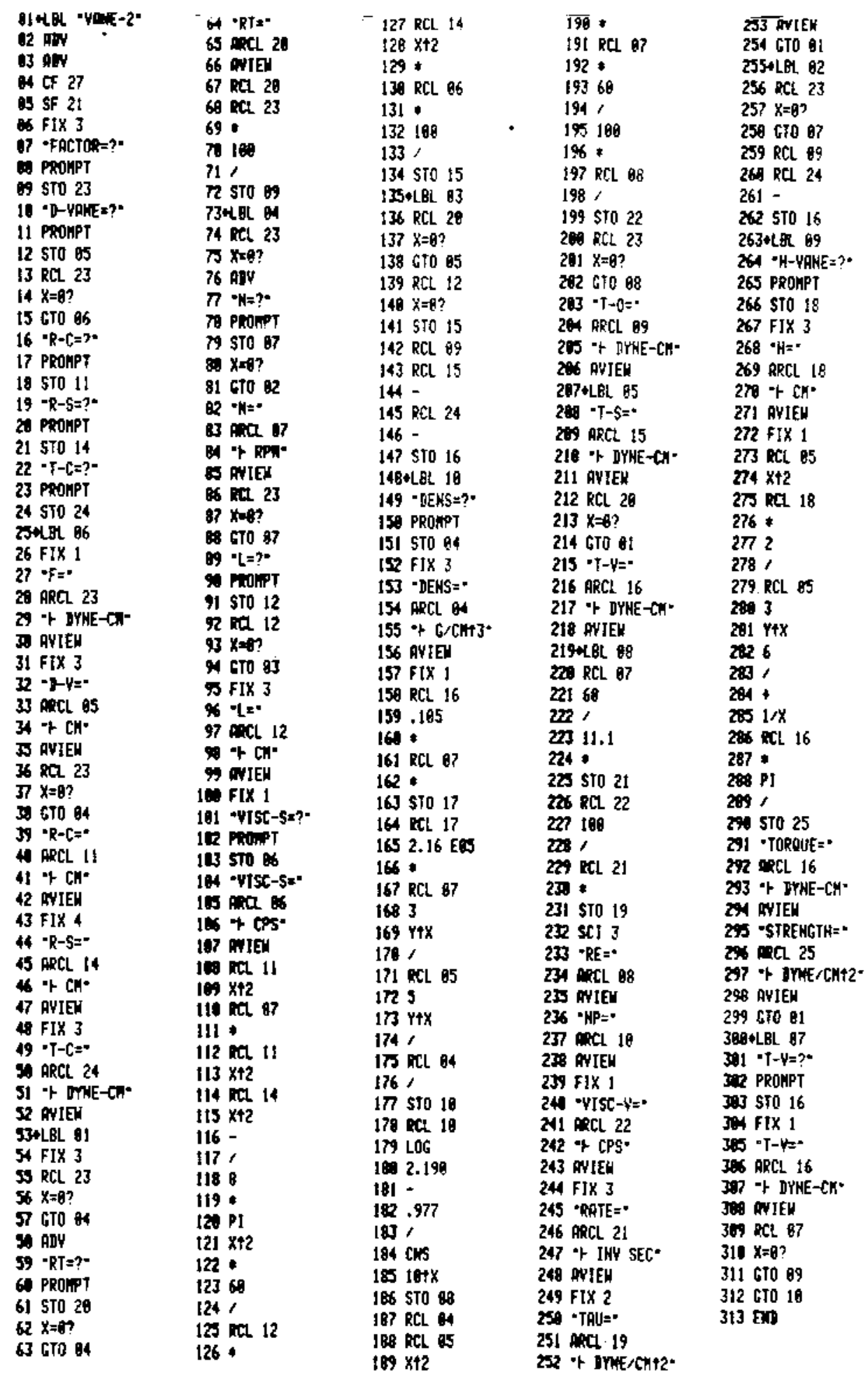




\section{DISTRIBUTION}

No. of

Copies

OFFSITE

30 DOE Technical Information Center

4 West Valley Nuclear Services Company

P.0. Box 191

West Valley, NY 14171

ATTN: C. C. Chapman

L. E. Rykken

M. A. Schiffhauer

J. M. Pope

2 DOE Office of Remedial Action and Waste Technology

Washington, DC 20545

ATTN: J. A. Coleman, NE-24

T. W. McIntosh, NE-25

4 DOE Office of Defense Waste

\& Transportation Management Washington, DC 20545

ATTN: C. H. Daly, DP-123

J. E. Lytie, DP-12

R. K. Hausser, DP-123

T. B. Hindman, DP-12

4 E. I. du Pont de Nemours \& Company, Inc.

Savannah River Laboratory

Aiken, SC 29808

ATTN: I. D. Goren

D. M. Grimm

B. A. Hamm

D. Boersma

\section{ONSITE}

6 DOE Richland Operations of fice

C. E. Collantes

C. R. Delannoy

M. J. Plahuta

M. W. Shupe
No. of

Copies

J. J. Sutey

J. D. White

23 Rockwell Hanford Operations

D. R. Bratzel

J. M. Allison

J. N. Appel

B. D. Bullough

A. J. DiLiberto

G. L. Dunford

W. R. Dworzak

M. W. Gibson

J. M. Henderson

N. W. Kirch

R. S. McBeath

D. E. McKenney

L. A. Mihalik

H. R. Risenmay

L. M. Sasaki

J. L. Scott

L. C. Stegen

D. M. Tulberg

R. E. Van der Cook

R. N. Wagner

R. D. Wojtasek

R. L. Salley (2)

53 Pacific Northwest Laboratory

C. R. Alten

W. F. Bonner

H. C. Burkholder

R. K. Farnsworth

C. L. Fow (5)

W. 0. Heath (20)

D. E. Knowlton

S. F. Liebetrau

R. 0. Lokken

D. McCarthy (2)

J. L. McEl roy

D. H. Mitchel?

J. M. Perez

M. E. Peterson (5)

C. M. Ruecker 
No. of

Copies

P. A. Scott

G. T. Thornton

R. L. Treat

Publishing Coordination (2)

Technical Report Files (5) 